\title{
Mirador II - Uma Extensão da Ferramenta \\ Mirador para Monitoramento e Gerenciamento do SPP3
}

\author{
Maxweel Silva Carmo
}

Orientador: Prof. Dr. Onofre Trindade Junior

Dissertação apresentada ao Instituto de Ciências Matemáticas e de Computação - ICMC-USP, como parte dos requisitos para obtenção do titulo de Mestre em Ciências - Área: Ciências de Computação e Matemática Computacional. 
Ao meu Deus, autor da vida e aos meus pais Carlim e Neidinha 


\section{Agradecimentos}

Ao meu querido pai, um grande incentivador e a quem devo tudo nesta vida. A minha

mamãe, a pessoa que mais amo neste mundo, e ao meu avô, a quem tenho profundo respeito e admiração. Não poderia me esquecer também de minha querida "Héliquinha". Uma irmã de verdade!

A minha doce amiga Aely, pelos bons momentos que passamos juntos.

Aos mancebos do velho LCAD, Alexandre, Fernando, Carinha, Sucrilhos, Yah, Luciano e Luciana. Agradeço também ao Emílio e ao Rômulo, um sujeito espirituoso e exótico, pelas contribuições prestadas a este trabalho.

Em especial, ao meu amigo, conselheiro e orientador Onofre, pelo imenso apoio e pela parceria na elaboração de piadinhas sobre o Rômulo. Não me esquecerei dos tradicionais churrascos nos fins de semana e muito menos da música tema "Let it be".

Não poderia me esquecer de meu amigo de infância Peter, pelos sonhos e pela determinação em proteger a Terra do Nunca.

A todos os colegas do ICMC pelo apoio e companheirismo ao longo desses dois anos.

A CAPES pelo apoio financeiro. 


\section{Sumário}

1 Introdução 3

1.1 Considerações Gerais . . . . . . . . . . . . . . . . . . . . 3

1.2 Objetivos do Trabalho . . . . . . . . . . . . . . 4

1.3 Organização do Texto . . . . . . . . . . . . . . . 4

2 Revisão Bibliográfica $\quad 6$

2.1 Considerações Iniciais . . . . . . . . . . . . . . . . . . 6

2.2 Processamento Paralelo . . . . . . . . . . . . . . . . . 6

2.3 Arquiteturas para Processamento Paralelo . . . . . . . . . . . . 7

2.3.1 Taxonomia de Flynn . . . . . . . . . . . . . . 7

2.3.2 Taxonomia de Duncan .................. 10

2.4 Programação Paralela . . . . . . . . . . . . . . . . . . 13

2.4.1 Comunicação e Sincronização entre Processos . . . . . . . . . . . . 13

2.4.2 A Natureza das Aplicaçōes Paralelas . . . . . . . . . . . . . . . . 14

2.4.3 Ferramentas para Desenvolvimento de Aplicações Paralelas . . . . . . 15

2.5 A Máquina Paralela SPP3 . . . . . . . . . . . . . . 18

2.6 O Projeto Beowulf . . . . . . . . . . . . . . . . . . 19

2.7 Ferramentas para Gerenciamento e Controle de Máquinas Paralelas . . . . 21

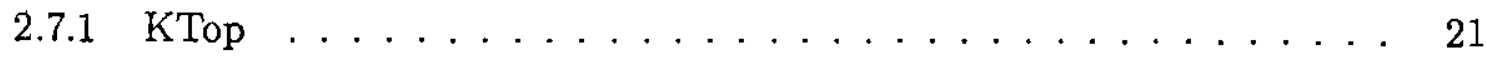

2.7 .2 Procps Cluster . . . . . . . . . . . . . . . 22

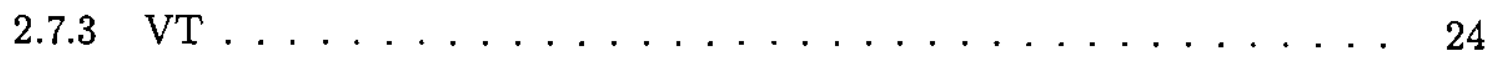

2.7 .4 gr-Monitor . . . . . . . . . . . . . . . 26

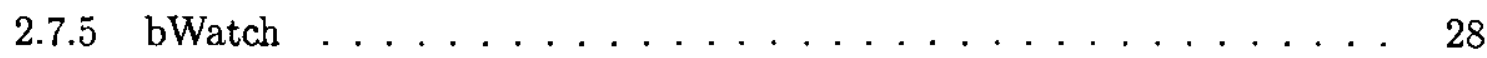

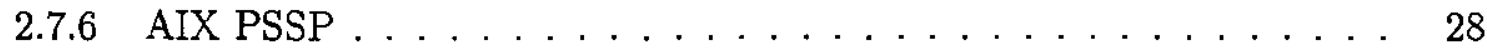


2.7.7 asMon - Monitoramento de C̣arga de CPU e Memória . . . . . . . . . 29

2.7.8 PCP (Performance Co-Pilot) . . . . . . . . . . . . . . 30

2.7.9 SCMS (Smile Cluster Management System) . . . . . . . . . . . 31

2.7 .10 Mirador . . . . . . . . . . . . . . . . . 34

2.7.11 Análise Comparativa das Ferramentas . . . . . . . . . . . . 46

2.8 SNMP (Simple Network Management Protocol) . . . . . . . . . . . . . 47

2.8.1 Características do Protocolo SNMP . . . . . . . . . . . 48

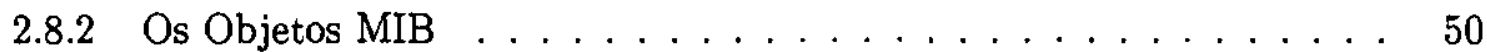

2.8.3 Versões do Protocolo SNMP . . . . . . . . . . . . . . . 52

2.8.4 Ferramentas para Monitoramento e Gerenciamento de Redes SNMP 。 52

2.8.5 RMON (Remote Network Monitoring) . . . . . . . . . . . . . 55

2.9 Considerações Finais . . . . . . . . . . . . . . . . . 57

3 Revisāo de Software da Ferramenta Mirador $\quad 58$

3.1 Considerações Iniciais . . . . . . . . . . . . . . . . . . . . . . 58

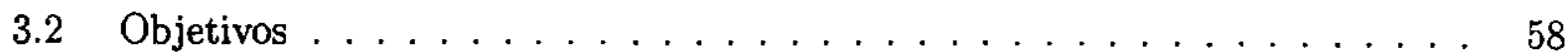

3.3 Validação da Ferramenta . . . . . . . . . . . . . . . . . . . . 59

3.3.1 Verificação e Alteração dos Módulos . . . . . . . . . . . . 60

3.3.2 Verificação de Integração entre os Módulos . . . . . . . . . . . . . . 66

3.4 Considerações Finais . . . . . . . . . . . . . . . . . . . . . 68

4 Definição e Especificaçāo das Extensōes $\quad 69$

4.1 Considerações Iniciais . . . . . . . . . . . . . . . . . . . . . 69

4.2 Definição das Extensões . . . . . . . . . . . . . . . . . . . . 69

4.3 Requisitos Funcionais . . . . . . . . . . . . . . . . 70

4.4 Requisitos não Funcionais . . . . . . . . . . . . . . . . 71

4.5 Diagrama de Fluxo de Dados . . . . . . . . . . . . . . . . . 72

4.6 Descrição das Funções . . . . . . . . . . . . . . . . . . . . . 74

4.6.1 Monitorar/Gerenciar Rede Myrinet . . . . . . . . . . . . . 74

4.6.2 Executar Comando Paralelo . . . . . . . . . . . . . 75

4.6 .3 Monitorar Hardware . . . . . . . . . . . . . . . 76

4.6 .4 Monitorar Nós . . . . . . . . . . . . . . . . . 76

4.6 .5 Gerenciar Nós . . . . . . . . . . . . . . . . . 77 
4.6 .6 Executar Funções/Coletar Informações . . . . . . . . . . . . 78

4.6 .7 Controlar Painel . . . . . . . . . . . . . . . 80

4.7 Considerações Finais . . . . . . . . . . . . . . . . . 80

5 Projeto e Implementação das Extensōes $\quad 81$

5.1 Considerações Iniciais . . . . . . . . . . . . . . . . . . 81

5.2 Ambiente de Implementação . . . . . . . . . . . . . . . . . 81

5.3 Arquitetura da Ferramenta Mirador II . . . . . . . . . . . . . . 82

5.3.1 Protocolo de Comunicação da Ferramenta Mirador II . . . . . . . . . 84

5.3 .2 Projeto dos Módulos . . . . . . . . . . . . . 85

5.4 O PMG (Painel de Monitoramento e Gerenciamento) . . . . . . . . . . . . 86

5.4.1 Descrição do Componente PMG . . . . . . . . . . . . . . 86

5.5 Projeto da Interface . . . . . . . . . . . . . . . . . . . . 87

5.6 Implementação das Funções . . . . . . . . . . . . . . . . . 88

5.7 Instalação da Ferramenta Mirador II e Resultados Obtidos . . . . . . . . . . 93

5.8 Considerações Finais . . . . . . . . . . . . . . . . . . . 96

6 Conclusōes $\quad 97$

6.1 Considerações Iniciais . . . . . . . . . . . . . . . . . . . . . . . 97

6.2 Avaliação Final da Ferramenta Mirador II . . . . . . . . . . . . . . . . 98

6.3 Contribuições do Trabalho . . . . . . . . . . . . . . . . . . . . 98

6.4 Propostas para Trabalhos Futuros . . . . . . . . . . . . . . . . 99

$\begin{array}{lr}\text { Referências Bibliográficas } & 107\end{array}$

$\begin{array}{lr}\text { A Interface da Ferramenta Mirador } & 108\end{array}$

$\begin{array}{ll}\text { B Painel de Monitoramento e Gerenciamento } & 117\end{array}$

C Instalação da Ferramenta Mirador II $\quad 124$ 


\section{Lista de Figuras}

2.1 Diagrama arquitetural de um computador SISD - Úm único elemento de processamento executando as instruções sequencialmente . . . . . . . 8

2.2 Arquitetura SIMD - Uma unidadë de controle e várias unidades de processa-

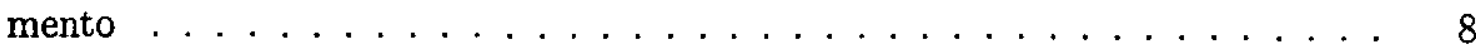

2.3 Arquitetura MISD - Várias unidades de processamento manipulando um único fluxo de dados $\ldots \ldots \ldots \ldots \ldots \ldots \ldots$

2.4 Arquitetura MIMD - Unidades de processamento independentes atuando sobre diferentes fluxos de dados . . . . . . . . . . . . . . . 10

2.5 Arquitetura MIMD com memória compartilhada . . . . . . . . . . 12

2.6 Arquitetura MIMD com memória distribuída . . . . . . . . . . . . . . 12

2.7 Arquitetura baseada em fluxo de dados. As instruções I1 e I4 podem ser executadas simultaneamente $\ldots \ldots \ldots \ldots \ldots \ldots$

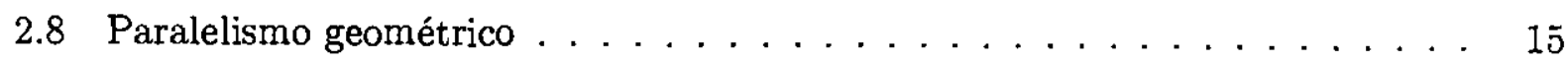

2.9 Paralelismo farm $\ldots \ldots \ldots \ldots \ldots \ldots \ldots \ldots \ldots \ldots \ldots$

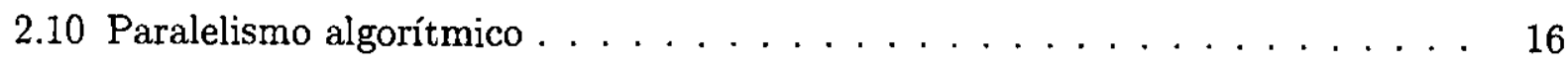

2.11 Visão geral da máquina SPP $3 \ldots \ldots \ldots \ldots \ldots$

2.12 KTop - Processos listados em uma estrutura de árvore . . . . . . . . . . 22

2.13 Monitoramento da máquina paralela SPP2 por intermédio do aplicativo top do pacote procps Cluster . . . . . . . . . . . . . . . 23

$2.14 \mathrm{VT}$ - Interface de visões . . . . . . . . . . . . . . . . 24

2.15 VT - Visão Interprocessor Communication $\ldots \ldots \ldots \ldots \ldots . \ldots .25$

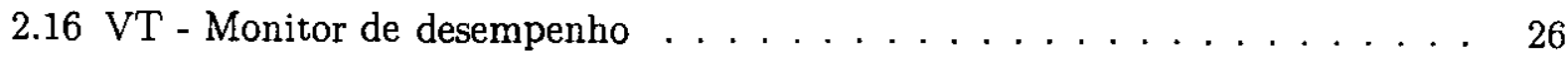

2.17 gr-Monitor - Representação das informações . . . . . . . . . . . . 27

2.18 Monitoramento de 8 nós da máquina SPP2. O nó p4 não está operacional . 28 
2.19 asMon - Interface gráfica $\ldots \ldots \ldots \ldots \ldots \ldots$

2.20 A ferramenta SCMS $\ldots \ldots \ldots \ldots \ldots \ldots \ldots \ldots$

2.21 Uma visão geral da Mirador . . . . . . . . . . . . . . . . 35

2.22 A ferramenta Mirador - os quadrados representam os processadores . . . . 35

2.23 Arquitetura da ferramenta Mirador . . . . . . . . . . . . . 36

2.24 Protocolos de comunicação da ferramenta Mirador . . . . . . . . . 38

2.25 O diagrama de fluxo de dados da ferramenta Mirador. Nivel $1 \ldots \ldots$

2.26 Função Executar Funçōes/Coletar Informações . . . . . . . . . . . . . . 42

2.27 Representação estrutural de parte da Management Information Base . . . . . 50

2.28 Multi Routter Traffic Grapher - Representação das informações. Cada retângulo representa um dispositivo de rede monitorado $\ldots \ldots \ldots \ldots \ldots$

2.29 Tkined - Monitoramento de um conjunto de redes . . . . . . . . . . 54

2.30 Sub-árvore RMON definida no RFC $1271 \ldots \ldots \ldots \ldots \ldots$

3.1 Arquitetura da ferramenta Mirador em nível de módulos . . . . . . . . 61

3.2 Configuração dos nós da máquina paralela $\ldots \ldots \ldots \ldots \ldots$. . . . . 62

3.3 DFD de interação dos módulos da ferramenta Mirador . . . . . . . . . 65

3.4 DFD dos módulos da ferramenta Mirador após a otimização do módulo SINGOG 66

4.1 Barra de LEDs representando informações de CPU e utilização de memória de um nó da máquina paralela . . . . . . . . . . . . . 70

4.2 DFD da ferramenta Mirador II. Nível $1 \ldots \ldots \ldots \ldots$

4.3 DFD da função Monitorar/Gerenciar Rede Myrinet . . . . . . . . . . . 74

4.4 DFD da função Executar Comando Paralelo . . . . . . . . . . . . 75

4.5 DFD da função Monitorar Hardware $\ldots \ldots \ldots \ldots \ldots \ldots$

4.6 DFD da função Monitorar Nós . . . . . . . . . . . . . . . . . . 77

4.7 DFD da fưnção Gerenciar Nós . . . . . . . . . . . . . . . . . 78

4.8 DFD da função Executar Funções/Coletar Informações . . . . . . . . . . 79

4.9 DFD da função Controlar Painel . . . . . . . . . . . . . . . . . . 80

5.1 Arquitetura da ferramenta Mirador II . . . . . . . . . . . . . 83

5.2 Protocolo de comunicação da ferramenta Mirador II . . . . . . . . . . . 84

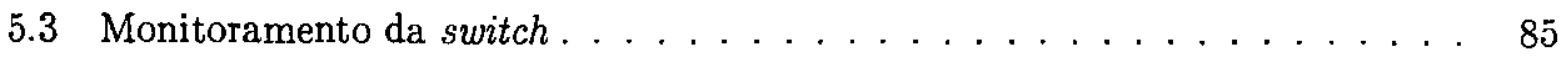


5.4 Interação entre componentes e nós . . . . . . . . . . . . . . . . . 86

5.5 Interface da ferramenta Mirador II . . . . . . . . . . . . . . . 87

5.6 Monitoramento do nó . . . . . . . . . . . . . . . 88

5.7 Monitoramento da rede Myrinet . . . . . . . . . . . . . . 89

5.8 Visão geral da ferramenta Mirador II . . . . . . . . . . . . . . . . . 95

A.1 Interface principal da ferramenta Mirador. 7 nós estão sendo monitorados, sendo que os nós 0,1 e 5 estão inoperantes . . . . . . . . . . . . . . 108

A.2 Menu Session . . . . . . . . . . . . . . . . . . 108

A.3 Login e password requeridos para autenticação . . . . . . . . . . . . . . . . . 109

A.4 Menu Report. . . . . . . . . . . . . . . . . . . . . . . . . 109

A.5 Data e hora dos nós monitorados . . . . . . . . . . . . . . . . . 109

A.6 Informações de hardware dos nós monitorados . . . . . . . . . . . . . . . . 109

A.7 Informações de memória dos nós monitorados . . . . . . . . . . . . . . . . . 109

A.8 Monitoramento das tarefas em execução nos nós . . . . . . . . . . . . . . . . 110

A.9 Menu suspenso. Ativado ao se clicar em um campo do formulário de informação de tarefas, oferece opções de alterar prioridade e encerrar tarefas em execução . . . . . . . . . . . . . . . . . . . . 110

A.10 Descrição dos nós da máquina paralela . . . . . . . . . . . . . . . . 110

A.11 Informações de utilização de CPU dos nós monitorados . . . . . . . . . . . . 110

A.12 Legenda das cores utilizadas na representação de carga de CPL . . . . . . . 111

A.13 Menu dos comandos paralelos disponíveis . . . . . . . . . . . . . . 111

A.14 Comando 'list' . . . . . . . . . . . . . . . . . . . . . . 112

A.15 Comando 'find' . . . . . . . . . . . . . . . . . . 112

A.16 Comando 'remove' . . . . . . . . . . . . . . . . . . . . . . 112

A.17 Comando 'copy' . . . . . . . . . . . . . . . . . . . . 112

A.18 Console para apresentação das saídas referentes às execuções dos comandos paralelos ............................... 113

A.19 Menu de controle . . . . . . . . . . . . . . . . . 113

A.20 Menu de gerenciamento dos nós, oferecendo opções para reiniciar nós via software e via hardware, e ligar e desligar nós . . . . . . . . . . . . . . . . . . 113

A.21 Menu de gerenciamento de usuário . . . . . . . . . . . . . . 113 
A.22 Lista de usuários cadastrados no sistema . . . . . . . . . . . . . . . 114

A.23 Menu de configuração do sistema . . . . . . . . . . . . . . . . 114

A.24 Configurações de gerenciamento . . . . . . . . . . . . . . . . 114

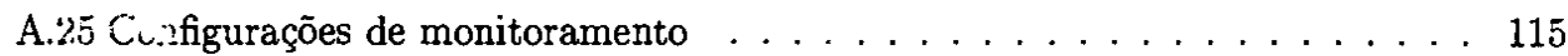

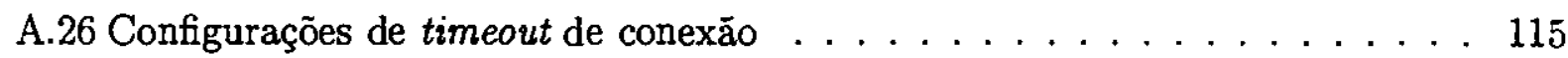

A.27 Monitoramento da rede Myrinet (simulação) . . . . . . . . . . . . 115

A.28 Informações sobre a switch Myrinet (simulação) . . . . . . . . . . . . 116

A.29 Estatísticas sobre as portas da switch Myrinet (simulação) . . . . . . . . 116

A.30 Número de pacotes que trafegam pela rede Myrinet e que deve ser considerado como $100 \%$ de tráfego $\ldots \ldots . \ldots \ldots \ldots \ldots \ldots$

B.1 Esquemático do Painel de Monitoramento e Gerenciamento . . . . . . . . 118

B.2 Indicação de níveis de utilização do nó . . . . . . . . . . . . . . . . 121

B.3 Padrões mostrados alternadamente quando o painel está tentando ligar a fonte de alimentação associada ao nó . . . . . . . . . . . . . . . 121

B.4 Padrões mostrados sequencialmente quando o painel está sendo configurado . 121

B.5 Padrões mostrados alternadamente quando o painel perde a comunicação com o nó após ter sido configurado . . . . . . . . . . . . . . . . . . . 122

B.6 Mapa de estados do painel . . . . . . . . . . . . . . . . . . . . 123

C.1 árvore de diretórios da ferramenta Mirador II f . . . . . . . . . . . . 124 


\section{Lista de Tabelas}

2.1 Comandos paralelos presentes no pacote SCMS $\ldots \ldots \ldots \ldots . \ldots 32$

2.2 Comparação entre as ferramentas de gerenciamento e monitoramento . . . . 47

4.1 Operações de gerenciamento permitidas . . . . . . . . . . . . 78

5.1 Ferramentas e bibliotecas utilizadas . . . . . . . . . . . . . . . 82

5.2 Relação entre funções e módulos . . . . . . . . . . . . . . . . . . . 84 


\section{Resumo}

A utilização de arquiteturas paralelas MIMD na resolução de problemas que exigem alta demanda computacional tem sido cada vez mais frequente. A máquina paralela SPP2 surge neste cenário como uma arquitetura alternativa, oferecendo alto poder computacional a baixo custo através da utilização de componentes de hardware amplamente disponíveis. Visando facilitar a interação dos usuários com o SPP2, novos mecanismos foram implementados, resultando na máquina paralela SPP3.

Para realizar o monitoramento e gerenciamento da máquina paralela SPP2 desenvolveu-se a ferramenta Mirador. Execução remota, gerenciamento de usuários, monitoramento de carga de CPU e memória, monitoramento e gerenciamento da execução de processos, são algumas de suas características.

A ferramenta Mirador, quando comparada com outras ferramentas do gênero, apresenta peculiaridades que a colocam em posição de destaque, motivando a continuidade de seu desenvolvimento. O presente trabalho leva adiante o desenvolvimento da Mirador, suprimindo certas deficiências e especificando novas funcionalidades que vão de encontro às necessidades de monitoramento e gerenciamento da máquina paralela SPP3.

A ferramenta Mirador II, como resultado deste trabalho, apresenta melhor desempenho e maiores facilidades de interação com o usuário, em relação à sua antecessora. A Mirador II disponibiliza também mecanismos de monitoramento das redes de conexão de alta velocidade Myrinet, mecanismos de gerenciamento autônomo dos nós da máquina paralela e dispositivos de monitoramento via hardware, dentre outras características. 


\section{Abstract}

The use of MIMD parallel architectures to solve problems that require high computational power has been more and more frequent. The SPP2 parallel machine was developed as an architecture alternative offering high computional power at low cost, using hardware components commonly available. In order to facilitate the interaction between the user and the SPP2, new mechanisms were developed resulting in the SPP3 parallel machine.

The Mirador tool was developed to allow the monitoring and management of the SPP2 parallel machine. Remote execution, user management, CPU and memory monitoring, processes execution, monitoring and management are among its main features.

The Mirador tool compares very well against similar tools. This has motivated its development. This work continue the development of the Mirador tool, suppressing its main problems and introducing new features to aim at the needs for monitoring and management of the SPP3 parallel machine.

The Mirador II tool, as a result of this work, presents better performance and better interaction with the user than its predecessor. The Mirador II makes avaliable monitoring mechanisms for Myrinet network, autonomous management of the parallel machine nodes and devices for hardware monitoring, among another features. 


\section{Capítulo 1}

\section{Introdução}

\subsection{Considerações Gerais}

A utilização de computadores para a resolução de problemas baseou-se, durante um longo período, em soluções estritamente sequenciais, impostas pela arquitetura de von Neumann. Alguns mecanismos foram implementados buscando-se atingir níveis mais elevados de desempenho na tentativa de superar as limitaçōes da computação sequencial como, por exemplo, o conceito de pipeline e de múltiplas unidades funcionais, que hoje estão presentes em praticamente todos os computadores. Apesar do aumento de desempenho crescer a uma taxa exponencial, fatores como limitaçōes físicas, impōem severas restrições sobre a velocidade máxima de processamento que pode ser obtida dessas arquiteturas.

Muitos dos problemas computacionais na atualidade exigem um poder computacional que não pode ser fornecido pelas máquinas sequenciais. Sabe-se que as necessidades de poder de processamento tem crescido sistematicamente, e com o intuito de atender a tais necessidades, novos modelos computacionais têm sido propostos. Particularmente, as arquiteturas paralelas com memória distribuída têm importância considerável por oferecer, entre outros benefícios, alto desempenho a baixo custo.

Com o advento das máquinas paralelas, surgiu todo um conjunto de ferramentas, procedimentos e paradigmas de programação. Uim programa paralelo requer, além das construções normais de um código sequencial, todo um conjunto adicional de construções para permitir a coordenação e a sincronização entre os vários processos que cooperam entre si. No desenvolvimento de tais programas, existe uma gama de ferramentas que auxiliam nas 
tarefas de especificação, projeto, codificação, depuração e análise de desempenho.

Analisar o comportamento de uma aplicação paralela em execução ou mesmo interagir diretamente com ela é um requisito básico em vários sistemas. Embora esta não seja uma tarefa t:iai $\mathrm{em}$ virtude de diversos fatores tais como a multiplicidade de recursos e a concorrência dos programas, as ferramentas para gerenciamento/monitoramento disponibilizam para o usuário diferentes informações a respeito do estado do sistema e da execução dos aplicativos (monitoramento), permitindo, no caso de gerenciaménto, a interferência direta do usuário (interrupção da execução de processos, mudanças de prioridades, por exemplo).

Dentre os aplicativos para gerenciamento/monitoramento de arquiteturas paralelas, destaca-se a ferramenta Mirador [ARA98]: Esta foi concebida com a intenção de preencher a lacuna funcional existente nas demais ferramentas do gênero.

A Mirador foi desenvolvida visando o gerenciamento da máquina SPP2 [Tri95b, TRI95a], fornecendo uma interface gráfica por meio da qual é possível visualizar as informações referentes ao monitoramento (carga, tarefas, memória utilizada, entre outras), e gerenciar todos os processos em execução (eliminação de tarefas de um nó, por exemplo). A ferramenta Mirador pode ser utilizada através de um navegador Internet com suporte à linguagem Java [Sun98].

\subsection{Objetivos do Trabalho}

Este trabalho tem como principal objetivo estender as funcionalidades ferramenta Mirador, de maneira a oferecer um leque mais completo de soluções (vide seção 4.3). A implementação de rotinas para monitoramento das redes de alta velocidade Myrinet [NJB95] e o monitoramento dos dispositivos de hardware dos nós, podem ser citados como exemplos dessas extensōes.

É também objetivo deste trabalho expor, analisar e implementar soluções para as deficiências presentes na ferramenta Mirador.

\subsection{Organização do Texto}

Este trabalho é dividido em 6 capítulos. O capítulo 2 apresenta a revisão bibliográfica de alguns conceitos da programação paralela, citando as principais arquiteturas, suas classifi- 
cações e paradigmas de programação. Também são descritas as máquinas paralelas Beowulf e SPP3. Em seguida é feita uma análise das principais ferramentas existentes para o gerenciamento e monitoramento de aplicações paralelas. Também é feita uma introdução ao protocolo SNMP, utilizado no monitoramento de redes de computadores. No capítulo 3 é apresentada a revisão de software da ferramenta Mirador, onde a ferramenta é analisada e melhorias são implementadas. O capítulo 4 apresenta as especificações referentes às extensões desenvolvidas. O projeto e a implementação dessas ex́tensões são discutidos no capítulo 5. O capítulo 6 apresenta as conclusões finais, fazendo uma avaliação geral da ferramenta desenvolvida. Também no capítulo 6 , são apresentadas as principais contribuições deste trabalho e sugestões para trabalhos futuros. 


\section{Capítulo 2}

\section{Revisão Bibliográfica}

\subsection{Considerações Iniciais}

Este capítulo tem por objetivo apresentar os tópicos relacionados à computação paralela que são de importância para o desenvolvimento do trabalho proposto, dando ênfase às ferramentas para o monitoramento de máquinas e aplicações paralelas.

A seção 2.2 apresenta os principais conceitos de processamento paralelo e suas aplicações. Na seção 2.3 são introduzidas as classificações das arquiteturas paralelas. A seção 2.4 enfoca a programação paralela e seus mecanismos. Na seção 2.6 é feita uma descrição do projeto Beowulf e na seção 2.5 é descrita a máquina paralela SPP3 citando sua arquitetura e opções de implementação. Na seção 2.7 é feita uma abordagem comparativa entre as diversas ferramentas disponíveis para o gerenciamento/monitoramento de máquinas paralelas, analisando as suas vantagens e desvantagens e enfatizando características peculiares como disponibilidade, desempenho e eficiência. Nesta mesma seção é apresentada também a ferramenta Mirador [ARA98], descrevendo sua finalidade, suas características e os problemas atualmente apresentados pela mesma.

\subsection{Processamento Paralelo}

O processamento paralelo, também referenciado como computação paralela, é uma forma de processamento eficiente, com ênfase na exploração de eventos paralelos no processo computacional através de uma coleção de elementos de processamento que cooperam e comunicam 
entre si [ALM94, NAV89].

A computação paralela tem sido impulsionada por uma necessidade crescente de poder computacional exigido pelas mais variadas aplicações, e que, devido a restriçōes físicas, não pode ser obtido por meio de arquiteturas puramente sequenciais.

O processamento paralelo também é um meio comum de se obter tolerância a falhas, utilizando para tal, a redundância de elementos de hardware e recursos de software embutidos na execução de aplicações intrinsecamente paralelas [ALM94].

São inúmeras as aplicações envolvendo computação paralela. Essas aplicações geralmente exigem um alto poder computacional e estão vinculadas a diversos setores como usinas de refinamento de petróleo, gerenciamento de reatores nucleares, equipamentos de coleta e processamento de dados meteorológicos, etc.

\subsection{Arquiteturas para Processamento Paralelo}

Com o intuito de suprir as diferentes necessidades das aplicações de processamento paralelo, várias arquiteturas foram propostas e desenvolvidas ao longo dos anos. Em virtude deste diversificado conjunto, percebeu-se a necessidade de algum esquema de classificação de tais arquiteturas segundo parâmetros pré-definidos. Nos itens abaixo são explanadas as duas taxonomias mais comuns.

\subsubsection{Taxonomia de Flynn}

A classificação proposta por Flynn baseia-se na multiplicidade do fluxo de dados e de instruções. De acordo com essa abordagem, as arquiteturas se dividem em quatro classes de computadores. São elas: SISD (Single Instruction Single Data), SIMD (Single Instruction Multiple Data), MISD (Multiple Instruction Single Data) e MIMD (Multiple Instruction Multiple Data) [DUN90].

\section{Arquitetura SISD}

Essa categoria é composta por computadores escalares tradicionais contendo um único elemento de processamento. As instruções operam em dados obtidos de um único fluxo de dados, como mostra a figura 2.1. As instruções são executadas sequencialmente, mas podem 
ter execução sobreposta caso sejam utilizados mecanismos para exploração de paralelismo em baixo nível (pipeline).

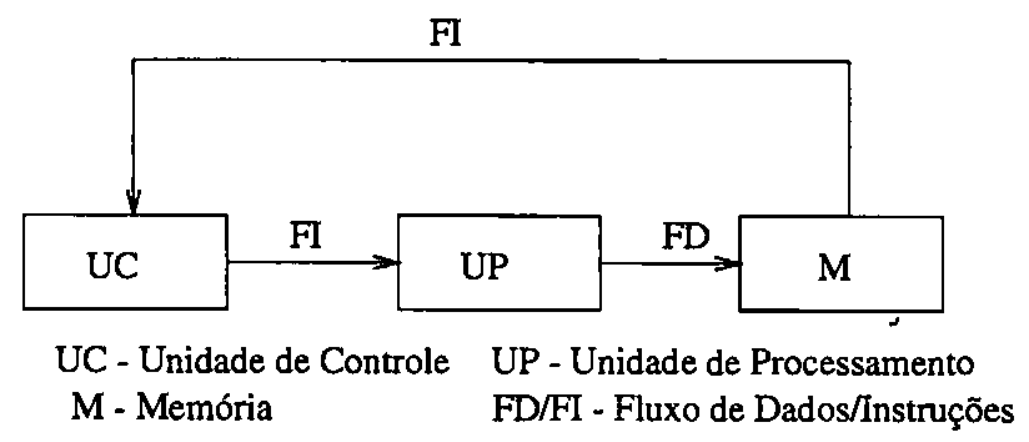

Figura 2.1: Diagrama arquitetural de um computador SISD - Um único elemento de processamento executando as instruções sequencialmente

Como exemplos dessa classe, podem ser citados os computadores sequenciais de um único processador da família IBM PC.

\section{Arquitetura SIMD}

Os computadores pertencentes a essa categoria executam a mesma sequência de instruções com dados oriundos de vários fluxos de dados. Essa arquitetura geralmente é composta de uma única unidade de controle (responsável por decodificar as instruções) e de várias unidades de processamento. Figura 2.2.

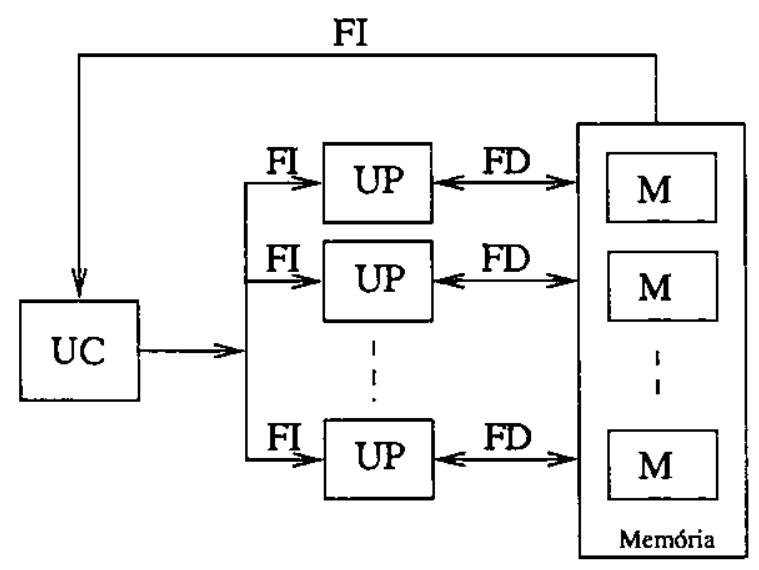

UC - Unidade de Controle

UP - Unidade de Processamento

M - Memória FD/FI Fluxo de Dados/Instruçð̃es

Figura 2.2: Arquitetura SIMD - Uma unidade de controle e várias unidades de processamento

Ao detectar uma instrução, a unidade de controle se encarrega de difundi-la entre os elementos de processamento para execução de acordo com dados locais. As máquinas SIMD 


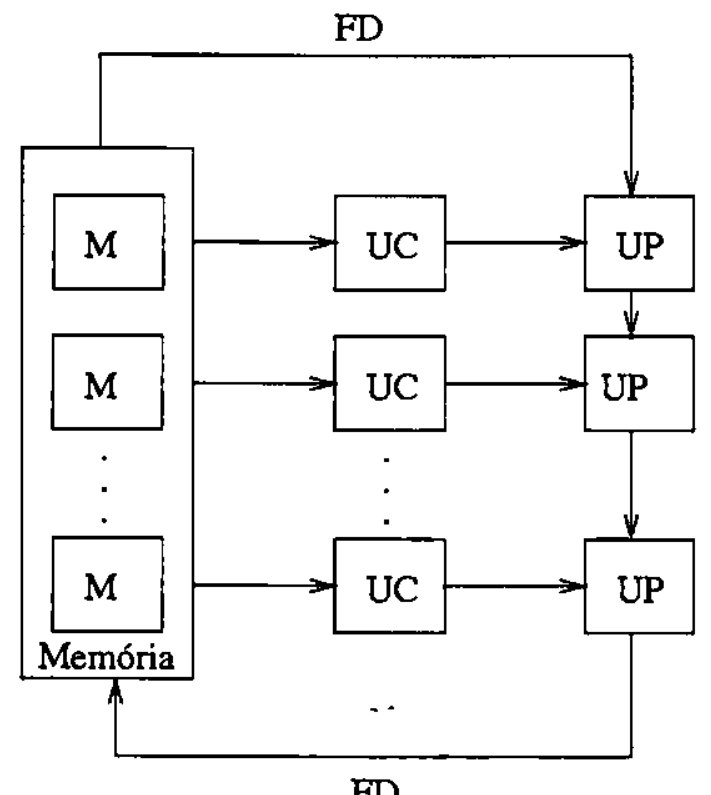

FD - Fluxo de Dados UC - Unidade de Controle UP - Unidade de Processamento M - Memória

Figura 2.3: Arquitetura MISD - Várias unidades de processamento manipulando um único fluxo de dados

geralmente possuem um grande número de processadores. Podem ser citados como exemplo o ILLIAC-IV e o MasPar MP [FOS95].

Também se enquadram nessa categoria os computadores vetoriais.

\section{Arquitetura MISD}

Essas máquinas se caracterizam pela existência de múltiplos elementos de processamento que, embora recebam instruções diferentes, são responsáveis pela execução de um mesmo fluxo de dados (figura 2.3). Nesse caso, o resultado do processamento de uma unidade serve como entrada para outra unidade.

Existem controvérsias quanto à possibilidade real de implementação dessa arquitetura. Alguns autores como Tanembaum [TAN92] afirmam que nào existem exemplos dessa classe, ao passo que outros (Almasi [ALM94]) consideram que as arquiteturas sistolicas e as baseadas em pipelines pertencem a essa categoria. 


\section{Arquitetura MIMD}

A classe MIMD inclui as máquinas constituídas de múltiplos processadores que executam de forma autônoma diferentes instruções em diferentes fluxos de dados, como ilustra a figura 2.4 .

Essa categoria inclui uma grande parte dos computadores de alto desempenho atuais, abrangendo desde elementos de processamento projetados para serem componentes de uma arquitetura paralela (por exemplo, os transputers), até computadores pessoais conectados por uma rede local [FOS95].

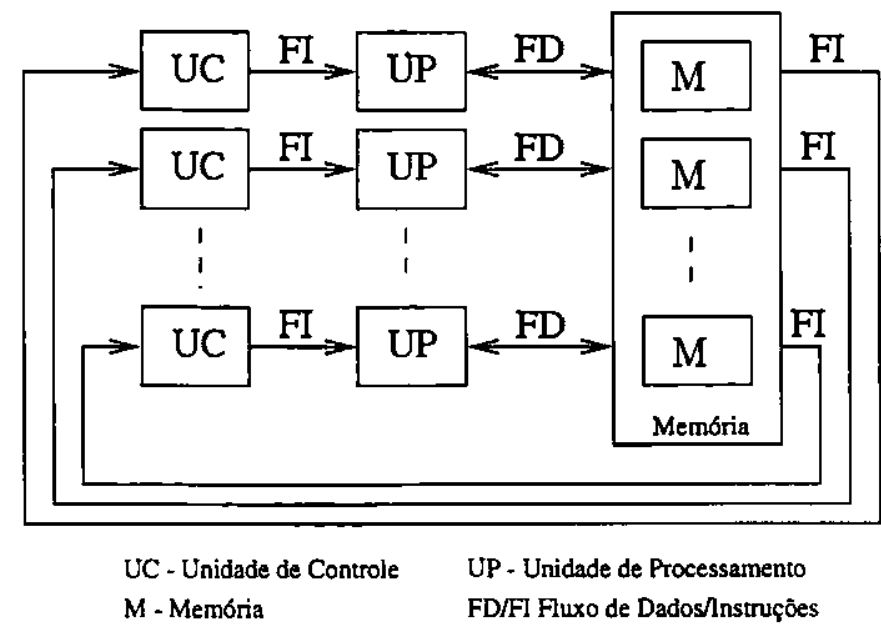

Figura 2.4: Arquitetura MIMD - Unidades de processamento independentes atuando sobre diferentes fluxos de dados

\subsubsection{Taxonomia de Duncan}

A classificação proposta por Duncan tem o intuito de abranger arquiteturas mais recentes que não se enquadram corretamente na taxonomia de Flynn.

Em sua abordagem, Duncan enfocou os seguintes pontos:

- Excluir máquinas que incorporam apenas paralelismo de baixo nível como pipelines $\mathrm{e}$ múltiplas unidades funcionais;

- Manter a essência da taxonomia de Flynn (classificação de acordo com fluxos de dados e de instruções); 
- Estender a classificação de Flynn de uma maneira que se possa abranger novas arquiteturas.

Pela taxonomia de Duncan têm-se as seguintes classes:

\section{Arquiteturas Síncronas}

Apresentam, como principal característica, um relógio global para a coordenação de suas operaçōes. Entre essas arquiteturas podem ser citadas:

\section{Arquiteturas de Processadores Vetoriais Pipeline}

Possuem múltiplas unidades funcionais que operam concorrentemente utilizando pipelines.

Sua organização básica consiste em um processador de instruções, várias unidades de processamento vetorial para a execução de operações vetoriais e um processador escalar reservado para operações de natureza escalar.

\section{$\underline{\text { Arquiteturas SIMD }}$}

Essa arquitetura é constituída de uma unidade de controle, vários processadores e uma rede de interconexão ligando processadores e memória. A unidade de controle é responsável por difundir uma instrução entre todos os processadores, que se encarregam de executá-la utilizando os dados locais.

\section{Arquiteturas de Arranjos Sistólicos}

Nos computadores pertencentes a esse grupo, os dados são transmitidos ritmicamente da memória para uma matriz de processadores, que fazem o processamento necessário e repassam os resultados adiante, até os dados regressarem novamente à memória.

\section{Arquiteturas Assíncronas Convencionais - MIMD}

Utilizam múltiplos processadores que operam de forma independente com relação à execução das instruções. Essa classe pode ainda ser subdividida de acordo com a organização de memória (compartilhada ou distribuída). 
$\mathrm{Na}$ topologia com memória compartilhada, todos os processadores têm acesso a um espaço de endereçamento comum. A comunicação e a sincronização entre os processadores são feitas através da memória (figura 2.5).

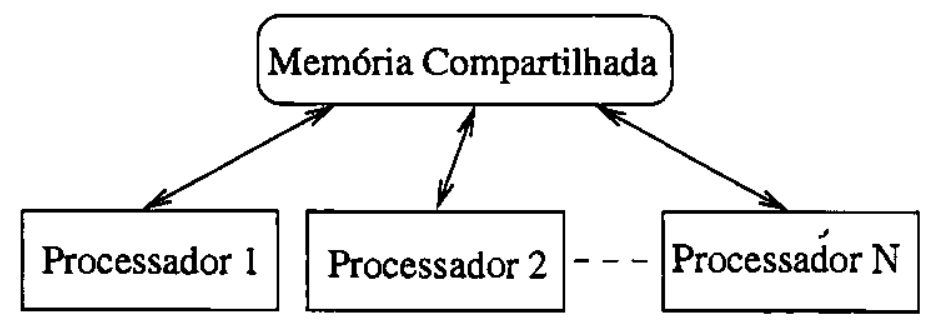

Figura 2.5: Arquitetura MIMD com memória compartilhada

$\mathrm{Na}$ topologia com memória distribuída, cada processador possui sua própria região de memória e a comunicação se torna possível por meio de troca de mensagens via uma rede de interconexão, como ilustra a figura 2.6.

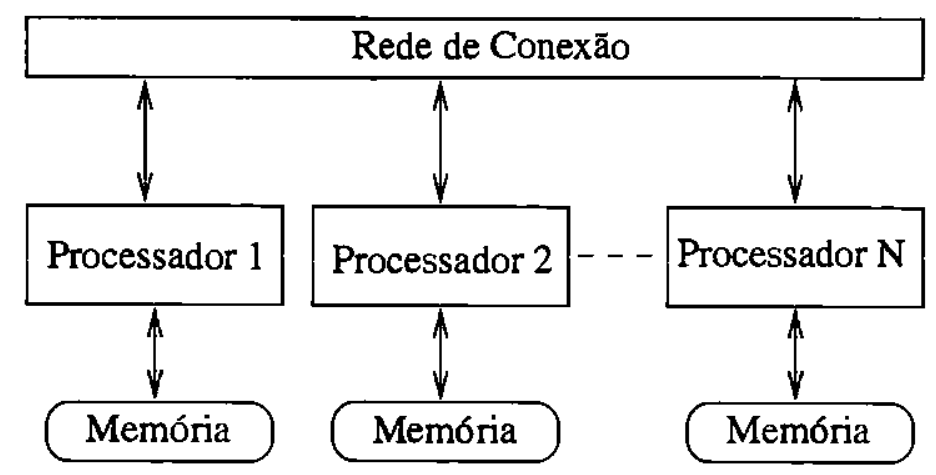

Figura 2.6: Arquitetura MIMD com memória distribuída

As máquinas com memória distribuída apresentam diversas vantagens tais como baixo custo, facilidade de implementação e alta escalabilidade.

\section{Arquiteturas Assíncronas Não Convencionais}

Existem certas arquiteturas que, por apresentarem determinadas características, não se adequam em nenhuma das classes anteriores, sendo necessário estender a classificação em algumas subclasses específicas.

Arquiteturas de Fluxo de Dados

Nestas arquiteturas, as instruções são executadas à medida que os seus operandos 
se tornam disponíveis, visando o aproveitamento do paralelismo intrínseco das instruções (figura 2.7).

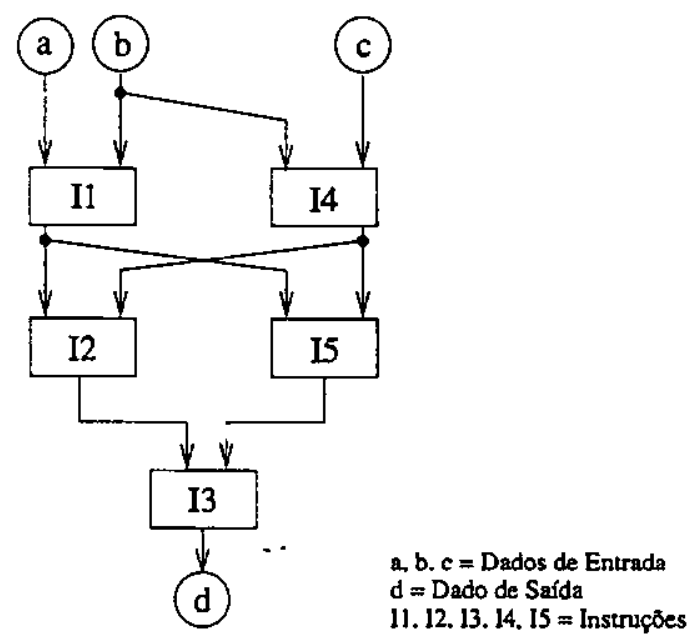

Figura 2.7: Arquitetura baseada em fluxo de dados. As instruções Il e I4 podem ser executadas simultaneamente

$\underline{\text { Arquiteturas Híbridas - SIMD e MIMD }}$

Este tipo de arquitetura é obtido mesclando-se as características de máquinas SIMD com as de máquinas MIMD. O resultado é uma arquitetura mais flexível, sendo bastante interessante para determinadas aplicações.

\subsection{Programação Paralela}

A programação paralela consiste em dividir um problema em partes menores de forma que estas partes possam ser executadas simultaneamente, chegando com maior eficiência aos resultados pretendidos [ALM94].

Como será visto a seguir, o paradigma da programação paralela utiliza uma série de construções e procedimentos para que seja possível especificar e coordenar os vários fluxos de execução que trabalham de forma concorrente.

\subsubsection{Comunicação e Sincronização entre Processos}

Em programas paralelos, é necessária a utilização de mecanismos que gerenciem a execução dos vários processos que estão cooperando para uma determinada finalidade. O gerencia- 
mento consiste em coordenar e sincronizar o fluxo de execução das atividades dos processos. Existem, basicamente, dois tipos de mecanismos com esse propósito.

\section{Mecanismo baseado em Troca de Mensagens}

Esse tipo de comunicação é utilizado para sincronizar os diversos elementos de processamento de uma arquitetura de memória distribuída. A comunicação é feita via troca de mensagens, utilizando primitivas do tipo send/receive. Esse mecanismo se encarrega também, de tornar transparente a interação entre os processos [HOA85].

\section{Mecanismo baseado em Dados Compartilhados}

A sincronização entre os processos é realizada por meio da utilização de variáveis compartiIhadas. Esse mecanismo é bastante difundido em arquiteturas com múltiplos processadores e memória compartilhada [BA90]. Um dos pontos cruciais desse método (e o que torna sua implementação um tanto mais complexa) é a forma pela qual estas variáveis são acessadas, sendo necessário a utilização de políticas que possam garantir o acesso exclusivo a essas regiões críticas [BRI72]. Busy-waiting [PET81], semáforos [DIJ68] e monitores [HOA74] são algumas das técnicas utilizadas.

\subsubsection{A Natureza das Aplicações Paralelas}

Existe uma gama de soluções para a implementação de paralelismo de aplicações. Em seu trabalho, Hey [HEY90] sugeriu três abordagens: o paralelismo geométrico, o paralelismo farm e o paralelismo algorítmico.

\section{Paralelismo Geométrico}

Neste tipo de paralelismo, o espaço de dados utilizado pelos processos são divididos em subregiões. Geralmente utiliza-se o mesmo programa para executar todos os processos (figura 2.8).

\section{Paralelismo Farm}

O paralelismo farm é representado por uma lista de tarefas que são distribuídas entre os processos. Nessa abordagem existe o conceito de um gerenciador, que é responsável por 


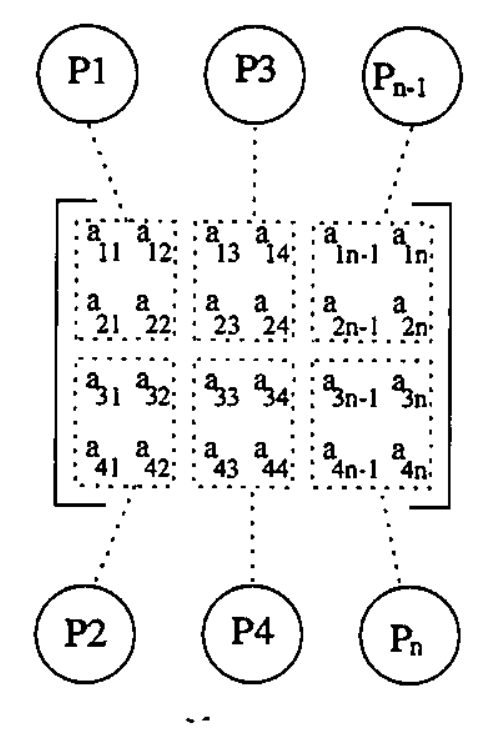

Figura 2.8: Paralelismo geométrico

dividir as tarefas e o conceito de trabalhadores que são encarregados de executar as tarefas recebidas e retornarem o resultado ao processo gerenciador (figura 2.9).

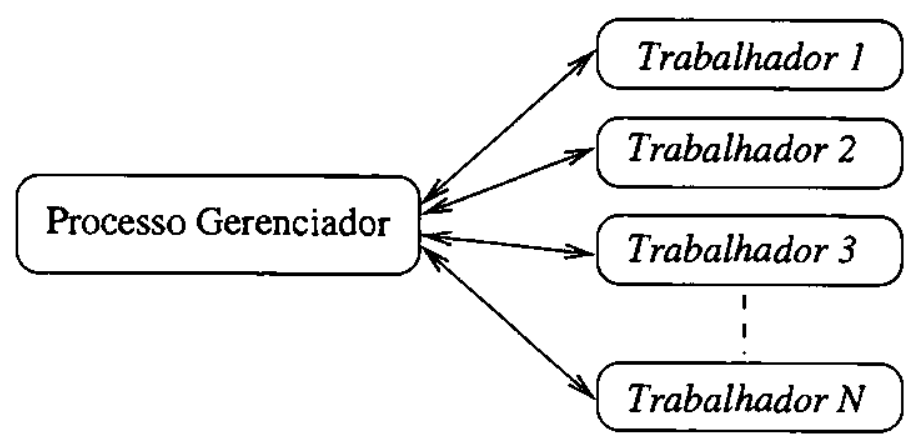

Figura 2.9: Paralelismo farm

\section{Paralelismo Algorítmico}

No paralelismo algorítmico, as aplicações são construídas de uma forma modular, onde cada módulo é representado por um processo. Os processos dessa abordagem apresentam funções especializadas e bem definidas dentro do programa. Entretanto, a quantidade de paralelismo permitida é bastante restrita e os resultados são pouco eficientes (figura 2.10).

\subsubsection{Ferramentas para Desenvolvimento de Aplicações Paralelas}

A forma mais natural de explorar o paralelismo na execução dos programas é construindo-os de forma paralelizada. Esses programas são mais complexos quanto ao seu projeto e im- 


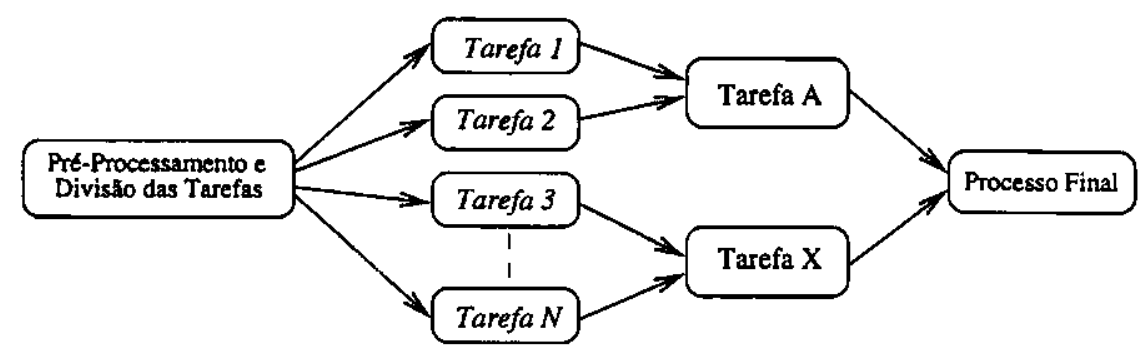

Figura 2.10: Paralelismo algorítmico

plementação que suas versões sequenciais correspondentes. Diversas técnicas existem para ajudar o programador em cada uma das fases do seu desenvolvimento. Uma série de ferramentas estão disponíveis, cada uma com características próprias, formando grupos distintos de aplicaçōes para a paralelizaçäo de programas [CAR99].

\section{Compiladores e Pré-processadores Paralelizadores}

Os compiladores e pré-processadores têm como objetivo a geração automática de programas paralelos. Os paralelizadores procuram realizar todo o trabalho, deixando a cargo do usuário apenas a tarefa de desenvolver o código sequencial.

O maior problema apresentado por essas ferramentas é o fato de que um programa sequencial ótimo não necessariamente resultará em um programa paralelo ótimo. Sendo, em muitos casos, uma solução paralela específica a melhor opção [PER96]. Exemplos de compiladores paralelizadores incluem o Parafrase2 [POL89] e PFC [ALL84, ALL87, CAL89].

\section{As Linguagens Paralelas}

Essas linguagens implementam os mecanismos necessários para a programação paralela. Podem ser citados como exemplo a linguagem OCCAM [BAR90] e a linguagem Fortran 90 [MET90].

As linguagens paralelas, se comparadas com a classe de ferramentas anterior, exigem um grande esforço por parte do programador, sendo necessário em muitos casos, o aprendizado de uma nova linguagem e conhecimentos adicionais envolvendo os paradigmas da programação paralela. Por outro lado, os códigos gerados por essas ferramentas são mais concisos e eficientes. 


\section{Extensōes às Linguagens}

Pode-se adicionar bibliotecas às linguagens convencionais de modo a oferecer suporte à programação paralela. O esforço de desenvolvimento concentra-se basicamente no aprendizado das rotinas pertencentes às extensões (bibliotecas). Neste contexto encontram-se o MPI (Message Passing Interface) [LAU96, EPC95] e o PVM (Parallel Virtual Machine) [BEG91, GEI92, GEI94, SUN90].

\section{Ferramentas de Auxílio à Paralelização}

A paralelização de códigos sequenciais além de ser um processo complexo, não gera resultados satisfatórios chegando, em certos casos, a produzir programas com desempenho equivalente ao do programa sequencial de origem.

As ferramentas de auxílio baseiam-se no fato de que a intuição humana, a análise automática e a transformação do código são importantes para uma paralelização com níveis de desempenho mais satisfatórios [KEN92]. Alguns exemplos dessas ferramentas são o P2D [PER96], o ParaScope [CAL88], o IDA [MER94] e o FORGE [Cal92, Cal95a, Cal95b].

\section{Ferramentas de Depuração}

Da mesma forma que na programação sequencial, as ferramentas de depuração visam a detecção e correção de erros durante o desenvolvimento de aplicações paralelas. A depuração no contexto paralelo, se depara com alguns problemas como a ausência de um relógio global e a não repetição dos resultados (o que dificulta a identificação de anomalias).

McDowell [MCD89] classificou essas ferramentas em duas categorias: Os depuradores interativos, onde é possível executar passo a passo o programa, permitindo sua suspensão temporária para a análise ou modificações de variáveis e os depuradores post-morten, onde qualquer verificação de resultados só é permitida após toda a execução do código (o que os tornam bastante limitados).

\section{Ferramentas de Análise de Desempenho}

As ferramentas de análise fornecem meios para o monitoramento da execução de aplicações paralelas. O objetivo central consiste na análise da execução para direcionar alteraçōes no 
código, visando ganhos de desempenho. Dentre as ferramentas pode-se citar o VT, o XPVM [GEI94, KOH97] e o XMPI [LAM00].

\subsection{A Máquina Paralela SPP3}

A máquina SPP3 é resultado do projeto de pesquisa em máquinas de alto desempenho, desenvolvido no LCAD-ICMC (Laboratório de Computação de Alto॰Desempenho do Instituto de Ciências Matemáticas e de Computação da Universidade de São Paulo). A primeira etapa desse projeto deu origem à máquina paralela SPP, um servidor de processamento paralelo baseado em processadores Transputers [HEN90]. Problemas como a dependência de um único fornecedor direcionaram as pesquisas no sentido de utilizar componentes comerciais amplamente disponíveis. A idéia central era a construção de uma máquina com alto poder computacional a baixo custo. Essa segunda etapa do projeto originou a máquina paralela SPP2 [Tri95b].

Visando facilitar o gerenciamento e a manutenção da máquina paralela SPP2, novos mecanismos de hardware foram propostos e implementados, resultando na máquina paralela SPP3.

O computador paralelo SPP3 pode ser classificado como uma arquitetura assíncrona MIMD com memória distribuída, ou multicomputador. Uma de suas características chave é a utilização de componentes amplamente disponíveis e de baixo custo, seguindo uma tendência no que tange ao desenvolvimento de máquinas MIMD de memória distribuída [Cra95, IBM93]. O SPP3 pode ser expandido até 256 nós de processadores. Os nós são interconectados entre si por meio de uma rede de alta velocidade constituída de switches e adaptadores Myrinet. É através dessa rede que se faz toda a comunicação para a execução das aplicações paralelas.

Cada nó do SPP3 é composto, basicamente, de uma placa mãe de um PC tradicional, um processador, memória e uma interface de rede. Um micro-controlador PIC [Mic95], cuja função é o gerenciamento via hardware dos nós da máquina, pode executar tarefas específicas como, por exemplo, retirar de operação os nós que estejam apresentando um comportamento anormal. A interligação entre os controladores se dá por intermédio de uma rede I2C [Phi95], formando assim, a rede de controle da máquina. A rede $\mathrm{I} 2 \mathrm{C}$ e o gerenciamento via hardware são explanados com mais detalhes na seção 5.4 . 
Uma rede Fast-Ethernet faz a interconexão entre o servidor e os nós, provendo a comunicação necessária para carregar o sistema operacional (boot remoto). É também através dessa rede que o usuário interage com os nós de processamento realizando toda a tarefa de monitoramento e gerenciamento. Essa é a única conexão entre os nós e o host $€$ permite que esses elementos fiquem separados por uma distância de até $100 \mathrm{~m}$. A figura 2.11 apresenta uma visão geral do SPP3.

Os nós podem ser configurados com ou sem disco local, cóm boot local ou remoto e com memória swap local ou remota. O boot remoto facilita a manutenção da máquina. A ausência de discos locais aumenta a confiabilidade e não se mostra essencial nos casos em que há pouco volume de operaçôes de $\mathrm{E} / \mathrm{S}$ com disco. O swap remoto é configurado em sistemas sem disco local apenas para evitar paradas por falta de memória, e não deve ser utilizado normalmente.

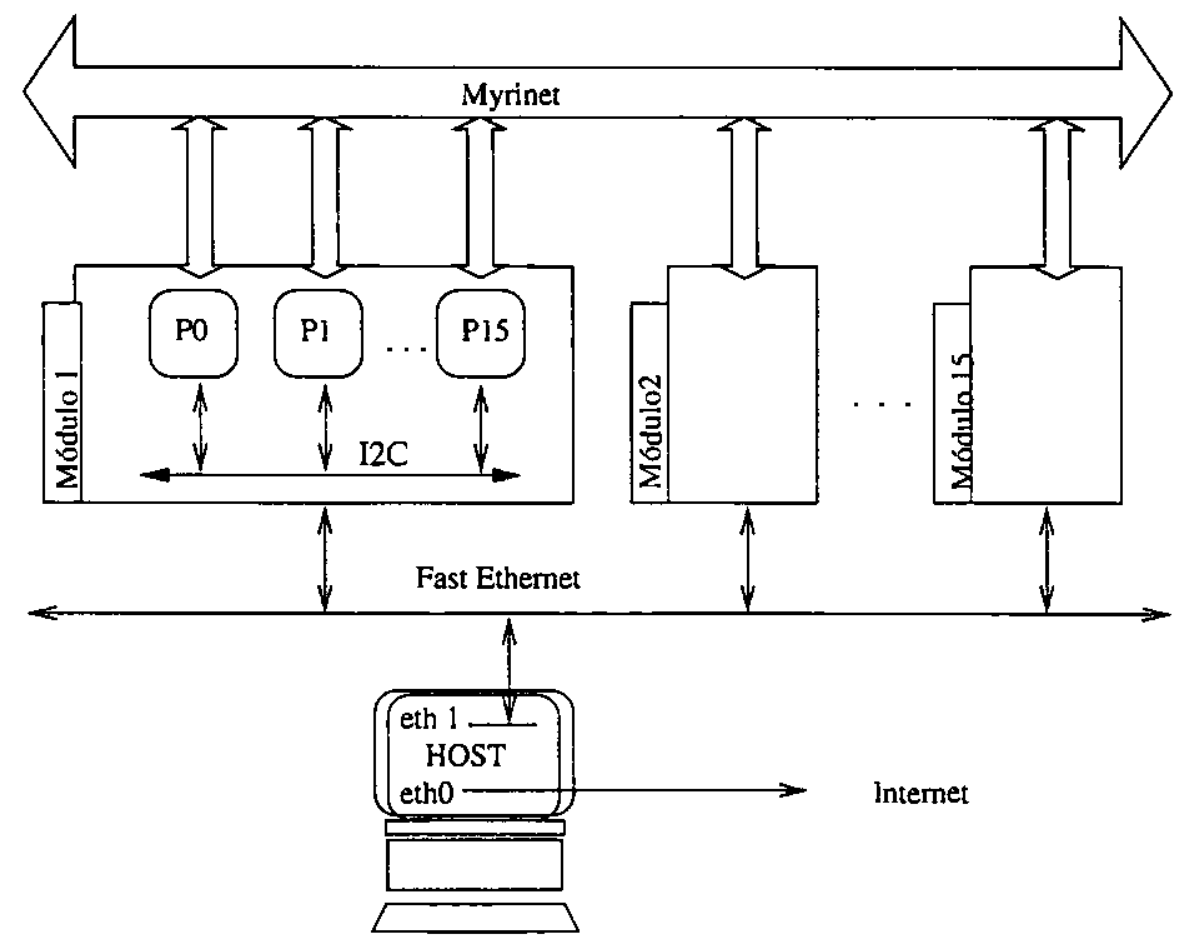

Figura 2.11: Visão geral da máquina SPP3

\subsection{O Projeto Beowulf}

O projeto Beowulf [MER98a] é a especificação e a implementação de uma arquitetura do tipo multicomputador para processamento paralelo. O sistema consiste de um nó de processa- 
mento servidor e um ou mais nós clientes interconectados por uma rede. Utiliza componentes de hardware tradicionais e adaptadores de rede (Ethernet, Myrinet ou Fast-Ethernet). No que se refere ao uso de software, o Beowulf utiliza ferramentas como o PVM e o MPI para auxiliar no processo de paralelização, e o Linux [WEL94] como sistema operacional. O nó servidor controla todo o cluster, funcionando como servidor de arquivos para os demais nós e como um gateway para o mundo exterior, sendo esse o único ponto de acesso à máquina. Os nós são configurados pelo servidor e não têm conhecimento prévio đe seus nomes e endereços IP.

Embora não utilize nenhum pacote especial de software, algumas modificações feitas no kernel [JOH97] do sistema, juntamente-com a utilização de algumas ferramentas de configuração, melhoraram o desempenho geral do sistema Beowulf, tornando a arquitetura mais eficiente, facilmente configurável e com maior usabilidade.

A primeira máquina Beowulf surgiu em 1994 com o propósito de auxiliar na resolução de problemas científicos espaciais do CESDIS (Center of Excellence in Space Data and Information Sciences) [YES99] da Universidade de Southern Queensland. A dependência de fornecedores dos computadores tipo MPP (Massively Parallel Processors) [FEL94] utilizados pelo CESDIS implicava em uma série de problemas tais como a indisponibilidade de ferramentas e dificuldades de manutenção, motivando assim as pesquisas que deram origem ao projeto Beowulf.

A primeira máquina Beowulf contava com 16 processadores $\mathrm{Dx} 4$ conectados por uma rede Ethernet.

O projeto Beowulf foi bem sucedido e rapidamente se espalhou pelos departamentos da NASA e outros centros de pesquisa envolvidos com aplicações voltadas para o processamento de dados espaciais.

\section{Classificação}

As máquinas Beowulf são construídas a partir de uma variedade de componentes. Para melhorar o desempenho, às vezes é desejável optar por soluções proprietárias de um ou alguns fabricantes. Baseado neste contexto, o sistema Beowulf se divide em duas classes: 


\section{Beowulf Classe I}

Essa classe de máquinas são projetadas utilizando componentes amplamente disponíveis. As vantagens são:

- O hardware é produzido por diversos fabricantes (baixo custo, fácil manutenção);

- Os drivers geralmente estão disponíveis para Linux;

- Os componentes seguem algum padrão (SCSI, Ethernet, etc.).

Desvantagem:

- Limitação de desempenho.

\section{Beowulf Classe II}

São as máquinas projetadas a partir de soluções proprietárias. A grande vantagem é:

- Melhor desempenho.

Desvantagens:

- Disponibilidade de drivers não é garantida;

- Dependência de fornecedor;

- Custos mais altos em relação aos computadores da classe I.

A escolha de uma classe ou outra vai depender fortemente do escopo em que se esteja trabalhando.

\subsection{Ferramentas para Gerenciamento e Controle de Máquinas Paralelas}

\subsubsection{KTop}

A KTop é uma ferramenta desenvolvida para o ambiente $K$ Desktop Environment (KDE) [KDE00]. Os processos em execução podem ser visualizados na forma de uma estrutura de 
árvore, como mostra a figura 2.12. A árvore é montada de acordo com o nível de relacionamento entre os processos. Clicando em cima de um processo com o botão direito do mouse, o usuário tem a opção de alterar a sua prioridade ou de enviar um sinal de controle. Os processos podem ser ordenados de acordo com a prioridade, utilização de CPU, utilização de Memória, etc. A ferramenta também disponibiliza um filtro que permite ao usuário visualizar somente os processos pertencentes ao sistema, a um grupo de usuários ou apenas os processos pertencentes ao próprio usuário.

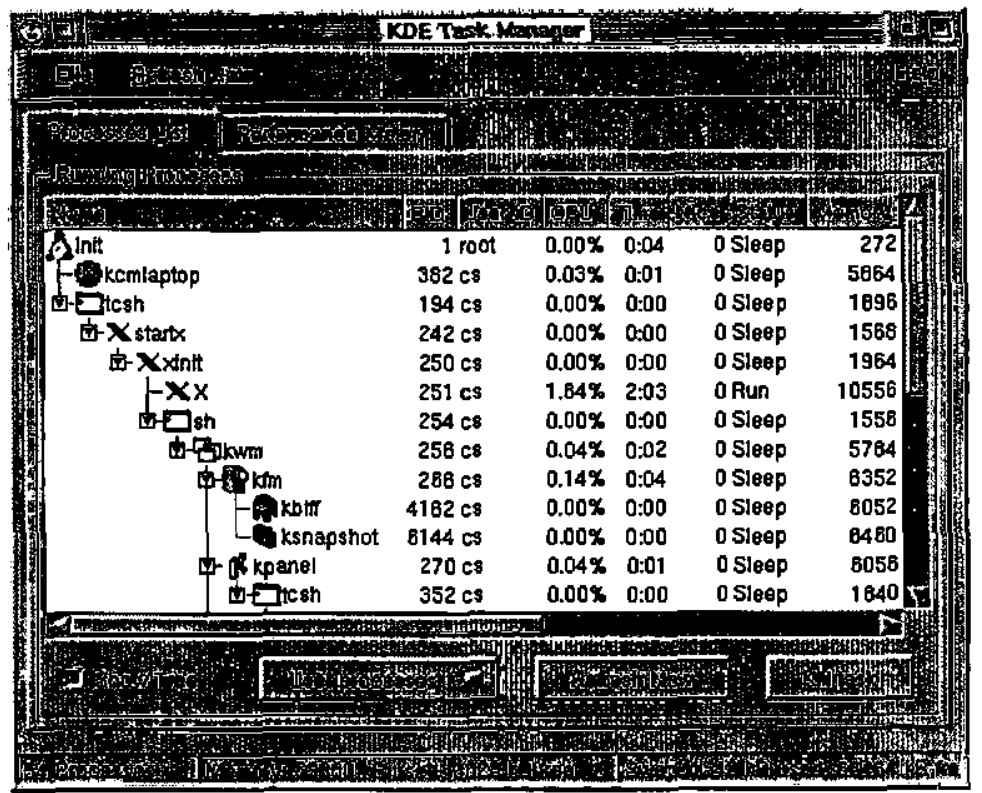

Figura 2.12: KTop - Processos listados em uma estrutura de árvore

\subsubsection{Procps Cluster}

Essa ferramenta consiste no pacote procps, com algumas modificações, que permitem o gerenciamento de vários processadores (cluster de processadores). Essas modificações se resumem na alteração da libproc (biblioteca necessária para a execução do aplicativo top), permitindo o envio de mensagens broadcast pela rede (via protocolo UDP [COM95]), e na implementação de um daemon (procd - executado na máquina a ser monitorada), para atender as requisições.

Esse programa utiliza o paradigma cliente/servidor, onde cada máquina pode fazer ao mesmo tempo o papel de cliente e de servidor, enviando e recebendo informações referentes ao estado dos processadores da rede. 
$\mathrm{Na}$ exibição das informações, além dos campos comuns ao procps convencional como PID, USER, \%MEM, etc., existe um campo adicional (HOST) que indica quais são as tarefas pertencentes a quais processadores do cluster (figura 2.13).

Em relação à figura 2.13:

- Os processos mostrados se referem à todos os processos em execução nos nós monitorados;

- Informações de memória principal (disponível e utilizada) e também de swap são interpretadas como sendo a soma geral (de todos os nós);

- A ociosidade dos nós indica a porcentagem de tempo que os nós não executaram nenhuma instrução desde a última atualização das informações.

Anexado a esse pacote está o beops, aplicativo similar ao $p s$, mas voltado para o ambiente paralelo. O pacote vem acompanhado também de outros utilitários que disponibilizam informações úteis como a quantidade de memória principal disponível (de todo o cluster), a taxa de atualização de cada nó, etc. Pelo fato de ser uma versão do procps estendida para um

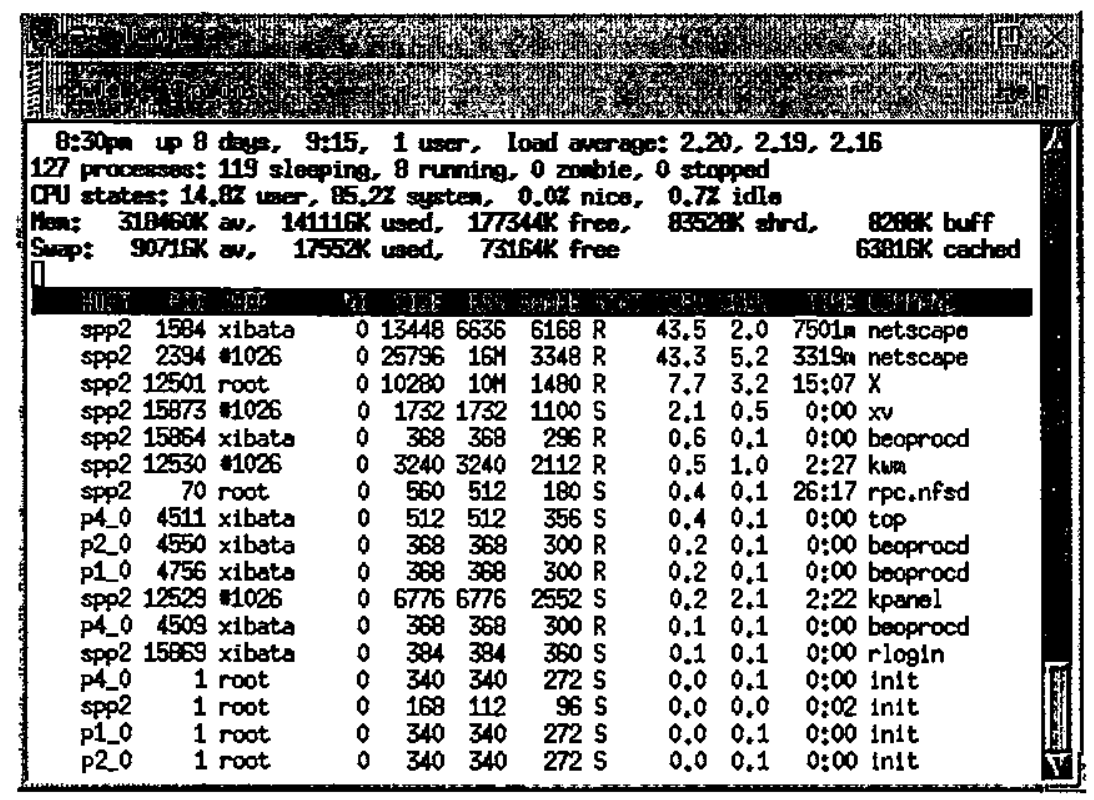

Figura 2.13: Monitoramento da máquina paralela SPP2 por intermédio do aplicativo top do pacote procps Cluster

ambiente paralelo, pode-se dizer que essa ferramenta é bastante familiar e consegue realizar a tarefa de monitoramento sem ocasionar grande perda de desempenho. 
Um ponto falho da ferramenta é a impossibilidade de gerenciar os processos, não existindo uma forma de abortar a execução ou alterar a prioridade de uma determinada tarefa, tornando-a apenas uma ferramenta de monitoramento.

\subsubsection{VT}

O VT é uma das ferramenta que compõe o pacote PE (Parallel Environmet) da IBM, desenvolvido para trabalhar com máquinas paralelas RISC System6000 Scalable POWER Parallel, ou para redes de máquinas RISC System600. O PE oferece recursos para o desenvolvimento e monitoramento de aplicações paralelas. O VT oferece uma interface gráfica composta de diversas telas de informações denominadas visões, utilizadas para a simulação da execução de um programa e para o monitoramento do desempenho do sistema. Essas visões podem ser mostradas em diversos formatos (gráfico de barras ou de malhas, por exemplo), procurando facilitar a interpretação das informações. A figura 2.14 apresenta a interface do VT, contendo visões divididas em categorias.

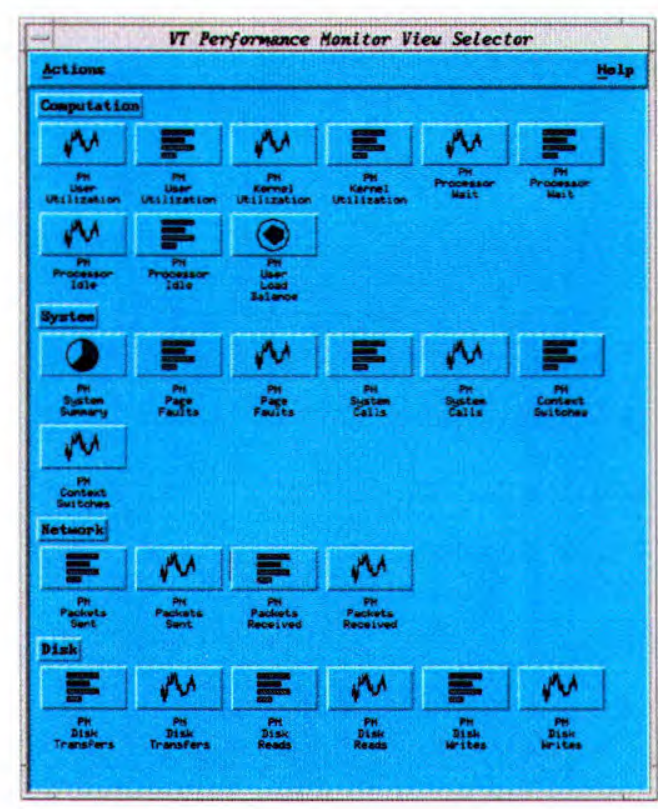

Figura 2.14: VT - Interface de visões

As visões do VT fornecem, de acordo com a categoria, as seguintes informações:

- Comunicação/Programa: Informações referentes a troca de mensagens entre os nós durante a execução de um programa; exibição do código fonte na simulação da execução. As visões desta categoria são usadas somente para a simulação de execuções; 
- Computação: Dados estatísticos da utilização dos nós de processamento que estão executando um certo programa;

- Disco: Informações sobre o número de transferências em disco;

- Rede: Dados sobre o número de pacotes TCP/IP enviados ou recebidos pelos nós;

- Sistema: Informações gerais do sistema, tais como chamadas a funções do sistema (System Calls) e chaveamento de contexto (interrupção da execução de um processo para que outro possa ser executado).

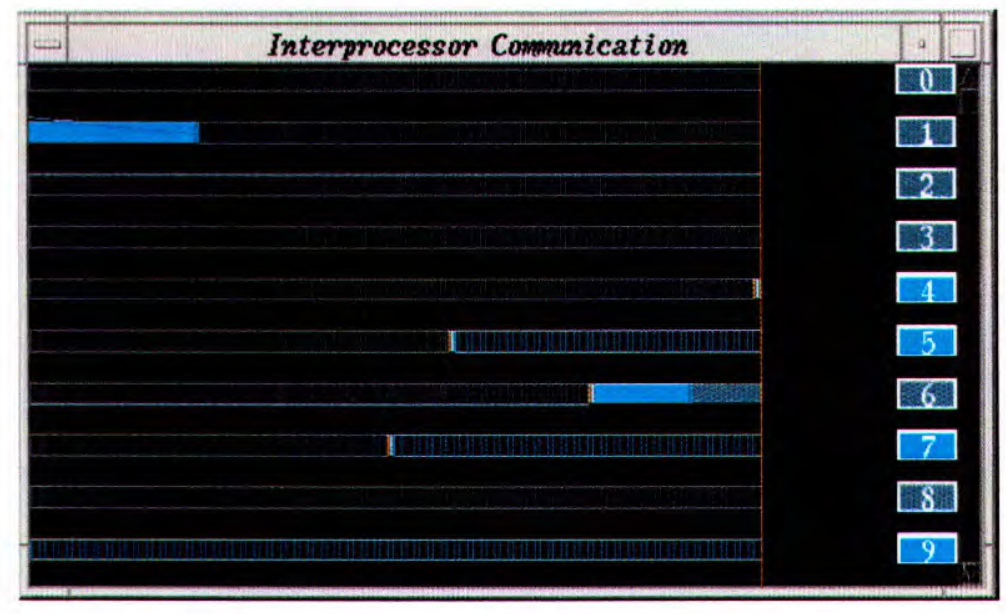

Figura 2.15: VT - Visão Interprocessor Communication

Para realizar o monitoramento de desempenho, o VT utiliza a simulação de execução de programas. Essa simulação é feita informando o nome do arquivo contendo os registros (informações) de execução do programa, cuja atividade se quer monitorar. Esse arquivo é criado configurando alguns parâmetros de compilação do programa a ser monitorado. Pela interface de visões pode-se escolher quais partes e atividades do sistema se quer visualizar. Uma destas visões poderia ser, por exemplo, o comportamento da rede (quantidade de pacotes recebidos, enviados, etc.). A Interprocessor Comunication é uma interface que fornece informações, em forma de barras horizontais, referentes à execução de um programa paralelo, como mostra a figura 2.15. As escalas representam intervalos de tempo. Os quadrados do lado direito das barras representam os nós e suas cores são de acordo com o seu estado durante a execução. Os blocos contínuos presentes nas barras indicam a existência de eventos de comunicação nos nós. O tamanho indica a duração destes eventos, e a cor a natureza do 
evento (bloqueante ou não bloqueante, por exemplo). Ao haver troca de mensagens entre os nós uma linha é traçada entre eles indicando uma comunicação.

Essa ferramenta permite ainda a escolha dos nós a serem monitorados. A seleção é feita através da interface para monitoramento de desempenho, onde se tem um conjunto de quadrados representando os nós de processamento da máquina paralela (figura 2.16). A escolha pode ser feita pelo quadrado correspondente ao nó, pelo nome do nó ou pelo nome da tarefa (monitoramento de todos os nós onde está sendo executada uma determinada tarefa).

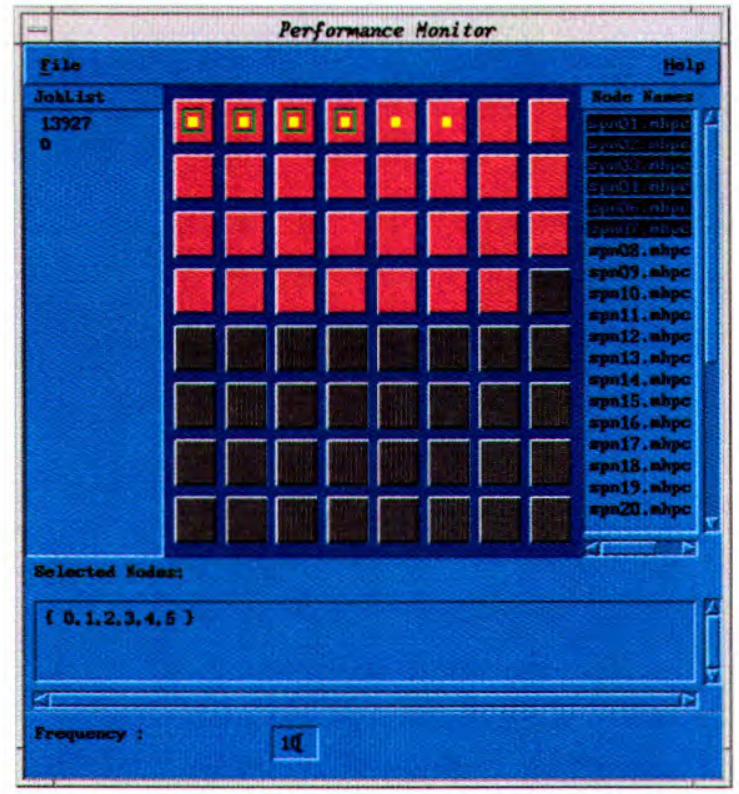

Figura 2.16: VT - Monitor de desempenho

\subsection{4 gr-Monitor}

Esse é um aplicativo de monitoramento onde cada processo é visualizado em gráficos de barras 3D. Para cada processo existem quatro barras que representam o consumo de CPU, utilização de memória, o tempo decorrido desde que o processo foi ativado e a quantidade de espaço em disco ocupada pelos aplicativos em execução. Na representação do gr-Monitor, os processos são agrupados pelo username (nome do usuário), e cada um destes agrupamentos estão dispostos em diferentes planos, como mostra a figura 2.17 .

O gr-Monitor [HAM98] permite que se escolha o ângulo de visão e a proximidade dos dados representados (mecanismos de rotação, translação e zoom). Essa ferramenta é 
constituída de dois componentes: o gr-monitor e o gr-gather. Esse último é responsável por coletar os dados necessários do sistema de arquivos proc e enviá-los ao gr-Monitor, que os exibe em uma janela X Window. As informações enviadas por esse módulo são apresentadas em uma interface gráfica bem definida e são facilmente compreendidas, possibilitando assim, que se visualize somente os valores de interesse ou até dados provenientes de outras aplicações. A taxa de atualização das informações é de total controle do usuário.

Essa ferramenta pode, opcionalmente, monitorar máquinas remotas. Neste caso, o gr-gather é executado no computador que se deseja monitorar. Os dados são passados ao gr-Monitor por intermédio do rsh (remote shell). No que tange à visualização das informações (barras 3D), o aplicativo foi desenvolvido utilizando os recursos da biblioteca gráfica OpenGL, exigindo uma máquina com maior capacidade computacional, para se ter uma boa interatividade com a ferramenta.

O gr-Monitor é considerado como uma ferramenta apenas de monitoramento, não permitindo nenhum tipo de gerenciamento de processos. Um outro problema reside em seus recursos gráficos que embora sejam bastante intuitivos e interessantes, exigem um alto esforço computacional.

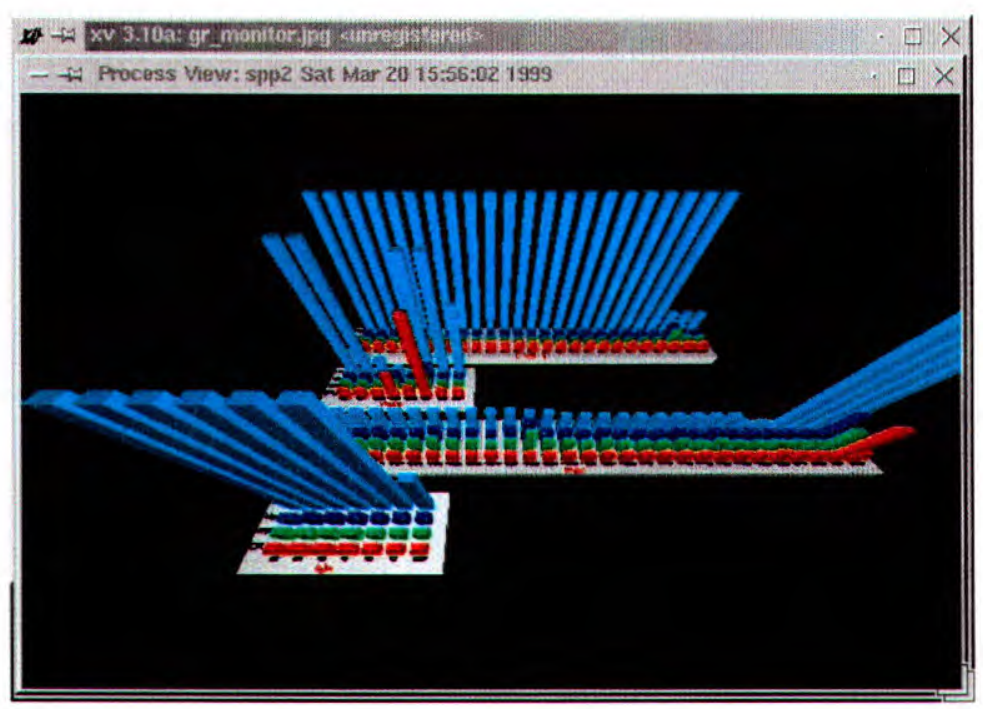

Figura 2.17: gr-Monitor - Representação das informações 


\subsection{5 bWatch}

O programa bWatch [MER98b, RAD98a, RAD98b] realiza o monitoramento de carga, de memória e do tempo de atividade de um nó de processamento em uma máquina paralela executando Linux. O monitoramento é realizado, a exemplo do gr-Monitor, através de comandos remotos (utilização do remote shell). Os comandos se resumem em requisições feitas aos nós, solicitando o retorno das informações de carga e memória. Essas informações são então listadas em uma tabela, como mostra a figura 2.18 .

\begin{tabular}{|c|c|c|c|c|c|c|c|c|c|c|c|c|c|}
\hline \multicolumn{14}{|c|}{ bWatch 1.02} \\
\hline $\begin{array}{l}\text { Mnct } \\
\text { Mante }\end{array}$ & $\begin{array}{l}\text { Wam } \\
\text { Users }\end{array}$ & There & $\begin{array}{l}7 \text { man } \\
\text { toad }\end{array}$ & $\begin{array}{l}5 \mathrm{~min} \\
\text { Load }\end{array}$ & $\begin{array}{c}15 \mathrm{~mm} \\
\text { load }\end{array}$ & $\begin{array}{l}\text { Mumin } \\
\text { Mrocs. }\end{array}$ & $\begin{array}{l}\text { Thtal } \\
\text { Mean }\end{array}$ & Mean & $\begin{array}{l}\text { Shamen } \\
\text { Mean }\end{array}$ & Burrars & Cache & $\begin{array}{l}\text { Inta } \\
\text { 3was }\end{array}$ & $\begin{array}{l}\text { Frep } \\
3 \text { wapp }\end{array}$ \\
\hline pu & U users & s:sy & 0.00 & 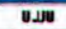 & Uater & 21 & b1 $\mathrm{Alb}$ & $59140 \mathrm{~Kb}$ & $4 \mathrm{Mb}$ & U MD & CMt & U NA & OAlt \\
\hline p 1 & 0 usars & 6:12 & 0.00 & 0.00 & 0.00 & 27 & 61 Mt & $59711 \mathrm{~Kb}$ & AMb & OMb & $2 \mathrm{Mt}$ & O Mat & a Mt \\
\hline$p^{2}$ & 0 users & 6:03 & 0.00 & 0.20 & 0.00 & 27 & $61 \mathrm{Me}$ & $50956 \mathrm{~kb}$ & 4 Mo & O Mb & $2 \mathrm{Mt}$ & O Net & $O M$ \\
\hline 03 & u users & b:1 & U. & U.Uz & ועט & 21 & b1 $\mathrm{Alb}$ & $\sin 44 \mathrm{~kb}$ & $+\mathrm{Mb}$ & U $\mathbf{~ M b}$ & C Mr & U Net & a $\mathrm{MB}$ \\
\hline$M$ & (x)..... & …... & ....... & ........ & & & & & & .......... & & & $\cdots$ \\
\hline$p^{5}$ & 0 users & $6: 26$ & 0.09 & 0.01 & 0.00 & 27 & G1 Nab & $53144 \mathrm{~kb}$ & $4 \mathrm{Mb}$ & $\mathrm{a} \mathrm{Mb}$ & $2 \mathrm{Mb}$ & $\mathrm{O} \mathbf{~ N b}$ & O Mt \\
\hline p6 & 0 users & 6:01 & 0.09 & 0.01 & 0.00 & 28 & $61 \mathrm{AbB}$ & $50996 \mathrm{~Kb}$ & 4 Mb & $\mathrm{O} \mathrm{Mb}$ & $2 \mathrm{Mn}$ & O Net & O A D \\
\hline$p^{7}$ & 0 users & $5: 54$ & 0.00 & 0.00 & 0.00 & 27 & $62 \mathrm{Mbh}$ & $59260 \mathrm{Kh}$ & $4 \mathrm{Mh}$ & $\mathbf{O M b}$ & $2 \mathrm{Mh}$ & $\mathbf{O} \mathbf{M b}$ & a Me \\
\hline \multicolumn{7}{|c|}{ Hetresh } & \multicolumn{7}{|c|}{ txit } \\
\hline
\end{tabular}

Figura 2.18: Monitoramento de 8 nós da máquina SPP2. O nó p4 não está operacional

Os campos apresentados por esse aplicativo são:

- Num users: o número total de usuários que estão utilizando o nó;

- Time: a quantidade total de horas que o nó está ativo;

- 1 min, 5 min, 15 min load: carga média de CPU nos últimos (1, 5 e 15) minutos;

- Num procs: número de processos em execução no nó;

- Total mem: memória principal total do nó;

- Free mem: quantidade de memória principal não utilizada;

- Total swap: quantidade de memória swap disponível;

- Free swap: memória swap não utilizada.

\subsubsection{AIX PSSP}

O PSSP é um conjunto de programas com funções operacionais e administrativas para o gerenciamento da máquina paralela SP2 da IBM. Essa ferramenta permite que o usuário 
tenha o controle de todo o sistema por meio de uma estação de trabalho podendo instalar, manter e desativar toda a máquina SP2. Dentre as atividades pertinentes ao gerenciamento e monitoramento podem ser citadas:

- Gerenciamento de impressão;

- Desligamento de um nó, de um conjunto de nós ou de todos os nós da máquina;

- Possibilidade de acesso exclusivo a um conjunto de nós;

- Interação com um outro nó qualquer, possibilitando assim, o conhecimento de seu estado;

- Execução de comandos do sistema em paralelo (por exemplo, enviar um sinal de reboot para todos os nós com um único comando);

- Controle de login para bloquear o acesso não autorizado de um usuário (ou grupo de usuários) a um nó específico ou a um conjunto de nós.

Um sistema gráfico facilita o gerenciamento de toda a máquina. Os objetos do sistema, tais como nós de processamento e conexões de rede, podem ser representados através de ícones, ficando a cargo do usuário criar uma representação dos eventos do sistema que se deseja monitorar.

\subsection{7 asMon - Monitoramento de Carga de CPU e Memória}

A ferramenta asMon [HAL98], concebida para a plataforma Linux, apresenta uma interface gráfica funcional, permitindo a visualização simultânea de diversas variáveis do sistema, como mostra a figura 2.19. As informações são dispostas analogicamente, em forma de gráfico de barras e discretamente, através de números. São representadas a carga de CPU, a quantidade total de memória utilizada, a quantidade de memória compartilhada, a quantidade de memória em cache e a quantidade de memória swap. Embora consiga refletir com fidelidade o estado do sistema consumindo poucos recursos, a ferramenta asMom não disponibiliza suporte para o monitoramento de múltiplos elementos de processamento, impossibilitando sua utilização em ambientes paralelos. 


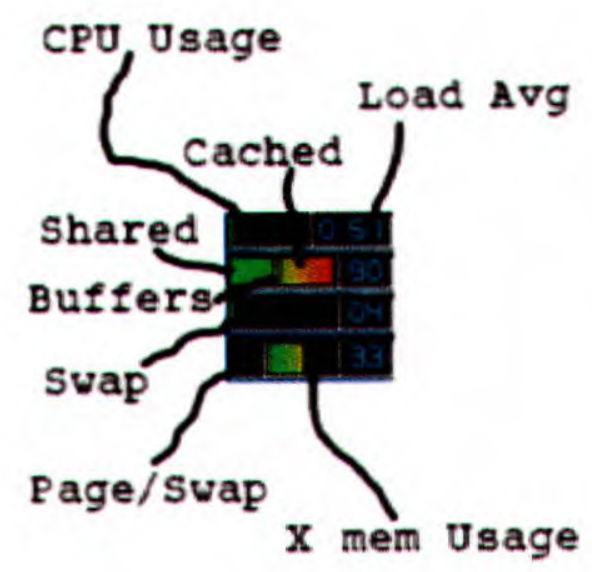

Figura 2.19: asMon - Interface gráfica

\subsubsection{PCP (Performance Co-Pilot)}

Esse pacote disponibiliza um conjunto de ferramentas que oferecem suporte às tarefas de gerenciamento e monitoramento de desempenho de um sistema centralizado ou distribuído (clusters, por exemplo). O pacote PCP [CHA99] implementa as seguintes características:

- Uma API para acesso aos dados de desempenho obtidos de um sistema monitorado. Essa API oculta detalhes de como os dados são coletados;

- Uma arquitetura cliente/servidor permitindo que um cliente monitore um servidor ou um conjunto de servidores. Essa abordagem, semelhante a usada na ferramenta Mirador (seção 2.7.10), centraliza o processo de monitoramento de sistemas distribuídos;

- Arquivos de $\log$ permitindo o armazenamento de dados históricos de monitoramento;

- Os mecanismos de monitoramento podem ser expandidos, incorporando novas funcionalidades;

- Um framework (bibliotecas, APIs, daemons, agentes) para coletar dados de monitoramento em nível de hardware, kernel, serviços de rede e de aplicações;

- Bibliotecas e implementações de utilitários que realizam o monitoramento e gerenciamento de desempenho;

- Camada de transporte para mover os dados de monitoramento entre o sistema monitorado e o sistema monitorador. Isso garante a interação entre plataformas heterogêneas; 
- Um agente responsável pela coleta de dados de monitoramento de sistemas Linux. Esses dados incluem informaçōes referentes a: CPU, disco, memória, swap, rede (NFS, $\mathrm{RPC})$ e filesystem;

- Agentes que exportam dados de monitoramento referentes a: atividades de servidores de Web, tráfego em roteadores Cisco, fila de mensagens do sendmail e atividades do próprio PCP.

A disponibilidade de APIs funcionais e interfaces bem definidas torna o PCP um pacote interessante tanto no desenvolvimento de novas aplicaçōes quanto no acréscimo de novas funcionalidades.

\subsubsection{SCMS (Smile Cluster Management System)}

O SCMS surgiu com o intuito de auxiliar os administradores de máquinas Beowulf (seção 2.6) no gerenciamento de todo o cluster de processadores. A ferramenta contém uma série de utilitários, que podem ser executados via linha de comando ou por uma interface gráfica. O SCMS dispõe das seguintes funções:

- Submissão de comandos paralelos para todos os nós;

- Oferece respaldo as tarefas de gerenciamento tais como reboot, shutdown, e execução de comandos remotos para um nó em particular, para um conjunto de nós ou para toda a máquina;

- Comandos paralelos Unix em modo texto e modo gráfico;

- Geração de informações estatísticas do estado dos nós (carga de CPL, memória principal e swap) e da configuração de hardware dos dispositivos como, por exemplo, a tensão da fonte de alimentação.

O pacote SCMS pode ser decomposto, de acordo com o tipo de tarefa a ser executada, nos seguintes módulos:

\section{Gerenciamento do Sistema}

O gerenciador de sistema consiste em um conjunto de comandos de menu, responsáveis por operações básicas do sistema como, por exemplo, a reiniciação de um nó. O usuário seleciona, 
através de um painel de controle, o comando e o (s) nó (s) em que o referido comando será executado.

\section{Configuração do Sistema}

Disponibiliza informações referentes à configuração da máquina (ou de nós individuais). É possível, entre outras coisas, visualizar o esquema sobre o qual está montado o sistema de arquivos de um certo nó.

\section{Monitoramento do Sistema}

Consiste de um daemon de coleta de dadō̄ e de ferramentas gráficas para visualização das informações geradas.

Tabela 2.1: Comandos paralelos presentes no pacote SCMS

\begin{tabular}{|l|l|}
\hline concatenate & concatena arquivos localizados em diferentes nós \\
\hline copy & copia os arquivos entre os nós do cluster \\
\hline execute & executa o comando shell em todos os nós especificados \\
\hline find & encontra um arquivo no cluster \\
\hline find process & executa a busca de um processo no cluster pelo número do processo \\
\hline kill process & interrompe um processo do cluster \\
\hline kill user & interrompe um processo do cluster pelo nome do usuário \\
\hline list & lista os arquivos do cluster \\
\hline load & informa a carga de todo o cluster \\
\hline move & move um arquivo de um nó para outro \\
\hline predicate & executa comandos em múltiplos nós condicionalmente \\
\hline process status & exibe informações dos processos em execução nos nós \\
\hline remove & remove arquivos do cluster \\
\hline test & executa teste de conexão em múltiplos nós \\
\hline
\end{tabular}




\section{Comandos Paralelos}

O sistema SCMS disponibiliza um conjunto de comandos Unix básicos capazes de serem executados em paralelo, permitindo assim uma maior interação entre o usuário e os nós da máquina. A tabela 2.1 lista os comandos e suas funções.

\section{Plug In}

Para tornar o sistema extensível, foi especificada uma interface Plug in, capaz de acomodar futuros utilitários. Um desses exemplos é o monitor de hardware Lm_sensors [LmS98], que vem como parte integrante da ferramenta.

O SCMS é composto por um programa servidor, cuja função é coletar e enviar informações referentes ao nó local para o host, e por um programa cliente, responsável pela coleta das informações que chegam dos nós e por executar (via rsh) os comandos paralelos. A ferramenta dispõe também de uma interface para a visualização das informações (figura $2.20)$.

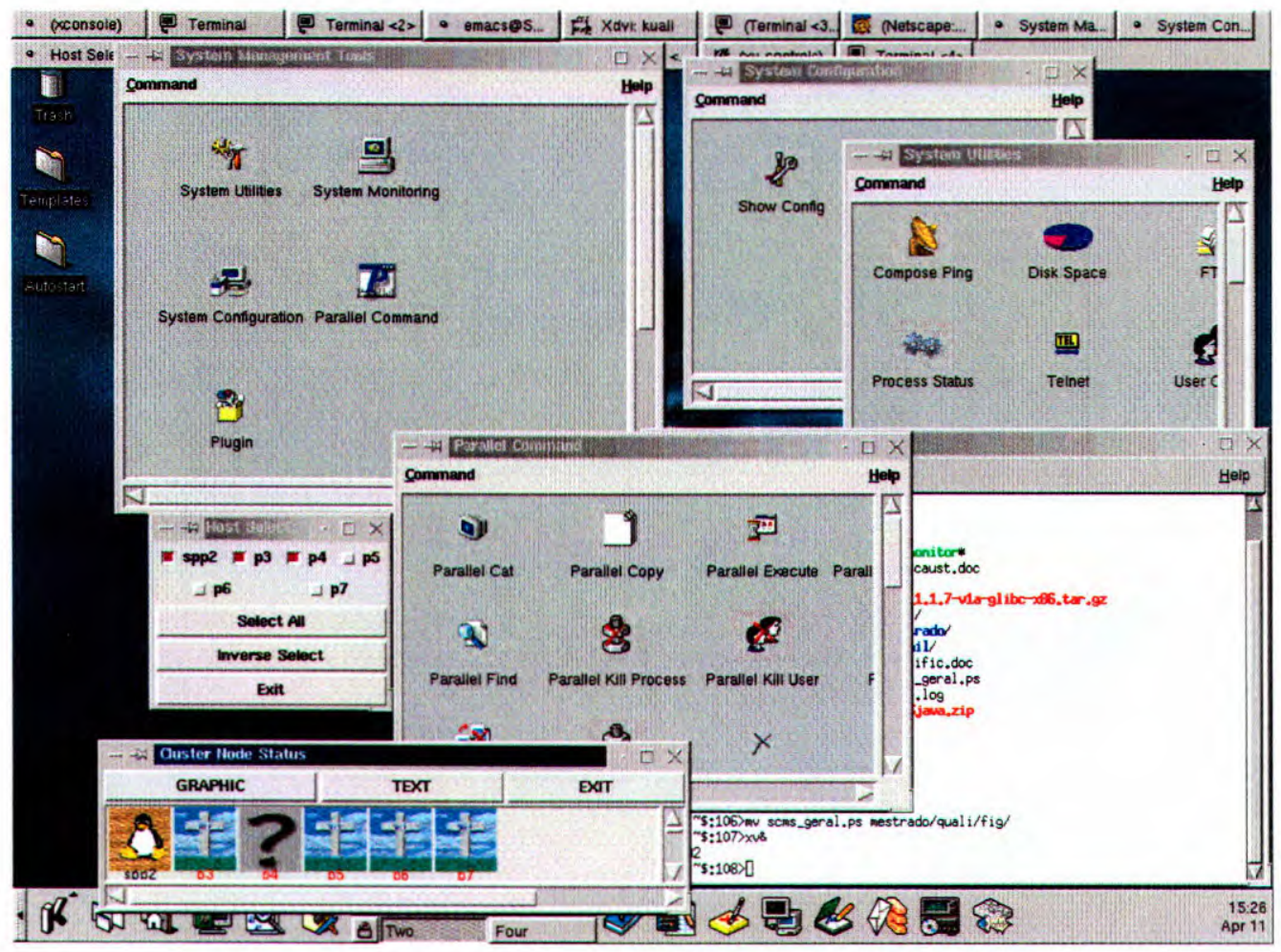

Figura 2.20: A ferramenta SCMS 


\subsubsection{Mirador}

A ferramenta Mirador [ARA98] foi concebida com o objetivo de gerenciar e monitorar a máquina paralela SPP2 [Tri95b, TRI95a], podendo ser estendida para a utilização em uma reae de computadores Linux. Essa ferramenta permite ao usuário ter o controle geral da máquina, possibilitando:

- O acesso às informações referentes aos nós de processamento como carga, memória principal e swap disponiveis, tarefas em execução, descrição e velocidade dos processadores, memória principal e swap instaladas e informaçōes de tempo;

- Interrupção de processos que executam nos nós;

- Obter informações referentes às tarefas do usuário, procurando assim facilitar o acompanhamento da execução de aplicações paralelas;

- Gerenciar as contas de usuários, permitindo adicionar, remover ou atualizar os usuários do sistema de uma maneira simples e eficiente;

- Monitoramento e gerenciamento remoto da máquina através da Internet de maneira independente de plataforma.

A ferramenta Mirador apresenta uma interface gráfica, exibindo as informações de uma forma estruturada e modular, facilitando assim a interação entre o usuário e o SPP2 bem como a visualização e comparação dos dados gerados (figura 2.21) [ARA98].

Cada um dos quadrados (ou ícone) da figura 2.22 [ARA98] representa um processador e de acordo com o formato e cor, indicam o estado operacional do nó, sua carga e o tipo de seleção (para monitoramento e/ou gerenciamento). As cores dos quadrados variam de acordo com a carga dos processadores, permitindo assim, uma fácil diferenciação de carga dos nós. Por exemplo, a cor preta representa a ausência de atividades nos nós, enquanto a cor branca representa um alto nível de atividades. Os ícones marcados com um " $\mathrm{X}$ " indicam processadores inoperantes.

O formato do ícone serve para informar se um nó está selecionado para gerenciamento (formato de um botão pressionado) ou não. Quando um nó está "selecionado para gerenciamento", certas operações sobre ele são permitidas. A reiniciação do processador é um exemplo de operação possível. 


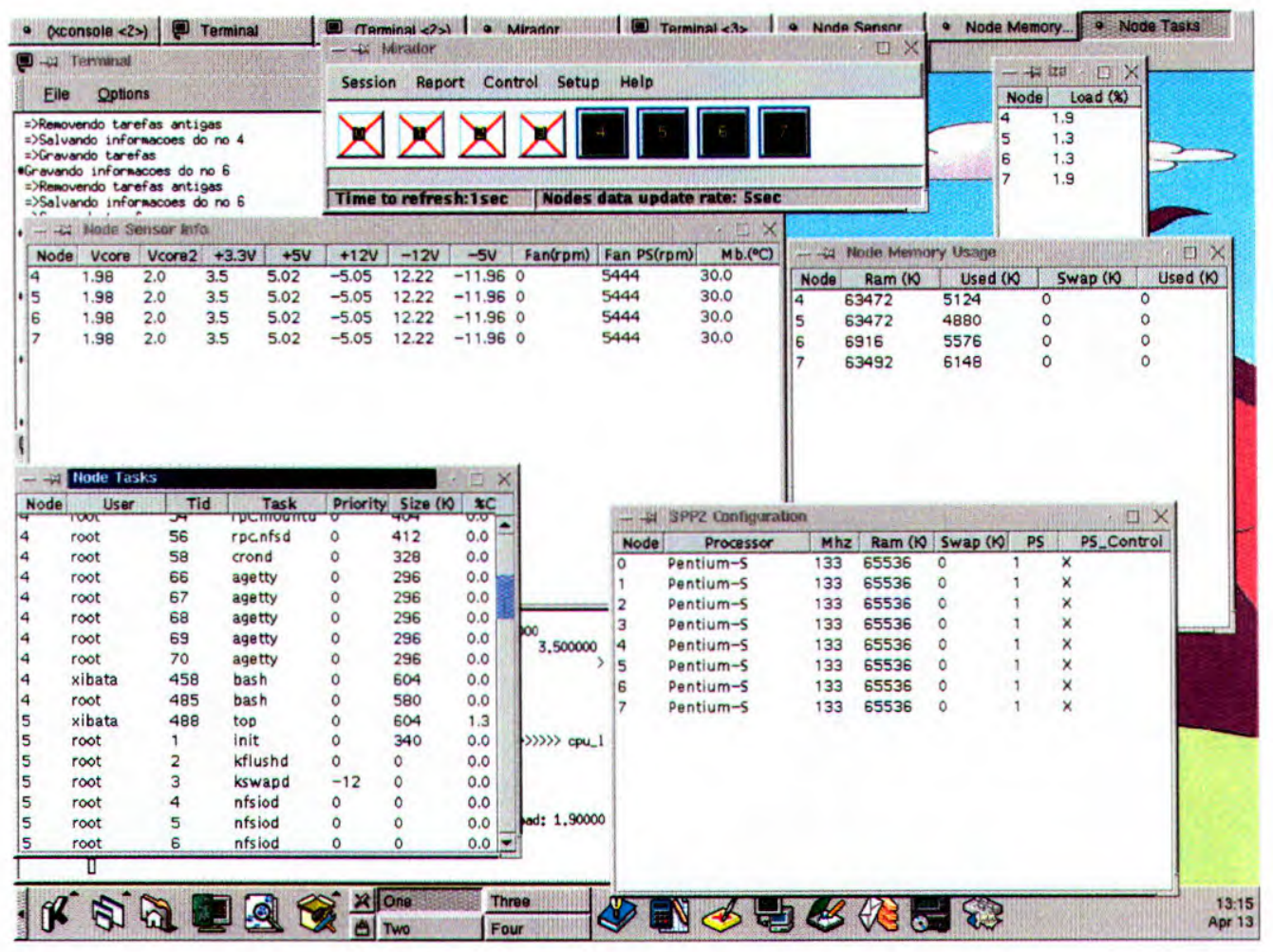

Figura 2.21: Uma visão geral da Mirador

A ferramenta Mirador é bastante flexível, permitindo que o usuário personalize e configure diversos parâmetros do sistema de acordo com suas necessidades. É possível, entre outras coisas, configurar a taxa de atualização das informações, selecionar os nós a serem monitorados e gerenciados, especificar os parâmetros de conexão como timeout e o tipos de mensagens enviadas aos nós (ponto a ponto ou broadcast). A ferramenta permite ainda a gravação, em um diretório profile, de todas essas configurações.

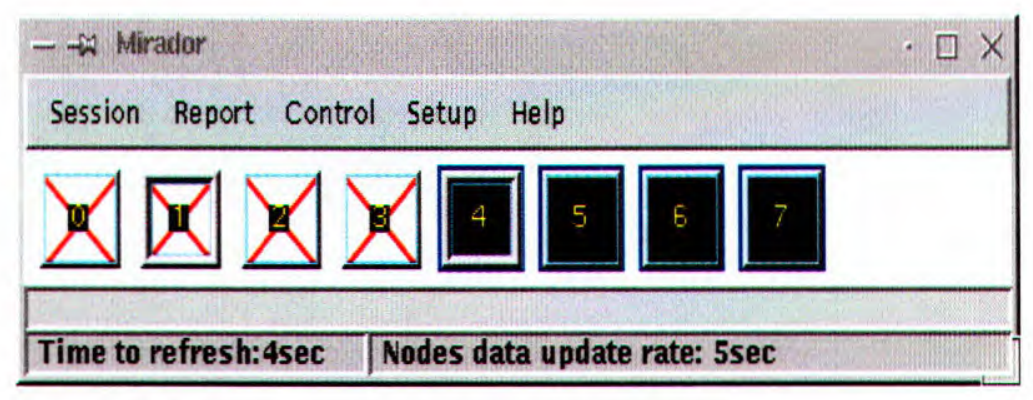

Figura 2.22: A ferramenta Mirador - os quadrados representam os processadores 


\section{Arquitetura da Ferramenta Mirador}

A ferramenta Mirador foi desenvolvida de forma a garantir uma menor troca de informações entre seus componentes, visando assim, o mínimo de interferência na rede de comunicação e nos nós de processamento.

Os módulos de software e bases de dados da ferramenta Mirador são ilustrados na figura 2.23 [ARA98].

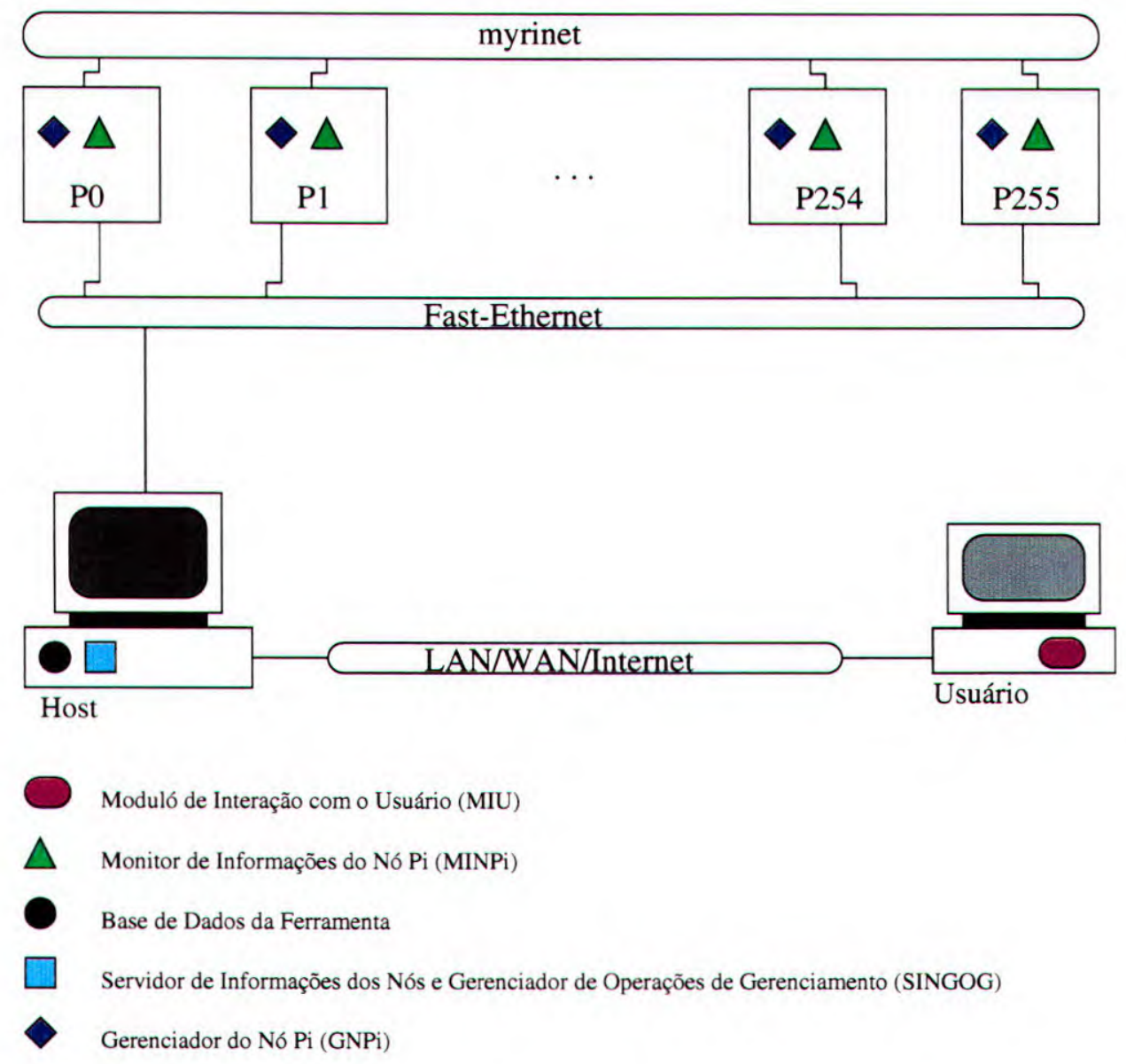

Figura 2.23: Arquitetura da ferramenta Mirador

A ferramenta Mirador é, basicamente, integrada pelos seguintes módulos:

MIU (Módulo de Interação com o Usuário)

Esse módulo é responsável por toda a interação entre o usuário e a máquina SPP2, sendo necessário que seja executado localmente (no computador do usuário). É através do MIU que se obtém a configuração de uso da ferramenta, as informações de monitoramento e 
configuração dos nós. É também por meio dele que se executa as operações de gerenciamento e de armazenamento das opções do usuário.

SINGOG (Servidor de Informações dos Nós e Gerenciador de Operações de Gerencia$\underline{\text { mento) }}$

Encarregado de obter a configuração de uso da ferramenta, armazenar as configuraçōes do usuário, obter informações de monitoramento, atualizar informações dos nós e executar operações de gerenciamento sobre um conjunto de nós ou de tarefas. Este módulo se localiza no host.

\section{$\underline{\text { GNP } i \text { (Gerenciador do Nó } \mathrm{P} i \text { ) }}$}

As funções desse módulo estão relacionadas às tarefas de gerenciamento dos nós. Para cada um dos nós que estiverem em atividade existe um módulo GNPi em execução. Assim, caso seja requisitado a reiniciação de um determinado processador, o servidor GNP $i$ do nó a ser reiniciado será acionado para executar a tarefa.

\section{$\underline{\text { MINP } i \text { (Monitor de Informações do Nó P } i \text { ) }}$}

Este módulo é responsável por obter e processar as informações de memória principal e swap, de tarefas e de carga de CPU dos nós. De acordo com intervalos especificados pelo usuário, é feita a coleta e o envio de tais informações ao módulo SINGOG.

Do mesmo modo que o GNP $i$, o MINP $i$ é executado em cada um dos nós em atividade.

\section{Protocolo de Comunicação entre os Módulos da Ferramenta}

O protocolo de comunicação entre os módulos da ferramenta é basicamente constituído por requisições de serviço (execução de funções remotas), onde para cada requisição enviada espera-se uma resposta. A figura 2.24 [ARA98] ilustra o esquema de protocolos da ferramenta Mirador.

\section{$\underline{\text { Protocolo Requisição de Serviço/Resposta }}$}

Uma requisição de serviço de um módulo a outro é constituída dos seguintes parâmetros:

- Identificação do serviço a ser executado. Um módulo pode implementar diversas 


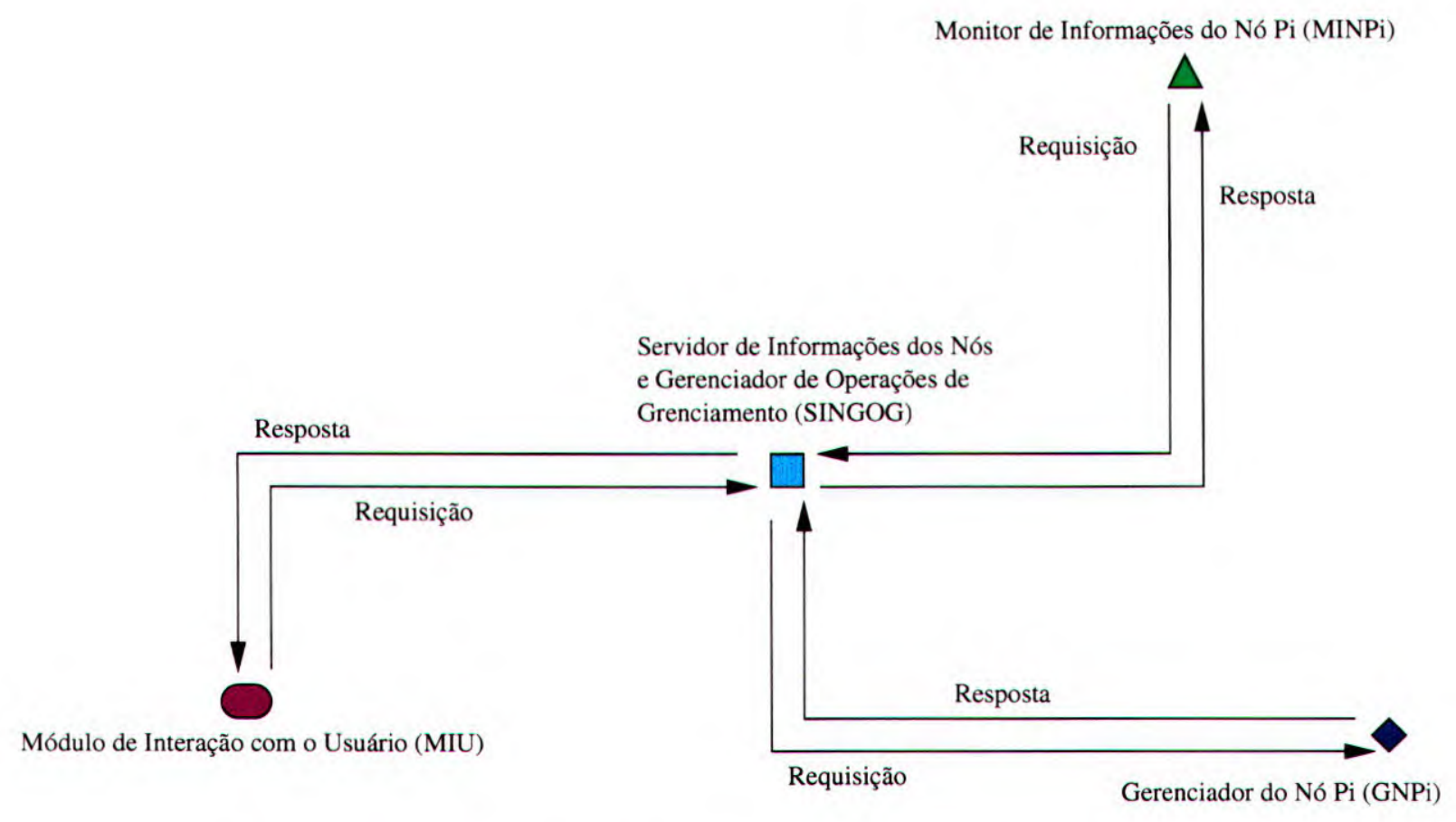

Figura 2.24: Protocolos de comunicação da ferramenta Mirador

funções (serviços), sendo necessário informar especificamente qual o serviço a ser requisitado. Na figura 2.24, a função de um módulo está ligada a função de outro módulo indicando a requisição de um serviço;

- Código de acesso ao serviço: o acesso a determinados serviços do módulo SINGOG requer a identificação do usuário (login e senha) de forma a não comprometer a segurança do sistema (um usuário comum não deve poder interromper a execução de tarefas que não pertençam a ele). A utilização deste tipo de autenticação pode ser vantajoso, visto que:

- Restringe o acesso dos serviços aos usuários da máquina;

- Garante o acesso aos serviços do módulo SINGOG por qualquer usuário da máquina paralela, divulgando apenas a interface desses serviços;

- Uma vez que o módulo SINGOG se localiza no host e possui acesso direto ao sistema operacional, o processo de autenticação torna-se bastante eficiente.

- Operação a ser executada pelo serviço. Alguns serviços implementam mais de um tipo de operação, sendo necessário informar a operação a ser executada. O serviço de 
gerenciamento de tarefas do módulo SINGOG pode tanto eliminar as tarefas quanto alterar suas prioridades de execução;

- Dados necessários à execução do serviço. Envolvem os dados que um serviço precisa para serem executados.

\section{Especificaçāo da Ferramenta Mirador}

A figura 2.25 apresenta o diagrama de fluxo de dados que especifica as funcionalidades da ferramenta Mirador. O conjunto dessas funções define uma API que pode ser usada no desenvolvimento de outras ferramentas.

\section{Descrição das funçōes da ferramenta}

\section{Gerenciar Nós}

Essa função é responsável pelo gerenciamento de um conjunto de nós, recebendo como parâmetros os identificadores dos nós a serem gerenciados e a operação de gerenciamento a ser executada sobre eles. Essas operações se resumem no reinicio dos nós por software e sincronização das datas e horários dos nós com a data e hora do host.

Ao se realizar uma operação com sucesso, a função retorna uma resposta afirmativa. Caso contrário é retornado um erro juntamente com a lista dos nós onde a execução da operação não teve êxito.

Para cada operação de gerenciamento é feita a atualização na base de dados que contém as informações dos nós (Informações dos Nós), de maneira que esta sempre reflita o estado atual dos nós. Por exemplo, se um nó for reiniciado, a base de dados dever ser modificada indicando que o nó não está operacional.

\section{Gerenciar Tarefas}

Essa função é responsável por coordenar o gerenciamento das tarefas que se encontram em execução nos nós, recebendo como parâmetro o identificador da tarefa e o nó de cada tarefa a ser gerenciada. As operações consistem em: interromper a execução das tarefas ou alterar suas prioridades de execução.

A operação de gerenciamento de tarefas é efetivada contatando o sistema operacional 


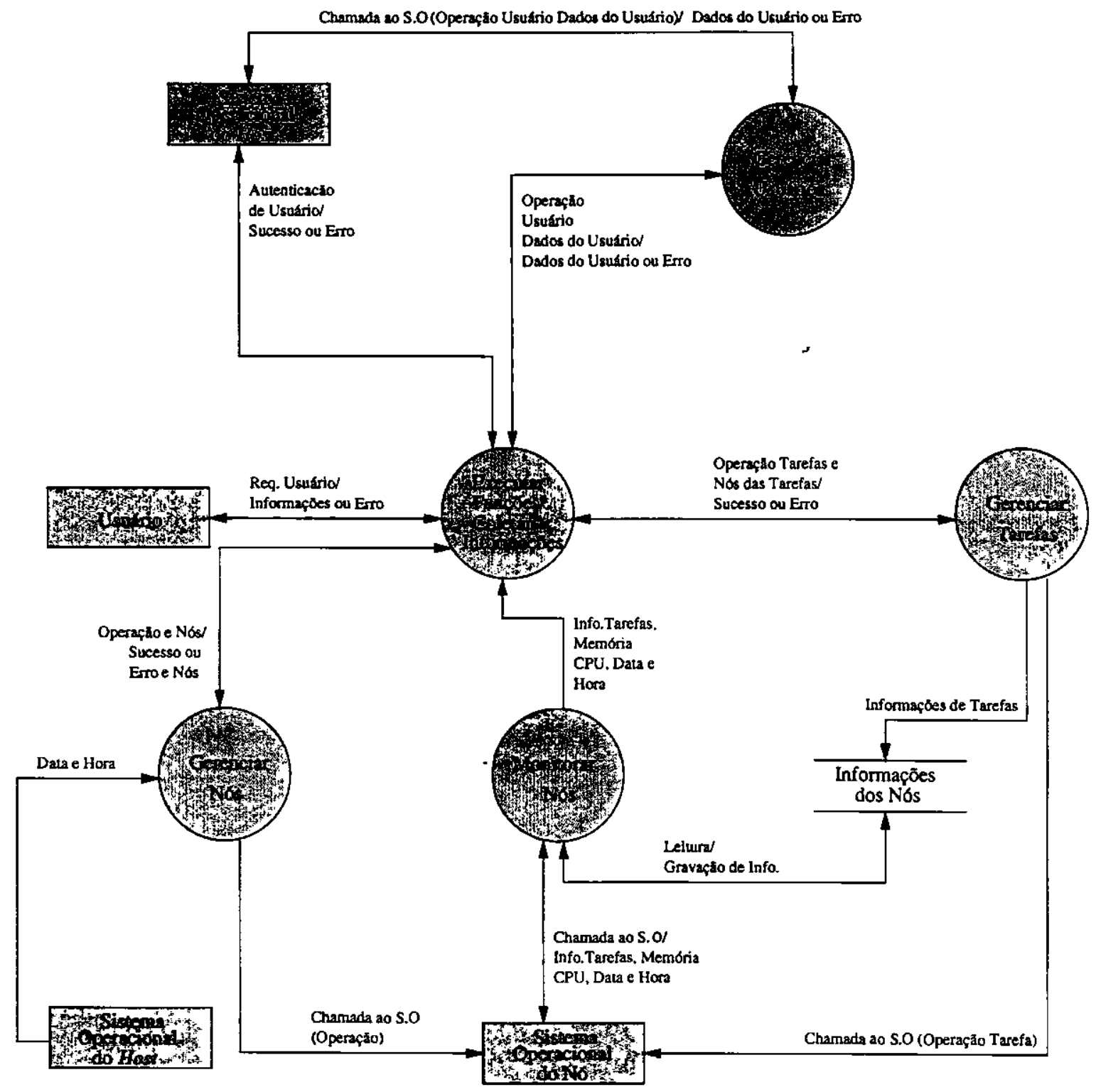

Figura 2.25: O diagrama de fluxo de dados da ferramenta Mirador. Nível 1

do nó que, através do parâmetro de identificador de tarefa, executa a operação de gerenciamento sobre a tarefa desejada.

A função retorna resposta afirmativa em caso de sucesso e erro caso contrário.

Ao final de cada operação de gerenciamento de tarefas, é feita uma alteração na base de dados de Informações dos Nós, atualizando-as conforme modificações realizadas. 


\section{Gerenciar Usuários}

Essa função permite o cadastramento e a remoção de usuários, bem como a listagem e a alteração dos dados do usuário cadastrados na máquina paralela. A função recebe o nome da operação a ser realizada e os dados necessários à sua execução. O cadastramento requer os dados do usuário. A remoção requer o identificador do usuário. A alteração requer os novos dados do usuário. A operação listagem não requer nenhự parâmetro.

Os possíveis erros nesta função são retornados à função Executar Funções/Coletar Informações.

\section{Monitorar Nós}

Função responsável pelo monitoramento dos nós da máquina paralela. Através de chamadas ao sistema operacional do nó, são obtidas as informações de tarefas, memória, data e hora, e mensagens de erro do nó. A carga do nó é determinada considerando a fração de tempo em que as tarefas estiveram em execução no processador.

Após o cálculo da carga, as informações do nó são armazenadas na base de dados Informações dos Nós. As informações data e horário do host também são armazenadas para permitir a deteç̧ão de um nó inoperante.

De acordo com os requisitos de monitoramento do usuário, a base de dados é consultada e as informaçōes retornadas. Assim, somente as informações necessariamente requeridas pelo usuário são retornadas.

\section{Executar Funções/Coletar Informações}

Essa função realiza toda a interação do usuário com a ferramenta e coordena as requisições de monitoramento enviadas pelo mesmo. As informações de monitoramento solicitadas pelo usuário são atualizadas periodicamente pela função, de acordo com valores preestabelecidos. A função é mostrada com maior nível de detalhamento no DFD da figura 2.26 . 


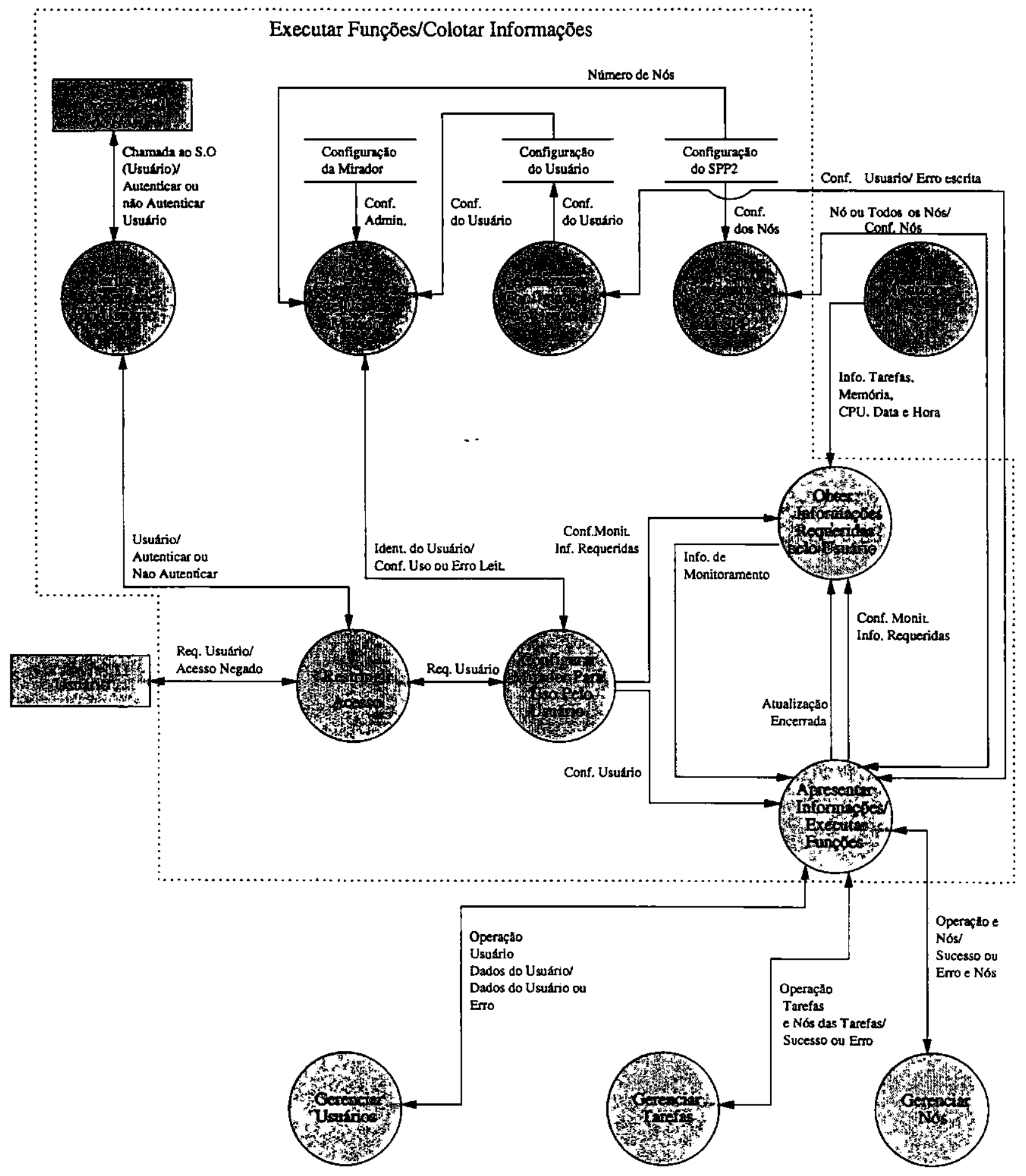

Figura 2.26: Função Executar Funções/Coletar Informações 
Segue abaixo uma breve descrição das funções presentes no DFD.

\section{Verificar Idoneidade do Usuário}

De posse da identificação e senha do usuário, essa função realiza a verificação de sua idoneidade. Através de consultas ao cadastro de usuários do sistema operacional do host, é possível saber se o usuário tem ou não permissão para utilizar a ferramenta e, em caso afirmativo, quais as funções estarão disponíveis a ele (privilégios de acesso).

\section{Ler Configuraçāo de Nós do SPP2}

A configuração dos nós da máquina paralela é enviada ao usuário através dessa função. O parâmetro de entrada da função é o nó ou conjunto de nós, dos quais se quer visualizar as configurações.

Caso haja algum erro na leitura da configuração dos nós essa função informa à função Executar Funçōes/Monitorar Informações sobre o ocorrido.

\section{$\underline{\text { Ler Configuração de Uso da Mirador }}$}

Essa função retorna a configuraçāo padrão para uso da ferramenta Mirador de acordo com as configurações da base de dados Configuração do Usuário ou de acordo com os parâmetros definidos na base de dados Configuração da Mirador, especificados pelo administrador do sistema.

\section{$\underline{\text { Armazenar Configuração do Usuário }}$}

Essa função realiza as operações de configuração da base de dados do usuário. A ocorrência de qualquer erro é reportada à função Executa Funções/Monitorar Informações.

\section{Descrição das Bases de Dados da Ferramenta}

Abaixo são descritas as bases de dados utilizadas pela ferramenta Mirador de acordo com o DFD da figura 2.26 . 


\section{Configuração da Mirador}

A configuração padrão para utilização da ferramenta é definida nessa base de dados, contendo as seguintes configurações padrões:

- Configuração padrão de seleção para o monitoramento:

Lista de identificadores de nós.

- Configuração padrão para apresentação dos nós:

Formato de apresentação dos ícones dos nós.

- Configuração padrão para o monitoramento:

Tempo especificado para a atualização das informações (taxa de atualização) requisitadas pelo cliente;

Tempo especificado para o timeout de conexão entre o cliente e o host.

- Configuração padrão para a obtenção de informações dos nós:

Tempo especificado para a atualização das informações dos nós;

Tempo especificado para o timeout de conexão entre o host e os nós.

\section{Configuração do Uisuário}

A configuração padrão para uso da ferramenta definida por um usuário específico é armazenada nessa base de dados, que apresenta as seguintes configurações padrões e valores associados:

- Configuração padrão de seleção para o monitoramento:

Lista de identificadores dos nós;

Usuário específico;

Tarefa específica.

- Configuração padrão para apresentação dos ícones dos nós:

Formato de apresentação dos ícones;

Apresentar os ícones dos nós não operacionais. 
- Configuração padrão para o monitoramento de informações dos nós:

Tempo especificado para a atualização das informações requisitadas pelo cliente; Tempo especificado para o timeout de conexão entre o cliente e o host.

- Configuração padrão para a determinação automática dos nós selecionados para gerenciamento:

Esta configuração padrão diz respeito à configuração automática dos nós em função das configuraçōes em que se encontram (por exemplo, atribuir automaticamente aos nós selecionados pelo monitoramento a condição de selecionado para gerenciamento).

\section{Configuração da Máquina Paralela}

Base de dados que armazena os dados referentes ao número de nós da máquina $\mathrm{e}$ a configuração de cada nó (tipo e velocidade do processador, a quantidade de memória principal e swap instaladas no nó).

\section{$\underline{\text { Informações dos Nós }}$}

Esta base de dados armazena as informações de cada nó da máquina paralela (carga, memória, tarefas, data e horário).

\section{Problemas com a Ferramenta Mirador}

A ferramenta Mirador tem se deparado com uma variedade de problemas. Úm dos entraves tem sido o baixo desempenho da ferramenta ao ser executada como um Applet Java. A utilização da Mirador através da Internet é dificultada, devido a restrições da própria rede e ao tamanho da aplicação. A comunicação com o módulo GNPi (vide seção 2.7.10) é pouco eficiente, podendo degradar o desempenho geral do sistema (problemas com as operações bloqueantes de comunicação [TAN95]). A segurança do sistema se baseia apenas nas interfaces RPC [Dis98, TAN95] entre o cliente (MIU) e o servidor (SINGOG), o que facilita o acesso de usuários não autorizados. O timeout de conexão (embora tenha sido especificado [ARA98]), não foi implementado. Uma vez que o tempo para tentativas de comunicação dependerá do ambiente onde se esteja trabalhando, a ferramenta deve permitir ao usuário a configuração desse parâmetro. 


\subsubsection{Análise Comparativa das Ferramentas}

As ferramentas apresentadas anteriormente possuem características distintas. O Ktop é apenas uma extensão do utilitário top para um ambiente gráfico, não oferecendo recursos extras para o monitoramento de mais de um nó, o que praticamente descarta sua utilização em ambientes paralelos. Com exceção da Mirador, do AIX PSSP, do SCMS e do framework $\mathrm{PCP}$, as demais ferramentas não apresentam funçōes para gerenciamento de clusters de processadores. Não é oferecido suporte para atividades básicas como eliminar dos nós tarefas pertencentes a um aplicativo paralelo. Essas atividades podem ser realizadas pela interação via comando de linha com um determinado nó. Tal procedimento é ineficiente e mais suscetivel a erros. Essas tarefas podem ainda estar impossibilitadas de execução quando a máquina for configurada para não permitir a interação direta de usuários comuns com os nós.

Outra característica ausente nessas ferramentas é o monitoramento vinculado à execução de aplicações paralelas. Essa funcionalidade seria interessante por permitir avaliar o desempenho ou possíveis problemas de nós responsáveis pela execução de determinadas tarefas pertencentes a uma aplicação paralela.

O SCMS é uma ferramenta a ser considerada, fornecendo uma gama de op̧ōes relacionadas ao monitoramento de nós e algumas facilidades de gerenciamento (seção 2.7.9), facilitando bastante a interação com a máquina.

O framework PCP é um pacote bastante flexível, facilitando o desenvolvimento e a extensão de aplicações de monitoramento. Apresenta-se também como um pacote abrangente, atendendo às várias necessidades de monitoramento do sistema.

A ferramenta Mirador visa atender aos principais requisitos de gerenciamento e monitoramento de uma máquina paralela. Procurando superar às várias deficiências presentes nas ferramentas anteriores (o monitoramento vinculado à execução de aplicações paralelas, por exemplo), ao mesmo tempo que reúne as principais características de cada uma. A Mirador tem-se mostrado como uma ferramenta bastante flexível, oferecendo um leque de opções de configuração. Dentre as ferramentas apresentadas, a Mirador é a única que permite o gerenciamento pela World Wide Web. Um quadro comparativo das ferramentas é apresentado na tabela 2.2 . 
Tabela 2.2: Comparação entre as ferramentas de gerenciamento e monitoramento

\begin{tabular}{|c|c|c|c|c|c|c|c|c|c|c|}
\hline $\begin{array}{l}\text { Característica/ } \\
\text { Ferramenta }\end{array}$ & Ktop & asMon & $\begin{array}{l}\text { Procps } \\
\text { Cluster }\end{array}$ & $\mathrm{VT}$ & $\begin{array}{l}\text { gr- } \\
\text { Monitor }\end{array}$ & bWatch & $\begin{array}{l}\text { AIX } \\
\text { PSSP }\end{array}$ & SCMS & Mirador & PCP \\
\hline $\begin{array}{l}\text { Monitoramento de } \\
\text { nós de processa- } \\
\text { mento }\end{array}$ & & & $x$ & $x$ & $x$ & $x$ & $x$ & $x$ & $x$ & $x$ \\
\hline $\begin{array}{l}\text { Monitoramento de } \\
\text { tarefas }\end{array}$ & $x$ & $x$ & $x$ & $x$ & $x$ & & $x$, & $x$ & $x$ & $x$ \\
\hline $\begin{array}{l}\text { Monitoramento da } \\
\text { máquina paralela } \\
\text { vinculado à exe- } \\
\text { cução de aplicaçōes } \\
\text { paralelas }\end{array}$ & & & & $x$ & & $x$ & & & $x$ & \\
\hline $\begin{array}{l}\text { Gerenciamento de } \\
\text { nós de processa- } \\
\text { mento }\end{array}$ & & & & & & & $x$ & $x$ & $x$ & $x$ \\
\hline $\begin{array}{l}\text { Gerenciamento de } \\
\text { tarefas }\end{array}$ & $x$ & & & & & & $x$ & $x$ & $x$ & \\
\hline $\begin{array}{l}\text { Facilidades de in- } \\
\text { teraçāo com o clus- } \\
\text { ter }\end{array}$ & & & & & & & $x$ & $x$ & & \\
\hline $\begin{array}{l}\text { Independência de } \\
\text { plataforma }\end{array}$ & & & & & & & & & $x$ & \\
\hline $\begin{array}{l}\text { * Auxilio ao geren- } \\
\text { ciamento do sis. } \\
\text { tema de software }\end{array}$ & & & & & & & $x$ & & $x$ & \\
\hline $\begin{array}{l}\text { Otimização do uso } \\
\text { da arquitetura pa- } \\
\text { raleia }\end{array}$ & & & & $x$ & & & & & & \\
\hline
\end{tabular}

* Se refere a tarefas de administração do sistema e interação com outros aplicativos. Por exemplo, a manutenção de contas de usuários e a configuração de algum utilitário, etc.

\subsection{SNMP (Simple Network Management Protocol)}

O Simple Network Management Protocol (SNMP) [CAS90] é um protocolo para monitoramento de redes de comunicação desenvolvido pela Internet Engineering Task Force (IETF) [IET99], e tem sido amplamente utilizado no monitoramento de dispositivos de redes como switches, roteadores e interfaces de redes. 
O protocolo SNMP é definido por um modelo cliente/servidor, no qual o Gerenciador (cliente) estabelece uma conexão com um dispositivo de rede remoto, onde se encontra o Agente (servidor). O Agente mantém uma base de dados denominada Management Information Base (MIB) [MCC91], cujas variáveis procuram representar o estado do dispositivo em um determinado instante. Tais variáveis (também referenciadas como objetos MIB) variam de acordo com os dispositivos a serem monitorados e de acordo com cada fabricante. Utilizando-se de um conjunto de variáveis privadas, torna’possível o monitoramento de diferentes dispositivos como roteadores, gateways e impressoras.

Os objetos MIB manipulados por um determinado Agente são definidos em arquivos descritores, escritos no formato Abstract Syntax Notation (ASN.1) [ISO87]. Tais arquivos são disponibilizados aos clientes, tornando conhecidas as variáveis que são manipuladas pelo Agente.

As mensagens enviadas ao Agente SNMP consistem nos identificadores das variáveis SNMP seguidos de instruçōes para obter ou para alterar seus valores.

O SNMP se mostra um protocolo bastante flexível. A possibilidade do Agente ser estendido para monitorar uma série de equipamentos teve um importante papel para a sua aceitação como um protocolo padrāo no monitoramento e gerenciamento de redes de comunicação.

Apesar de sua aceitação, o protocolo SNMP apresenta algumas deficiências tais como dificuldades de implementação e eficiência. O SNMP, como um protocolo para monitoramento, apresenta-se pouco eficiente. Largura de banda é perdida com o tráfego de dados redundantes como, por exemplo, a versão do protocolo, presente em todas as mensagens retornadas pelo Agente. Adicionalmente, os tipos de dados definidos pelo MIB aumentam consideravelmente o tamanho de cada mensagem [DDR99].

\subsubsection{Características do Protocolo SNMP}

Abaixo são citadas algumas características relevantes do protocolo SNMP.

- Formato das Mensagens - por melhorar o desempenho, as mensagens utilizam o protocolo de comunicação UDP;

- Objetos Gerenciados - o protocolo SNMP define um conjunto padrão de valores (objetos) que são manipulados pelo Agente; 
- Árvore de Objetos Extensível - uma das principais razões da popularização do protocolo SNMP é a possibilidade de expansão das variáveis SNMP, tornando factível a inclusão de variáveis específicas de acordo com as necessidades de cada fabricante.

\section{Mensagens SNMP}

Quatro tipos de operações são definidas no protocolo SNMP:

- Get - através dessa operação se obtém os objetos da base de dados MIB. Cada requisição retorna o valor de um único objeto.

- Get Next - permite ao cliente percorrer a árvore de objetos, possibilitando assim que todos os objetos sejam alcançados. Um objeto inicial é escolhido e a partir dele se alcança o próximo via a requisição Get next. Essa operação é repetida até se obter um erro advertindo que todos os níveis da árvore (e consequentemente todos os objetos) foram percorridos;

- Set - essa operação permite que o dispositivo de rede seja configurado. É possível, por exemplo, desabilitar interfaces, desconectar usuários, alterar registradores, etc.;

- Trap - permite ao dispositivo (Agente) se comunicar com o Gerenciador para informálo sobre um potencial problema no dispositivo local. Esta opção pode ser desabilitada se necessário.

Todas as operações são encapsuladas em pacotes UDP.

\section{Gerenciamento dos Objetos}

A base de dados MIB define os objetos que armazenam os valores referentes às descrições gerais do sistema e ao monitoramento das interfaces de rede, pacotes IP, conexões TCP, UDP, roteamento de pacotes IP, etc. A cada objeto é associado um nome como, por exemplo, sysUpTime, e/ou um valor numérico (por exemplo, 1.3.6.1.2.1.1.3.0, que é o Identificador de Objeto para sysUpTime). 


\section{Árvore de Objetos Extensível}

Essa característica permite que objetos específicos de determinada aplicação ou dispositivo sejam acoplados à arvore de objetos. Novas funcionalidades podem, assim, ser monitoradas e controladas.

É importante notar que essas extensões não afetam as funçōes do software de gerenciamento. Esse pode monitorar diferentes bases de dados MIB sem a necessidade de mudanças em seu código.

\subsubsection{Os Objetos MIB}

A base de dados MIB é organizada em um formato de árvore (figura 2.27) que provê um único caminho para que um objeto possa ser alcançado. No nível quatro da árvore está o diretório internet, que contém quatro sub-árvores: a mgmt, contendo objetos que são geralmente suportados por todos os dispositivos de rede; a private, contendo os objetos estendidos e que são definidos pelo fabricante do dispositivo; a experimental e a directory que, inicialmente, não guardam nenhum objeto ou dado relevante. Os objetos MIB se dividem em:

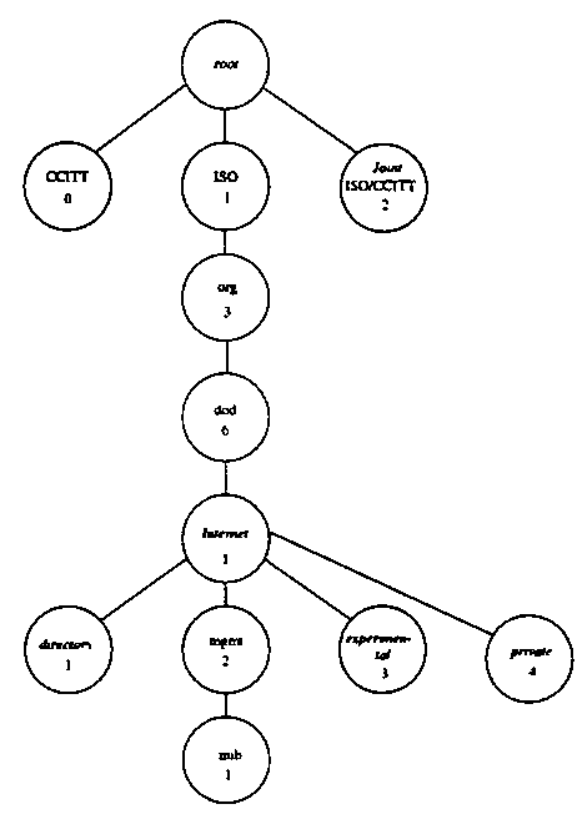

Figura 2.27: Representação estrutural de parte da Management Information Base 


\section{Objetos Discretos}

Utilizam uma única variável para armazenar o valor de monitoramento. Esses objetos se distinguem dos objetos Tabela pela inclusão de uma extensão ".0" no final de seu nome. O objeto sysUpTime, por exemplo, que conta o tempo de atividade de um dispositivo é uma variável discreta.

\section{Objetos Tabela}

Os objetos Tabela utilizam múltiplas variáveis para representar a informação de monitoramento. Como exemplo, pode-se citar uma switch onde o objeto Ports é uma tabela na qual cada linha (entrada) representa uma porta específica e cada coluna representa uma determinada informação sobre a porta.

\section{Tipos de Objetos MIB}

- Objetos Tipo Text - informação textual (geralmente de 256 caracteres);

- Objetos Tipo Counter - valores numéricos que podem ser apenas incrementados. É um dos objetos mais comuns na base de dados MIB;

- Objetos Tipo Gauge - valores numéricos que podem ser incrementados e decrementados;

- Objetos Tipo Integer - valores inteiros positivos e negativos;

- Objetos Tipo EnumVal - valor enumerado que associa uma cadeia de caracteres a um valor numérico;

- Objetos Tipo Time - tempo decorrido com a precisão de um centésimo de segundo;

- Objetos Tipo Objeto - objeto que referencia um outro objeto;

- Objetos Tipo IPAddr - endereço IP do dispositivo de rede;

- Objetos Tipo PhysAd - endereço físico do dispositivo de rede;

- Objetos Tipo String - armazena informações textuais;

- Objetos Tipo Table - objeto que contém entradas de tabelas; 
- Objetos Tipo Branch - objetos que podem conter outras sub-árvores, tabelas, ou qualquer um dos objetos listados acima.

A cada um dos objetos MIB está associada uma restrição de acesso, podendo ser: read-only, read-write ou write-only.

\subsubsection{Versões do Protocolo SNMP}

Com a ampla utilização do protocolo SNMP, tornou-se necessária a especificação de novas versões para minimizar deficiências. A segunda versão do protocolo, o SNMPv2, enfoca a solução de vários problemas funcionais da-versão anterior. Como exemplo, pode-se citar as novas especificações para a transferência de volumes de dados entre o Agente e o Gerenciador, visando um melhor desempenho. A terceira geração do protocolo SNMP (SNMPv3) surgiu com o objetivo de especificar mecanismos de segurança e facilidades de administração, proporcionando um maior nível de segurança às transações e ampliando o leque de opções de gerenciamento dos dispositivos de rede [Int99].

\subsubsection{Ferramentas para Monitoramento e Gerenciamento de Re- des SNMP}

Nesta seção são apresentadas algumas ferramentas que utilizam o protocolo SNMP para o monitoramento e gerenciamento dos diversos dispositivos de uma rede de comunicação.

\section{MRTG (Multi Router Traffic Grapher)}

A MRTG [GUE97] é uma ferramenta que realiza o monitoramento de carga das conexões de rede. As informações coletadas são apresentadas ao usuário em páginas HTML, como mostra a figura 2.28. A ferramenta MRTG utiliza o protocolo SNMP para ler os objetos contadores de tráfego, localizados nos roteadores. Além desses objetos a MRTG permite também a leitura de qualquer outro objeto solicitado pelo usuário.

\section{SNMP Monitor Ex}

A ferramenta SNMP Monitor Ex [Uni97] é utilizada para monitorar valores críticos. Certas variáveis em um dispositivo representam dados onde não são esperadas mudanças em 


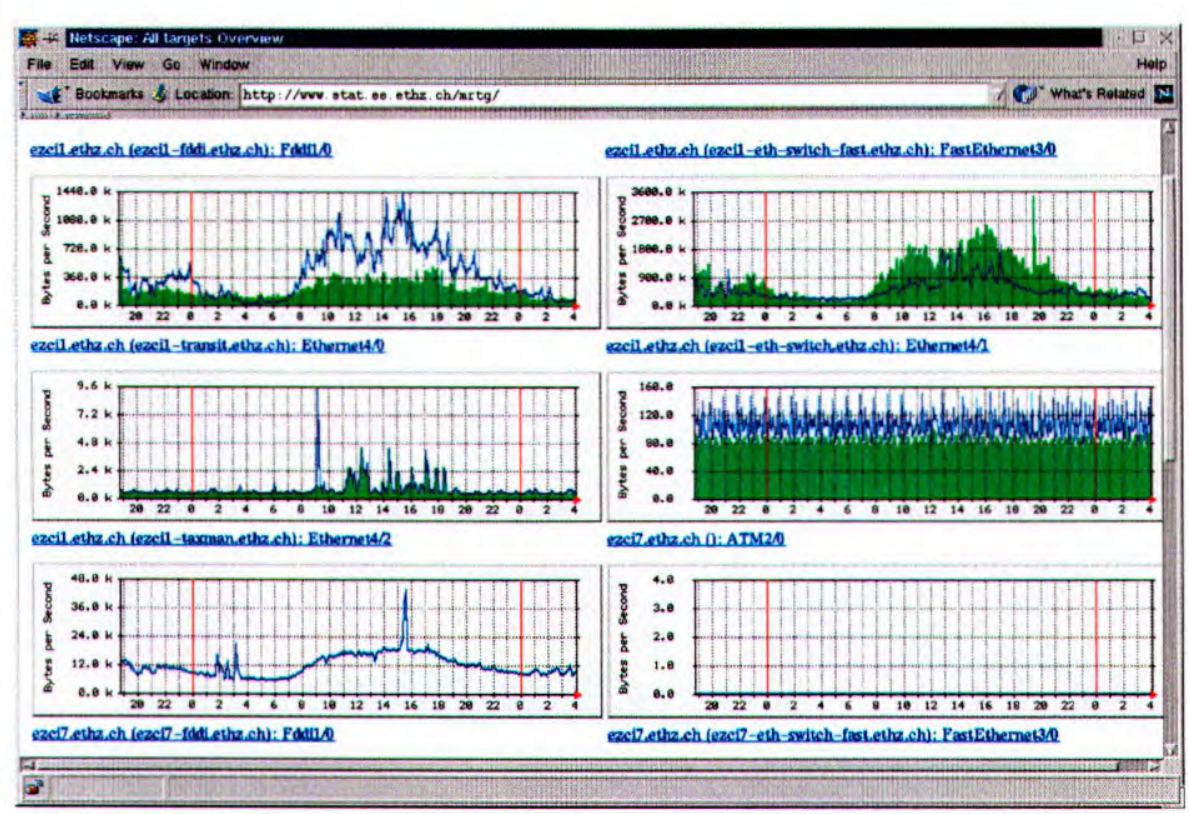

Figura 2.28: Multi Routter Traffic Grapher - Representação das informações. Cada retângulo representa um dispositivo de rede monitorado

seus valores. Tais variáveis (ou objetos) podem estar, por exemplo, refletindo a voltagem, temperatura ou a corrente elétrica de um componente. Se esses objetos sofrem variação, algo anormal pode estar acontecendo. Assim, uma mensagem de notificação é enviada ao administrador da rede que tomará as devidas providências. A notificação pode ser enviada via mail ou via SMS (Short Message Service) [Mob99].

\section{Scotty}

O Scotty apresenta um conjunto de ferramentas que oferecem suporte ao desenvolvimento de software para o monitoramento de redes. O Pacote é baseado na linguagem Tcl [Scr99] e utiliza-se da extensão Tcl Tnm [SCH00] para obter acesso às informações de monitoramento. A extensão Tnm fornece suporte aos seguintes protocolos: SNMP, ICMP, DNS, HTTP, SUN RPC, NTP e UDP. Essa extensão é também amplamente utilizada por fabricantes de dispositivos para realização de testes.

O editor de mapas de rede Tkined [NEW96], também presente no pacote Scotty, provê um frame work para o monitoramento gráfico das redes, como mostra a figura 2.29. O Tkined é configurável e pode ser utilizado como um frontend gráfico por diversas aplicações, bastando para isso utilizar um protocolo específico para esse fim. A forma mais comum para 


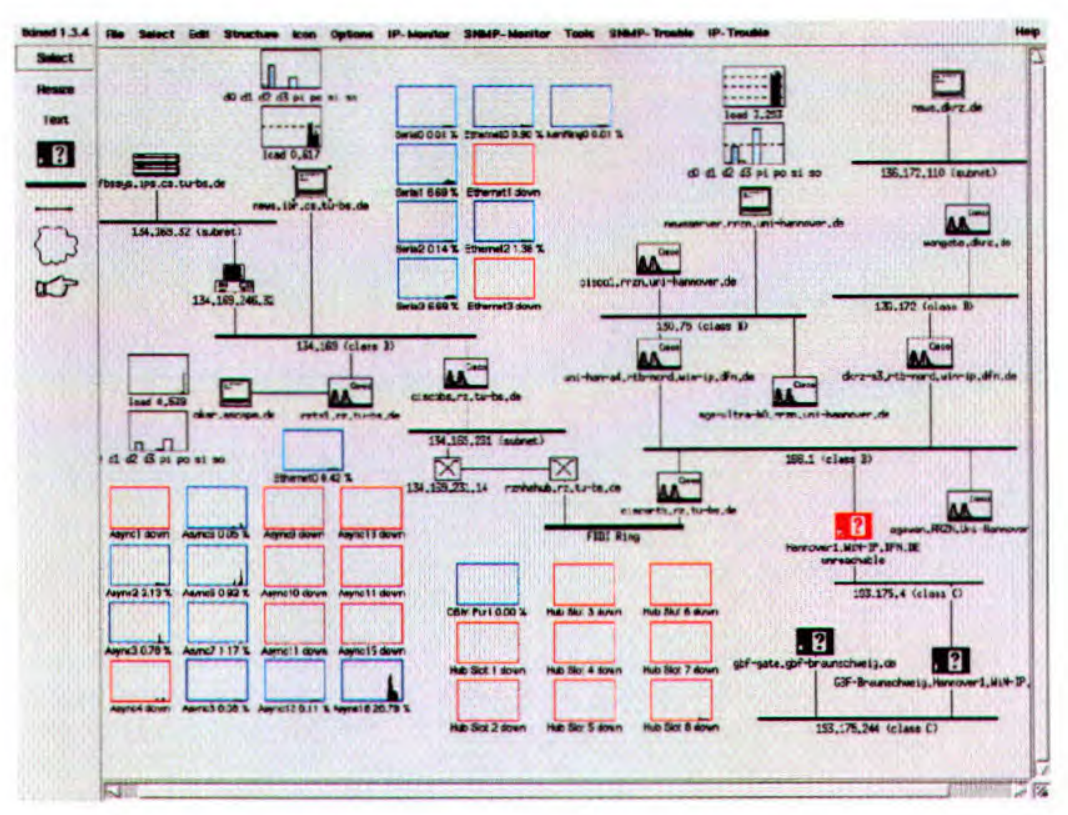

Figura 2.29: Tkined - Monitoramento de um conjunto de redes

se desenvolver uma aplicação Tkined é através da extensão Tnm que encapsula o protocolo utilizado e facilita o acesso às funções do editor.

\section{Linux CMU}

A CMU é uma biblioteca SNMP de domínio público desenvolvida pela Universidade de Carnegie Mellon. Implementada na linguagem C, a biblioteca CMU apresenta um bom desempenho, embora tenha funcionalidade limitada [GEO93]. A biblioteca CMU fornece suporte tanto para a criação de Gerenciadores SNMP como para a criação de Agentes. A distribuição contém algumas aplicações que interagem com os Agentes SNMP, realizando operações como, por exemplo, a obtenção e configuração dos objetos da base de dados MIB. Todas essas aplicações são implementadas utilizando a biblioteca CMU.

\section{UCD SNMP}

Esse pacote é uma extensão da biblioteca CMU e suporta as seguintes versões do protocolo SNMP: SNMPv1, SNMPv2 (RFCs 1901-1908) e SNMPv3. O pacote é composto por uma biblioteca SNMP, por algumas ferramentas que manipulam as informações MIB e por um browser que permite a visualização da base de dados MIB. Ambos os pacotes (Linux CMU e UCD) contém daemons SNMP que fazem o papel de Agentes. 


\subsubsection{RMON (Remote Network Monitoring)}

O RMON MIB (Remote Network Monitoring Management Information Base) [OTT93] define um modelo de monitoramento de redes onde são propostas diversas melhorias em relação aos nıodelos SNMP utilizados atualmente. Dentre essas melhorias pode-se citar a incorporação de filtros para a análise individual de pacotes e a disponibilidade de registros históricos.

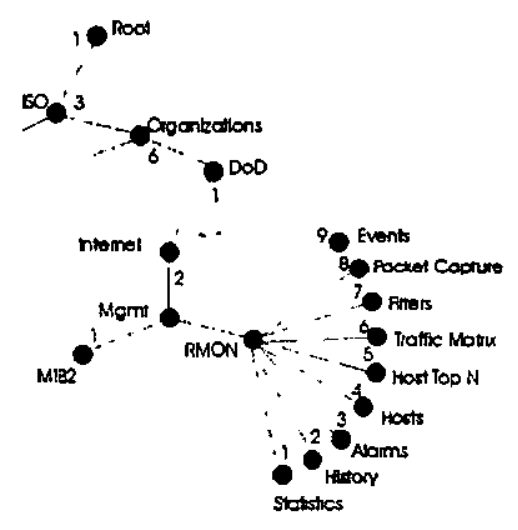

Figura 2.30: Sub-árvore RMON definida no RFC 1271

O RMON MIB define uma extensão à base de dados MIB, adicionando uma subárvore RMON contendo nove grupos, como mostra a figura 2.30.

Segue-se uma breve descrição de cada grupo pertencente à sub-árvore RMON:

\section{Segment Statistics}

Esse grupo disponibiliza dados estatísticos referentes ao número de colisões e ocorrências de broadcast e multicast em um dispositivo de rede. É possível também obter, em tempo real, o tamanho dos pacotes que trafegam pelo dispositivo.

\section{History}

Disponibiliza dados históricos das estatísticas geradas pelo grupo Segment Statistics, com exceção dos dados referentes ao tamanho dos pacotes. 


\title{
Host Table
}

O grupo Host Table disponibiliza uma tabela com dados estatísticos referentes aos dispositivos presentes na rede. Tais dados incluem pacotes enviados e recebidos, número de colisões, ocorrência de broadcast e multicast. Esse agrupamento de dispositivos reduz o tráfego de mensagens na rede.

\section{Host Top N}

Faz uma classificação dos dados estatísticos da tabela gerada pelo grupo anterior. Como um exemplo de classificação pode-se citar, por exemplo, os dez $(\mathrm{N}=10)$ dispositivos onde ocorreram o maior número de colisões nas últimas cinco horas.

\section{Traffic Matrix}

Disponibiliza dados refletindo o tráfego e a quantidade de erros entre dois dispositivos quaisquer.

\begin{abstract}
Alarms
Provê mecanismos para a configuração de valores limites que, caso sejam ultrapassados, disparam o envio de uma notificação do Agente ao Gerenciador. Por exemplo: caso o tráfego em um determinado ponto exceda o valor limite preestabelecido, é possivel que problemas de desempenho venham a ocorrer. Assim, uma notificação é enviada ao Gerenciador para que as devidas providências sejam tomadas.
\end{abstract}

\section{Filters}

Fornecem mecanismos para que os pacotes que passam pelo dispositivo sejam filtrados de acordo com parâmetros pré-determinados. Estatísticas dos pacotes filtrados são mantidas para consultas posteriores.

\section{Packet Capture}

Possibilita a criação de buffers de captura de pacotes. Em caso de ocupação total do buffer, pode-se optar por sobrepor os pacotes armazenados ou encerrar as atividades de captura. 


\section{Events}

Permite ao usuário especificar eventos que, quando disparados, forçam os Agentes a enviar mensagens de notificação aos Gerenciadores, informando o ocorrido.

\subsection{Considerações Finais}

Neste capítulo foram apresentados alguns conceitos essenciais dé programação paralela, a descrição das arquiteturas paralelas e suas respectivas classificaçōes. Algumas considerações foram feitas a respeito do projeto Beowulf e da máquina paralela SPP3. Também foram revistas as principais ferramentas para monitoramento e gerenciamento de máquinas paralelas, mostrando as principais características de cada uma. Üm quadro comparativo das aplicações foi apresentado no final da seção 2.7.11. A maior ênfase foi dada na descrição da ferramenta Mirador, que é o enfoque deste trabalho. Não seção 2.8 discorreu-se sobre o protocolo SNMP, citando algumas aplicações que utilizam o referido protocolo para o monitoramento e gerenciamento de redes de comunicação.

No próximo capítulo são apresentados os resultados dos testes realizados com a ferramenta Mirador, bem como um levantamento dos pontos críticos do sistema e suas devidas alteraçōes. 


\section{Capítulo 3}

\section{Revisão de Software da Ferramenta}

\section{Mirador}

\subsection{Considerações Iniciais}

Este capítulo descreve a primeira etapa do trabalho, onde a ferramenta Mirador é analisada e alterações são propostas e implementadas. A análise leva em consideração o desempenho, a eficiência e a usabilidade da ferramenta.

A segunda etapa do trabalho, apresentada nos capítulos 4 e 5, está relacionada com o desenvolvimento de extensões, onde se procura adequar a ferramenta às necessidades da máquina paralela SPP3, ao mesmo tempo que disponibiliza novas funcionalidades.

Na seção 3.2 são descritos os objetivos dessa primeira etapa. Em seguida, na seção 3.3.1 é feita a verificação, de forma sistemática, de cada um dos módulos da ferramenta Mirador. A verificação de integração entre os módulos é discutida na seção subsequente $(3.3 .2)$.

\section{$3.2 \quad$ Objetivos}

A análise comparativa, realizada na seção 2.7.11, revelou a importância da ferramenta Mirador no cenário das aplicações para monitoramento e gerenciamento de máquinas paralelas, ressaltando características e peculiaridades que a colocam em uma posição de destaque.

Torna-se evidente o interesse no término da sua implementação conforme a especifi- 
cação descrita no capítulo anterior e, consequentemente, a elaboração de uma versão final que possa ser utilizada pelo usuário.

Visto que o desempenho, a usabilidade e a funcionalidade do sistema são requisitos básicos, a revisão de software da ferramenta Mirador consiste em:

- Realizar um levantamento geral de toda a ferramenta, identificar falhas e propor e implementar soluções para estas falhas:

Consiste na submissão da ferramenta a uma bateria de testes com a finalidade de averiguar as possíveis falhas. Uma vez que o sistema não foi submetido a condições reais de trabalho, a probabilidade de existência de falhas é elevada;

- Reestruturar partes do código visando maior eficiência e desempenho:

Alguns trechos do sistema estão comprometendo o funcionamento da ferramenta, como é o caso das funções que implementam os serviços de gerenciamento dos nós. Outro exemplo de problema que pode ser citado é a quantidade de classes extras utilizadas pela aplicação. Isso gera tráfego excessivo na rede, dificultando a utilização da ferramenta pela Internet;

- Implementar o restante da especificação do projeto inicial:

Vários requisitos da especificação inicial não estão implementados. O gerenciamento de contas de usuário é um exemplo;

- Manutenção da documentação da ferramenta e a disponibilização da mesma ao usuário final por meio da criação de um site de divulgação do projeto SPP3 e da ferramenta Mirador.

\subsection{Validação da Ferramenta}

Os testes realizados foram orientados no sentido de auxiliar na análise de desempenho da ferramenta, apontando eventuais módulos ou funções do sistema que estariam apresentando um desempenho abaixo do esperado. De acordo com os resultados obtidos, foram estudadas e implementadas soluções para sanar essas falhas e que realizassem a otimização de código.

Tendo em vista que a ferramenta Mirador é voltada primeiramente para o monitoramento de sistemas, o desempenho deve ser considerado durante toda a etapa de verificação. 
Em seguida são listados os principais testes aos quais foi submetida a ferramenta Mirador:

- O módulo desenvolvido em linguagem Java foi testado em diferentes plataformas (Windows $95 / 98 / \mathrm{NT}$, Linux, Solaris). O restante dos módulos foram compilados e executados em diferentes distribuiçōes do Linux (Slackware e RedHat);

- A ferramenta foi testada localmente e remotamente executando como um Applet Java e como uma aplicação stand-alone;

- Execução de aplicações nos nós para geração de carga de CPU e memória;

- Desligamento/ligamento dos nós e/ou do host para observação do comportamento da ferramenta em condições de queda de energia ou pane nos nós/host;

- Gerenciamento de tarefas e das contas dos usuários;

- Medidas de tamanho das requisições/respostas entre o usuário e o host;

- Medidas de tempo de resposta das requisições entre o usuário e o host.

A revisão de software da ferramenta Mirador foi realizada sistematicamente, módulo a módulo. Na próxima seção são analisados os módulos em particular; na seção seguinte leva-se em consideração as integrações entre eles.

\subsubsection{Verificação e Alteração dos Módulos}

Uma arquitetura simplificada da Ferramenta Mirador é apresentada na figura 3.1.

\section{Módulo MIU}

O módulo MIU, responsável pela interação entre o usuário e a máquina paralela, foi submetido à várias alterações funcionais e estruturais.

\section{Verificação de Entradas e Saídas}

Devido ao fato do módulo MIU realizar toda a interação com o usuário, uma ênfase maior foi dada à verificação de erros provenientes das entradas e saídas da ferramenta. Isso 


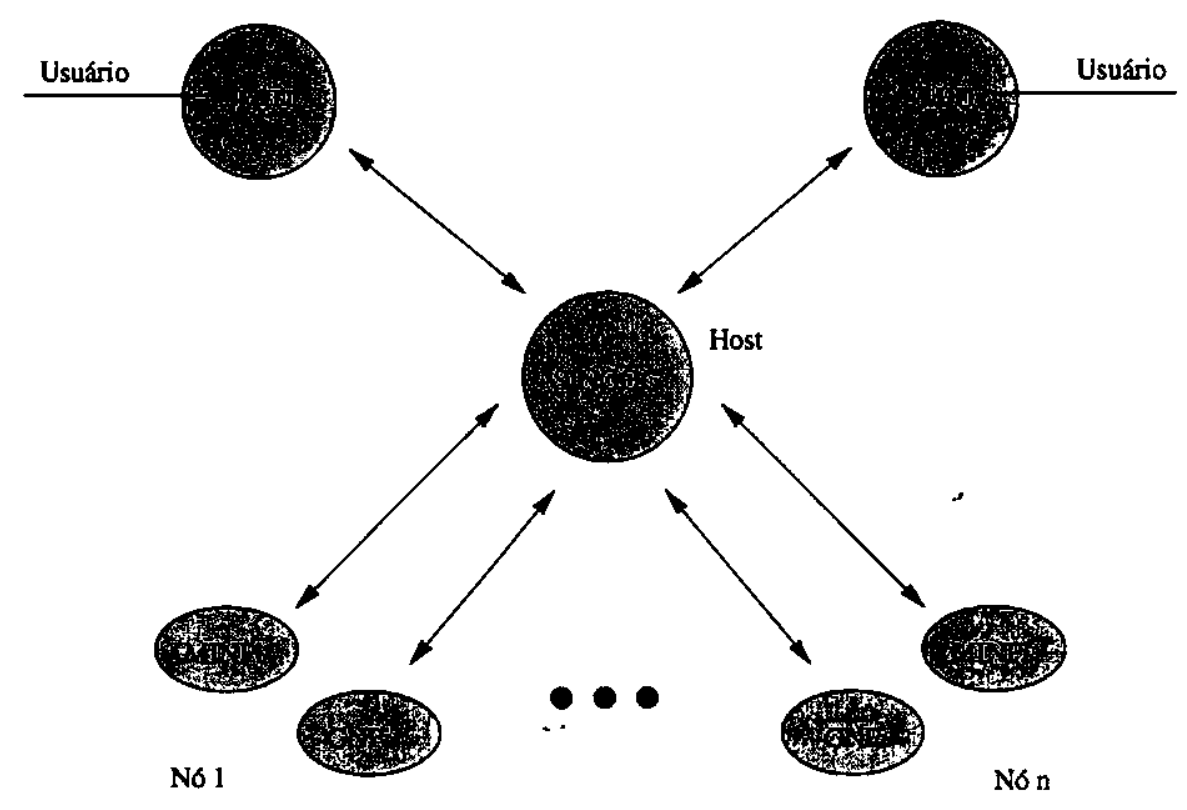

Figura 3.1: Arquitetura da ferramenta Mirador em nível de módulos

inclui os campos de entrada de dados, a correta manipulação de eventos (clicks de mouse, por exemplo), a exibição de frames e formulários (saídas), e a consistência da interface gráfica. Os erros remanescentes foram corrigidos e as entradas e saídas foram novamente verificadas.

O Apêndice A apresenta a interface gráfica da ferramenta.

\section{Substituição de Componentes}

A grande maioria dos componentes utilizados para a construção da interface gráfica foi substituída por componentes atualizados e que oferecem melhores recursos e desempenho. Os componentes substituídos dizem respeito às classes Java AWT [Sun99], que cederam lugar às classes Java Swing [Sun99]. Isso permitiu uma interação mais eficiente com o usuário.

\section{Ferramenta na Web}

As maiores restrições quanto à utilização da Ferramenta Mirador via Web (Applet) são referentes ao tamanho da aplicação que, em virtude da utilização do pacote Swing, aumenta consideravelmente o tráfego na rede. Com a recente disponibilidade de Plug ins com suporte às aplicações que utilizam o pacote Swing, a quantidade de bytes que realmente precisa ser transportada se resume nos códigos fontes da ferramenta (os plug ins possuem uma máquina virtual Java [Sun98] contendo os pacotes recentemente desenvolvidos - isto 
inclui o pacote Swing, Java 2D, etc.). Desta forma, o maior entrave para a utilização da ferramenta Mirador pela Internet foi superado.

O restante das alterações, juntamente com a implementação das novas extensões (seção 4.2), foram realizadas sem dificultar a execução da ferramenta Mirador como um Applet (visto que o tal é passível de diversas restrições que vão desde permissões de acesso a recursos do sistema até questões de desempenho e segurança).

\section{Verificação de Relatórios}

Os relatórios (reports) representam uma grande parte das saídas da ferramenta Mirador. De uma maneira geral, os relatórios se mostraram consistentes e funcionais. Foram necessárias alterações apenas no relatório "SPP3 configuration", para tornar disponíveis as informações de configuração dos nós da máquina paralela. Essas informações são: o nome do elemento de processamento (ou nó), a descrição do processador e a quantidade de memória RAM e swap. O relatório é mostrado na figura 3.2.

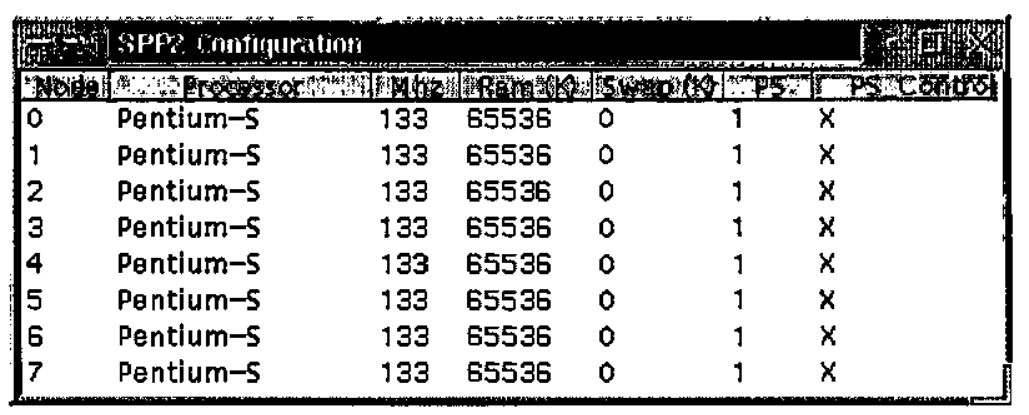

Figura 3.2: Configuração dos nós da máquina paralela

\section{Modificações Estruturais}

Visando facilitar a manutenção e simplificar a inclusão de futuras extensões, algumas estruturas internas do módulo MIU sofreram alterações (vide seção 3.3.2). Algumas classes que executam funções semelhantes foram agrupadas em uma mesma classe.

O paralelismo fornecido pela linguagem Java através da utilização dos threads [Sun99] é explorado pela ferramenta Mirador. O seu desempenho foi otimizado, aumentando o nível de paralelismo em certos trechos do módulo MIU. 


\section{Especificação da Interface}

Parte da interface gráfica foi novamente especificada e substituída, como será visto na seção 5.5. Tais alterações visam uma interação mais intuitiva entre o usuário e a ferramenta Mirador.

\section{Módulo MINPi}

Esse módulo é responsável por transportar as informações de monitoramento do nó até o servidor (Módulo SINGOG). As únicas saídas do módulo são referentes às informações enviadas ao servidor. Estas se mostraram consistentes.

\section{Alterações Necessárias}

O módulo MINPi sofreu pequenas alterações para transformá-lo em um aplicativo daemon. As informações referentes a mensagens de erros e avisos foram direcionadas para o syslog [JOH97] do sistema, como ocorre com a maioria das aplicações desse gênero.

\section{Extensões}

Extensōes foram especificadas e implementadas para incorporar novas funcionalidades. Essas funcionalidades dizem respeito ao monitoramento de hardware dos nós e a interação com a rede $\mathrm{I} 2 \mathrm{C}$ da máquina paralela SPP3. Tais extensões são tratadas com detalhe nos capítulos 4 e 5 .

\section{Módulo GNPi}

O Módulo GNPi, assim como o módulo MINPi, executa nos nós da máquina paralela. Enquanto que o MINPi realiza as tarefas de monitoramento, o GNPi é responsável pelas tarefas de gerenciamento.

\section{$\underline{\text { Requisitos do Módulo GNPi }}$}

Esse módulo foi especificado inicialmente no trabalho de Araújo [ARA98]. Segue abaixo uma síntese das funçōes do módulo.

- Sincronização da data e horário de cada nó com a dada e horário do servidor; 
- Disponibilização de mecanismos que permitam reiniciar remotamente um nó;

- Mecanismos responsáveis pelo gerenciamento dos processos (finalização e mudança de prioridade das tarefas em execução).

Seguindo o projeto e as especificações propostas inicialmente, o módulo GNPi foi implementado e testado. Os testes levaram em conta a eficiência da execução das funções e a verificação das saídas (que se resumem no retorno das requisições ao módulo SINGOG).

\section{Extensōes}

Assim como no módulo MINPi, extensões foram propostas para o módulo em questão e são analisadas nos próximos capítulos.

\section{Módulo SINGOG}

O módulo SINGOG é o elo de conexão entre o usuário (módulo MIU) e os nós da máquina paralela. Uma vez que sua função se restringe em atender as requisições tanto do usuário como dos módulos que executam nos nós (módulos MINPi e GNPi), o desempenho é um requisito não funcional de grande importância, sendo que o não cumprimento desse requisito pode comprometer toda a ferramenta.

\section{Atendimento de Requisições}

O mecanismo de atendimento de requisições do módulo SINGOG foi sensivelmente modificado em virtude dos requisitos de desempenho. O DFD da figura 3.3 ilustra a interação do módulo SINGOG com os demais módulos da ferramenta.

O módulo SINGOG foi implementado de maneira a atender e processar sequencialmente todas as requisições que chegam até ele. Desta forma, enquanto uma determinada requisição não for totalmente processada, todas as demais requisições que chegam ao módulo, deverão aguardar o término da execução da requisição anterior. Em situações onde se tem vários usuários utilizando a ferramenta simultaneamente o desempenho geral do sistema é baixo, em virtude do gargalo gerado nesse módulo. Os testes de verificação também indicaram que em requisições onde há um maior atraso no tempo de resposta, o desempenho é 


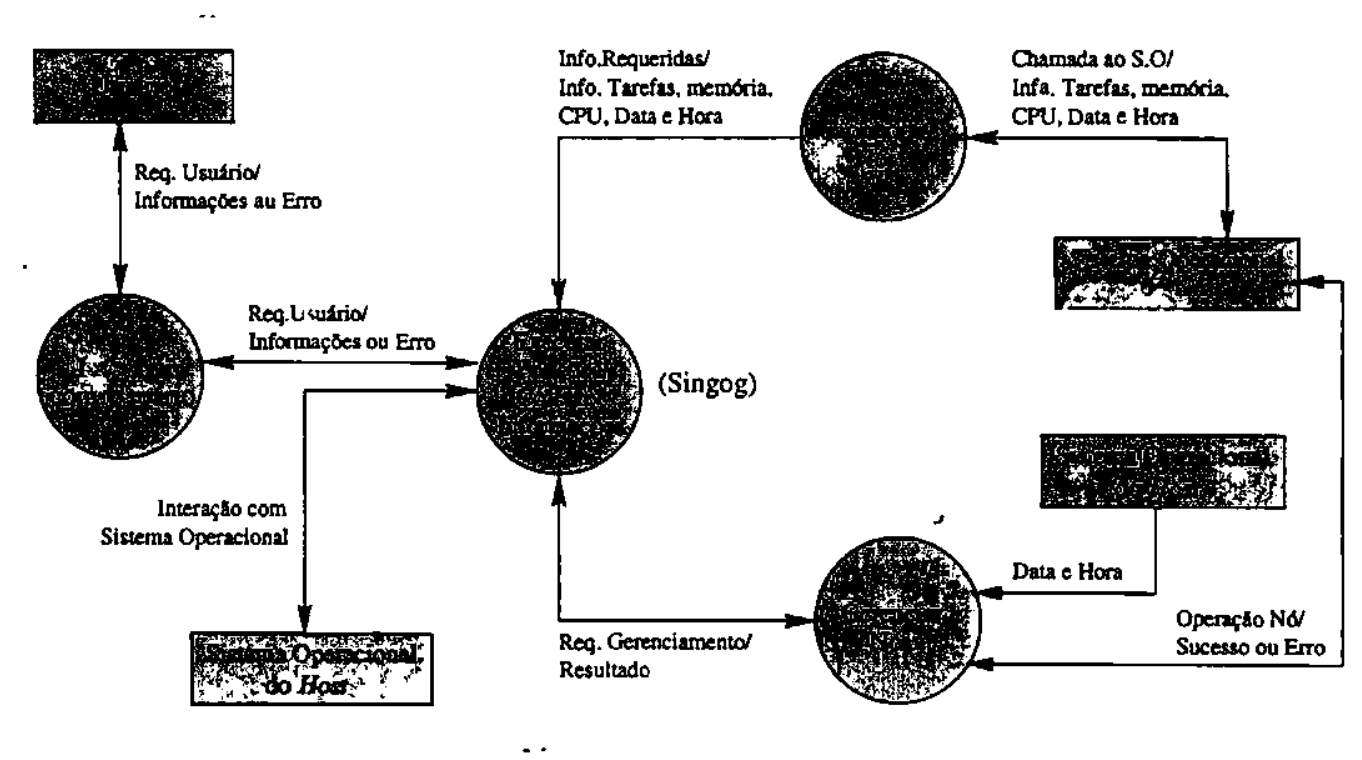

Figura 3.3: DFD de interação dos módulos da ferramenta Mirador

prejudicado mesmo em uma configuração mono-usuária (isto é, um único usuário utilizando a ferramenta em um determinado instante).

A comunicação entre os módulos se faz via RPC (Remote Procedure Call). Uma vez que a implementação da biblioteca RPC para plataformas Linux não oferece suporte à paralelização das aplicações (isso se dá através do uso de trheads ou instruções fork), torna-se necessário implementá-la.

As alterações no módulo SINGOG foram realizadas de acordo com as seguintes diretrizes:

- Para cada requisição originária do módulo MIU é gerado um novo processo que se encarrega de executá-la. Se, por exemplo, o usuário requisitar a sincronização da data dos nós, o módulo SINGOG recebe a requisição, verifica sua origem e, em seguida, gera um novo processo que se torna responsável por executar as tarefas pertinentes a tal requisição e retornar os resultados ao usuário. A figura 3.4 ilustra as interações entre os módulos após as devidas alteraçōes;

- As informações de monitoramento geradas pelo módulo MINPi chegam ao módulo SINGOG e são armazenadas. Assim, é necessário uma comunicação IPC (Interprocess Comunication) entre o processo principal do módulo SINGOG e os processos gerados, para que tais informações sejam conhecidas entre todos os processos. 


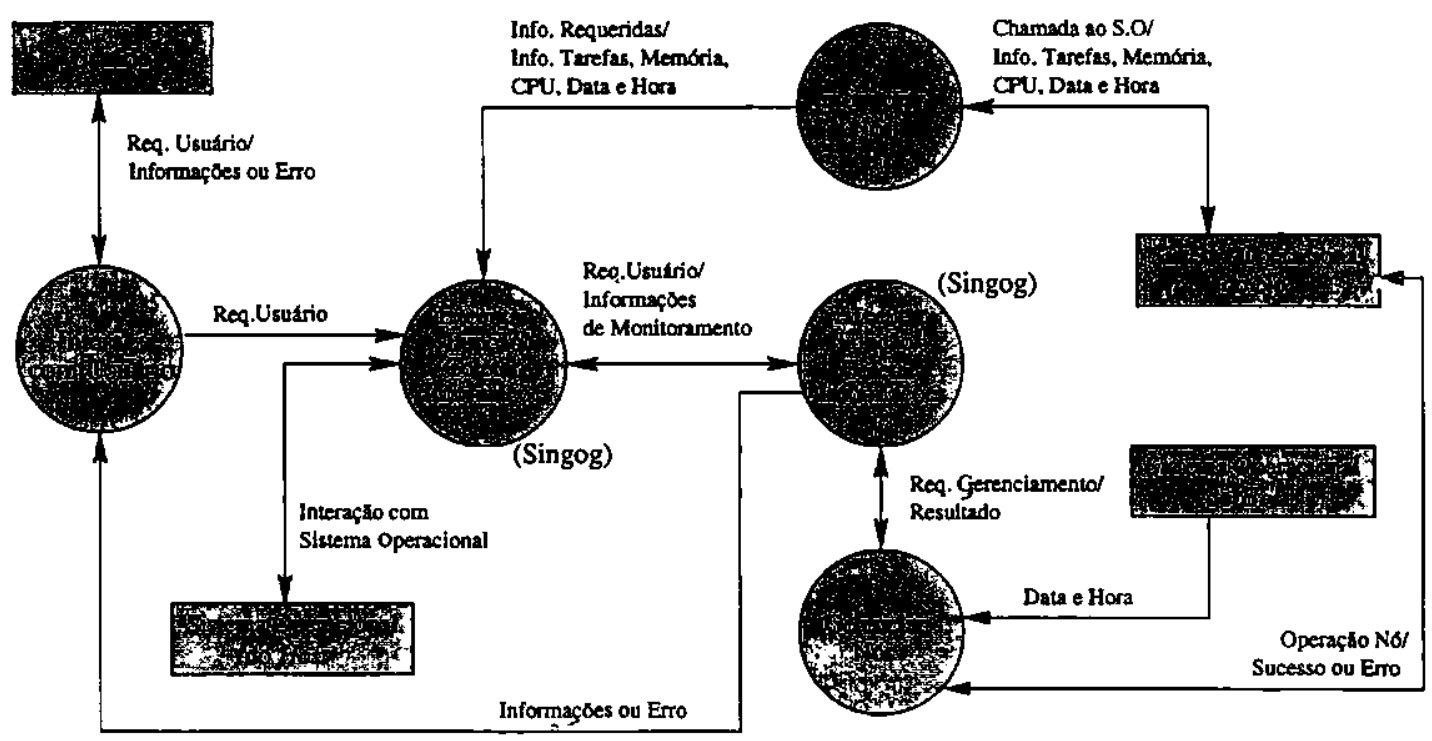

Figura 3.4: DFD dos módulos da ferramenta Mirador após a otimização do módulo SINGOG

Verificação de Entradas e Saídas

As entradas e saídas verificadas foram:

- Acesso ao arquivo de usuário;

- Acesso à fila de mensagens (utilizada para a comunicação IPC);

- Acesso ao arquivo de configuração da ferramenta;

- Comunicação do módulo SINGOG com os demais módulos (MIU, MINPi, GNPi).

As entradas e saídas do módulo se mostraram consistentes. Os testes com relação à comunicação do módulo SINGOG com outros módulos são examinados na próxima seção.

Alterações foram necessárias para transformar o módulo SINGOG em uma aplicação daemon. As mensagens de avisos e erros foram direcionadas para o syslog do sistema.

\subsubsection{Verificação de Integração entre os Módulos}

A verificação de integração consiste em analisar as interdependências entre os módulos, identificando e corrigindo possíveis falhas. O protocolo de comunicaçāo utilizado entre os módulos SINGOG e MINPi, e SINGOG e GNPi corresponderam às especificações iniciais quanto ao desempenho e consistência das informações, não necessitando alterações. Os 
esforços foram concentrados no protocolo de comunicaçāo entre os módulos SINGOG e MIU. A seguir, descreve-se os pontos que foram sujeitos a modificações após os testes de verificação.

\section{Autenticação de Usuários}

Todas as requisições que partem do usuário (módulo MIU) chegam ao módulo SINGOG. Por questões de segurança todas essas requisições devem ser primeiro autenticadas antes de serem processadas. A implementação vigente exigia a auténticação apenas no início da sessão do usuário (primeira requisição enviada ao módulo SINGOG). Todas as requisições seguintes não sofriam processos de autenticação. Desta forma, a segurança se restringia apenas no nível de protocolo de comunicação; caso o login ou password enviados pelo usuário não fossem autenticados pelo servidor (SINGOG), a interface gráfica não permitia o acesso a novos serviços. Esse mecanismo introduz falhas de segurança. Uma vez que o usuário conheça o protocolo de comunicaçāo usado entre o servidor e o módulo MIU, é possível obter qualquer serviço fornecido pelo SINGOG através de uma aplicação qualquer, bastando para isso, a não solicitação do serviço de autenticação inicial.

O problema foi contornado autenticando-se cada requisição que parte do usuário e chega ao servidor. Desse modo, a cada requisição foram adicionados os campos contendo o login e password do usuário.

\section{Modificações Estruturais do Protocolo}

O protocolo de comunicação sofreu alterações no que diz respeito à solicitação das informaçōes de monitoramento dos nós, por parte do módulo MIU. Essa solicitaçāo encontravase estruturada da seguinte forma: para cada combinação de informações de monitoramento solicitadas havia uma estrutura específica, encarregada de transportar os dados pertinentes à combinação. Por exemplo: caso as informações fornecidas pelos nós fossem a carga de CPL, a quantidade de memória e a data do nó, haveriam as seguintes estruturas disponíveis para transportar essas informaçōes:

- CargaCpu;

- QtdMem;

- Data人io; 
- CargaCpu_QtdMem;

- CargaCpu_DataNo;

- CargaCpu_QtdMem_DataNo:

- QtdMem_DataNo.

Caso o usuário optasse por monitorar a carga da CPU e a quantidade de memória do nó, a estrutura utilizada seria CargaCpu_QtdMem. Essa implementação torna o protocolo bastante eficiente visto que não há perda de largura de banda em virtude de campos não utilizados da estrutura. Por outro lado, tal implementação dificulta a extensão do protocolo. Caso se deseje disponibilizar novas informações de monitoramento, o número de estruturas necessárias crescerão consideravelmente.

O protocolo foi modificado, reunindo todas as informações em uma única estrutura. Essa abordagem facilita a adição de futuras informações de monitoramento (monitoramento da temperatura da CPU, por exemplo). Em contraposição, tal abordagem pode aumentar o tráfego na rede. Por exemplo, se o usuário solicitar o monitoramento da memória dos nós, todos os outros campos da estrutura (CPU, data) estarão vazios.

\section{Timeout de Conexāo}

Deve-se permitir ao usuário configurar o timeout de conexão entre o módulo MIU e o servidor. Essa configuração leva em consideração o desempenho da rede entre esses dois pontos. Assim, caso o desempenho seja baixo, atribui-se um timeout maior para as conexões.

O timeout de conexão foi implementado e submetido a testes de verificação.

\subsection{Considerações Finais}

O presente capítulo relatou as atividades envolvidas na revisão de software da ferramenta Mirador. Na seção 3.3.1 foram descritos, sistematicamente, os testes de verificação dos módulos da ferramenta Mirador, bem como os esforços de manutenção. A seção 3.3.2 discorreu sobre a verificação de integridade entre os módulos. Os capítulos 4 e 5 enfocam a segunda etapa do trabalho, isto é, as especificações, o projeto e a implementação de extensões à ferramenta Mirador. O capítulo 4 se concentra nos requisitos e especificações de tais extensões. 


\section{Capítulo 4}

\section{Definição e Especificação das}

\section{Extensões}

\subsection{Considerações Iniciais}

No capítulo 3 foi relatada a revisão de software a que foi submetida a ferramenta Mirador. O capítulo 4 e o capítulo 5 se concentram na segunda etapa do trabalho, focando o desenvolvimento de extensões para a ferramenta Mirador. A definição e especificação das extensões são tratadas no presente capítulo. O projeto e implementação são assuntos do capítulo 5.

A seção 4.2 discorre sobre a necessidade das extensões. Em seguida, na seção 4.3 são descritos os requisitos funcionais dos módulos a serem implementados, e na seção 4.4 os requisitos não funcionais. O diagrama de fluxo de dados é apresentado na seção 4.5. As funções pertencentes ao diagrama são descritas na seção 4.6 .

\subsection{Definição das Extensões}

Com o intuito de ampliar as funcionalidades da ferramenta Mirador e buscando facilitar as tarefas de monitoramento e gerenciamento, novas extensōes foram implementadas tanto em nível de software quanto em nível de hardware. 


\subsection{Requisitos Funcionais}

Os requisitos a seguir delimitam o escopo das extensões:

- Devem ser fornecidos ao usuário, mecanismos que possibilitem o monitoramento do nível de carga de CPU e memória utilizada, de forma simples, funcional e independente de interação direta com software ou com o sistema operacional. Esse mecanismo deve ser implementado utilizando mostradores (barras) de LEDs para cada nó da máquina paralela. De acordo com a utilização desses recursos, os LEDs acenderão ou apagarão gradativamente, como mostra a figura 4.1;

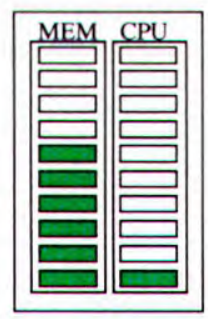

Figura 4.1: Barra de LEDs representando informações de CPU e utilização de memória de um nó da máquina paralela

- É importante que o usuário tenha controle sobre os nós da máquina paralela em situações normais e em situações de pane, permitindo o desligamento e a iniciação de qualquer um dos nós, mesmo que esses estejam impossibilitados de realizar qualquer tarefa. Desse modo, caso um determinado nó entre em pane e não responda aos comandos do usuário, o sistema deve permitir a execução remota (via ferramenta Mirador) dos comandos de reiniciação ou desligamento do nó, na tentativa de restabelecer seu estado normal de funcionamento.

Para que esse requisito seja atingido deve ser especificado um componente de hardware que interaja com a ferramenta Mirador (seção 5.4);

- Facilitar a interoperabilidade dos nós através da execução de comandos de sistema em paralelo (por exemplo, "ls", "copy", "mv"), tornando possível a movimentação de arquivos entre os nós, a listagem de arquivos e diretórios de vários nós, etc.;

- A interface gráfica com o usuário deve ser mais intuitiva, disponibilizando as principais informações de forma rápida e eficaz. As informações de utilização de memória, 
a exemplo do que ocorre com as informações de carga de CPU, devem estar sempre visíveis. As CPUs são representadas através de ícones e suas cargas são representadas por uma matiz de cores, como visto na seção 2.7.10. Para distinguir melhor as informações visualiza ìs. os dados referentes à utilização de memória devem ter uma representação semelhante à barra de LEDs;

- Permitir o monitoramento das redes de conexão de alta velocidade (Myrinet) que conectam os nós da máquina paralela. Devem ser utilizados mapas que representem a topologia da rede e o tráfego de dados entre os nós. O usuário também deve poder visualizar tais informações em tabelas:

- Possibilitar o monitoramento dos dispositivos de hardware de cada um dos nós da máquina paralela. Informações da temperatura da placa mãe, velocidade de rotação do ventilador e valores de tensões da fonte de alimentação devem estar disponíveis;

- Um módulo autônomo de monitoramento de variáveis críticas deve ser implementado. Será permitido ao usuário estabelecer valores limites (mínimo e máximo), dentro dos quais as variáveis sejam consideradas em estado de normalidade. Caso esses valores preestabelecidos sejam ultrapassados, a ferramenta Mirador tomará providências informando o administrador ou intervindo diretamente sobre o sistema, na tentativa de evitar que consequências mais graves venham a ocorrer. Entre os valores críticcs estão a temperatura da placa mãe, a velocidade de rotação do ventilador e as tensões da fonte de alimentação.

\subsection{Requisitos não Funcionais}

Seguem abaixo os requisitos não funcionais a serem atendidos:

- A implementação das extensões não deve impedir a utilização da ferramenta via WWW (Applet);

- A ferramenta Mirador deve ser executada com os parâmetros de restrições de segurança default, impostos pelos navegadores mais comuns. Dessa forma, não deverá haver 
nenhuma necessidade, por parte do usuário, de reconfigurar os parâmetros de segurança do navegador ${ }^{1}$;

- As eventuais alterações nos protocolos de comunicação utilizados entre os módulos da ferramenta Mirador devem ser implementadas de forma a minimizar o tráfego na rede;

- Os módulos de monitoramento e gerenciamento não devem sobrecarregar os nós que estão monitorando. O mesmo é válido para o monitoramento das redes de conexão;

- O pacote no qual é distribuída a ferramenta Mirador deve oferecer suporte ao utilitário de instalação make, automatizando, assim, o processo de compilação (no caso dos módulos desenvolvidos em linguagem $\mathrm{C}$ ) e instalação da ferramenta.

\subsection{Diagrama de Fluxo de Dados}

O diagrama de fluxo de dados da ferramenta Mirador (incluindo as extensões) é apresentado na figura 4.2 .

A ferramenta Mirador, incluindo as extensões, será referenciada por Mirador II.

\footnotetext{
${ }^{1}$ A atual política de segurança dos Applets é bastante flexível, possibilitando ao usuário configurar diversos niveis de restriçōes.
} 


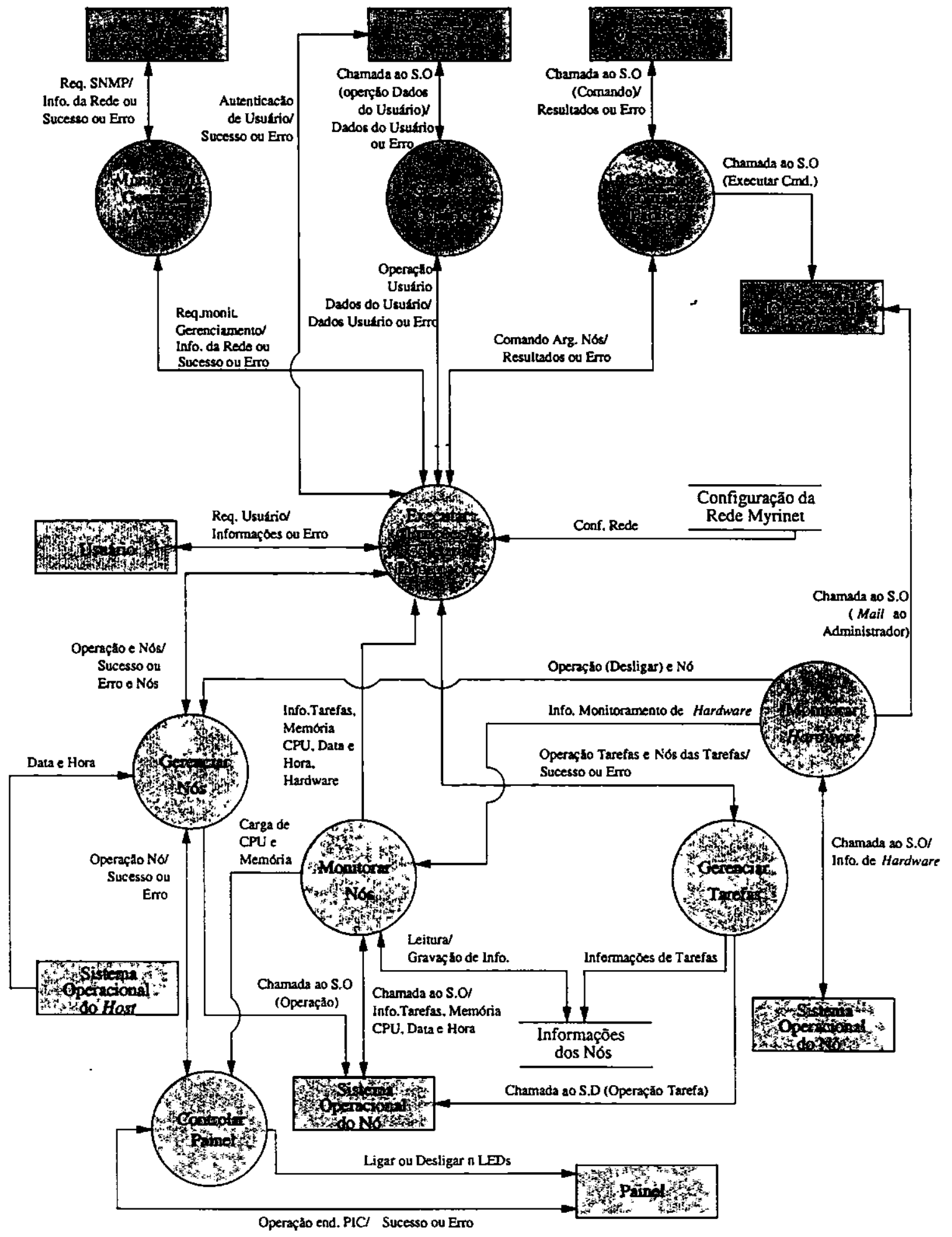

Figura 4.2: DFD da ferramenta Mirador II. Nível 1 


\subsection{Descrição das Funções}

As funções apresentadas no DFD da figura anterior são descritas nos itens seguintes.

\subsubsection{Monitorar/Gerenciar Rede Myrinet}

A rede Myrinet disponibiliza diversas informaçōes de monitoramento. $O$ número de pacotes recebidos em uma determinada porta da switch pode ser citado como exemplo (maiores detalhes na seção 5.3.2). Essas informações podem ser obtidas por qualquer aplicação, desde que utilize o protocolo SNMP para a comunicação.

A figura 4.3 mostra esse processo em um nível mais detalhado. A requisição de monitoramento/gerenciamento chega às funções Ler Informações da Switch ou Reiniciar Switch onde é encapsulada de forma a utilizar o protocolo SNMP. Em seguida, a requisição é enviada a entidade externa Switch, onde as informações são coletadas (ou alteradas, no caso de gerenciamento). No passo seguinte a função Formatar Requisição/Retornar Informações organiza tais informações e as retorna à função Executar Funções/Coletar Informaçōes. Caso não se obtenha êxito na coleta das informações de rede ou no gerenciamento da switch, um flag de erro é retornado.

É importante notar que as informações de monitoramento da rede Myrinet são disponibilizadas pelas switches que interligam os nós.

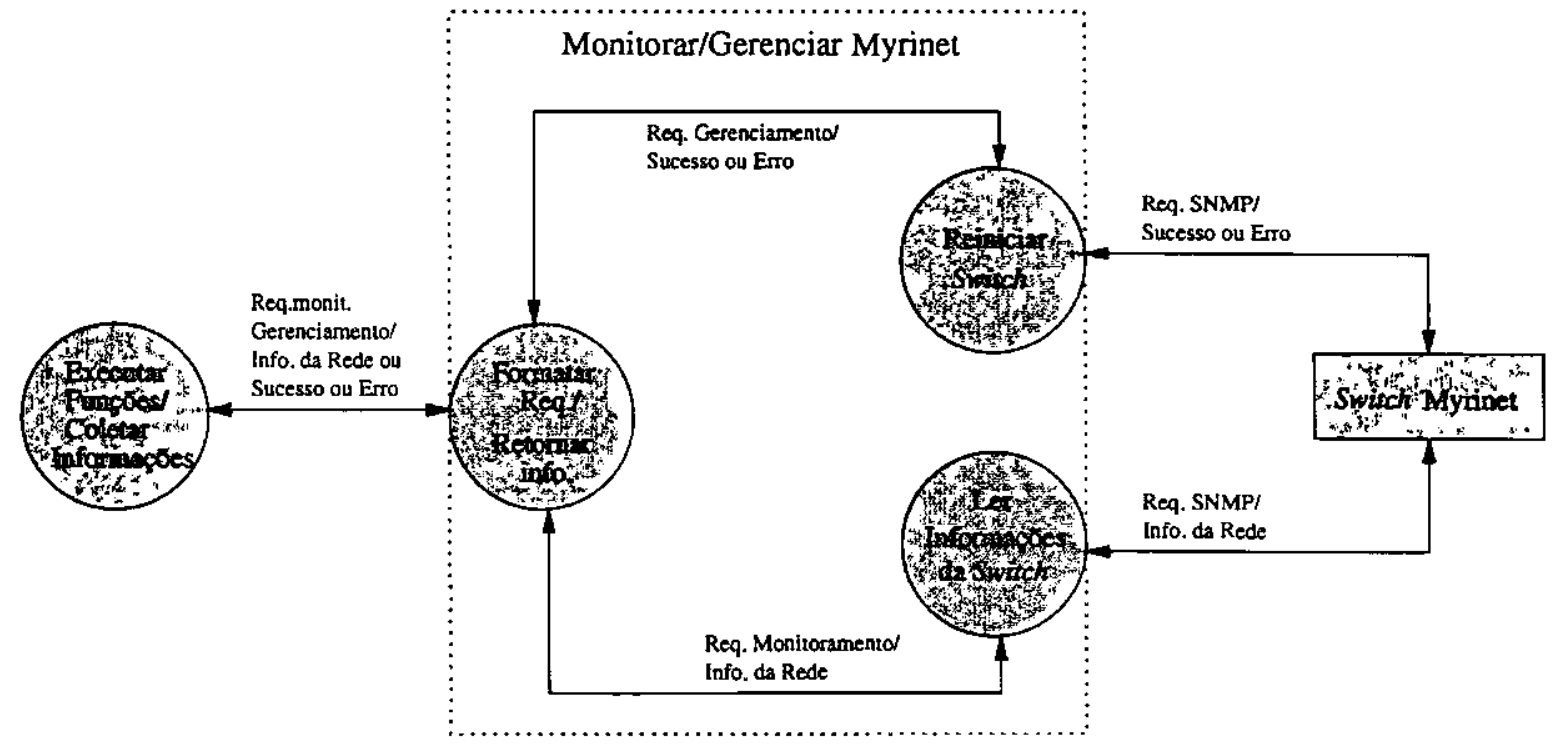

Figura 4.3: DFD da função Monitorar/Gerenciar Rede Myrinet 


\subsubsection{Executar Comando Paralelo}

A função Executar Comandos Paralelos permite a execução de comandos básicos do Unix, envolvendo todos os nós se necessário. Os comandos Unix disponibilizados pela ferramenta Mirador 11 são listados a seguir:

- 'ls': lista arquivos e diretórios em um ou vários nós;

- 'find': localiza um arquivo ou diretório em um ou vários nós';

- ' $c p$ ': copia arquivos ou diretórios de um nó para o mesmo nó, de um nó para outro nó e de um nó para vários nós;

- 'mv': move arquivos ou diretórios de um nó para o mesmo nó, de um nó para outro e de um nó para vários nós;

- 'rm': remove arquivos ou diretórios de um ou vários nós.

De acordo com a figura 4.4, a requisição para executar os comandos é formatada de maneira que o sistema operacional possa interpretá-la corretamente. Em seguida, os comandos são executados (no sistema operacional do host e/ou no sistema operacional dos nós, dependendo da requisição) e uma lista com os resultados da execução é retornada.

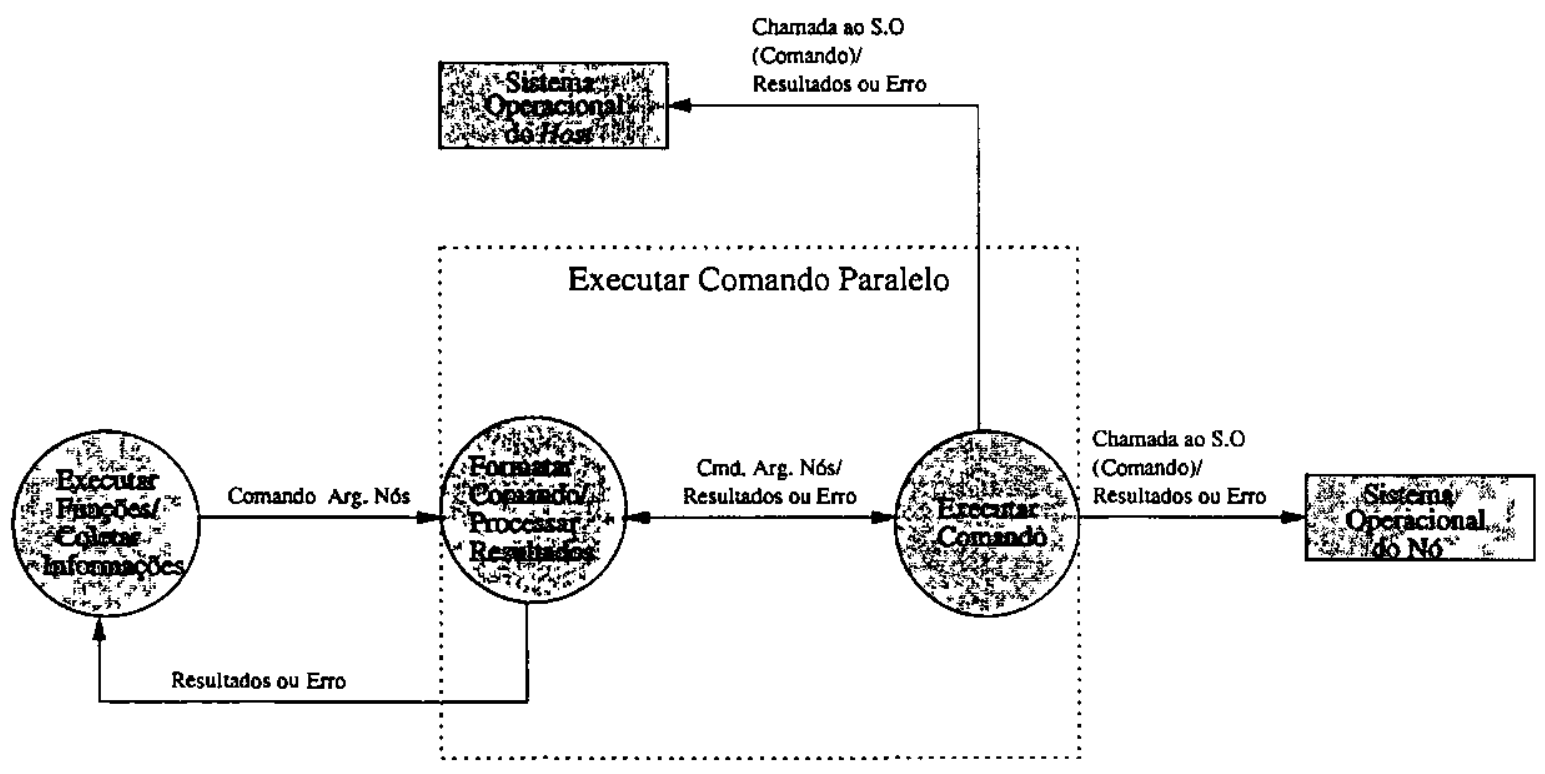

Figura 4.4: DFD da função Executar Comando Paralelo

A função Executar Comando gerencia todo o processo, contatando os nós/host necessários à execução dos comandos. 


\subsubsection{Monitorar Hardware}

Essa função realiza o monitoramento dos dispositivos de hardware dos nós, como descrito nos requisitos funcionais (seção 4.3). O DFD dessa função é mostrado na figura 4.5.

As informações monitoradas (temperatura da placa máe, velocidade de rotação do ventilador e as tensões da fonte de alimentação) são obtidas periodicamente e armazenadas na base de dados Informações de Hardware. A função Ler Informações consulta continuamente a base de dados e repassa as informações de monitorámento adiante. A função Verificar Normalidade de Hardware verifica o valor dessas informações. Caso estejam fora dos limites estabelecidos, uma mensagem é enviada ao administrador por email e, caso os valores permaneçam fora dos limites em pösteriores verificações, a função Gerenciar os Nós é contatada para desligar automaticamente o nó.

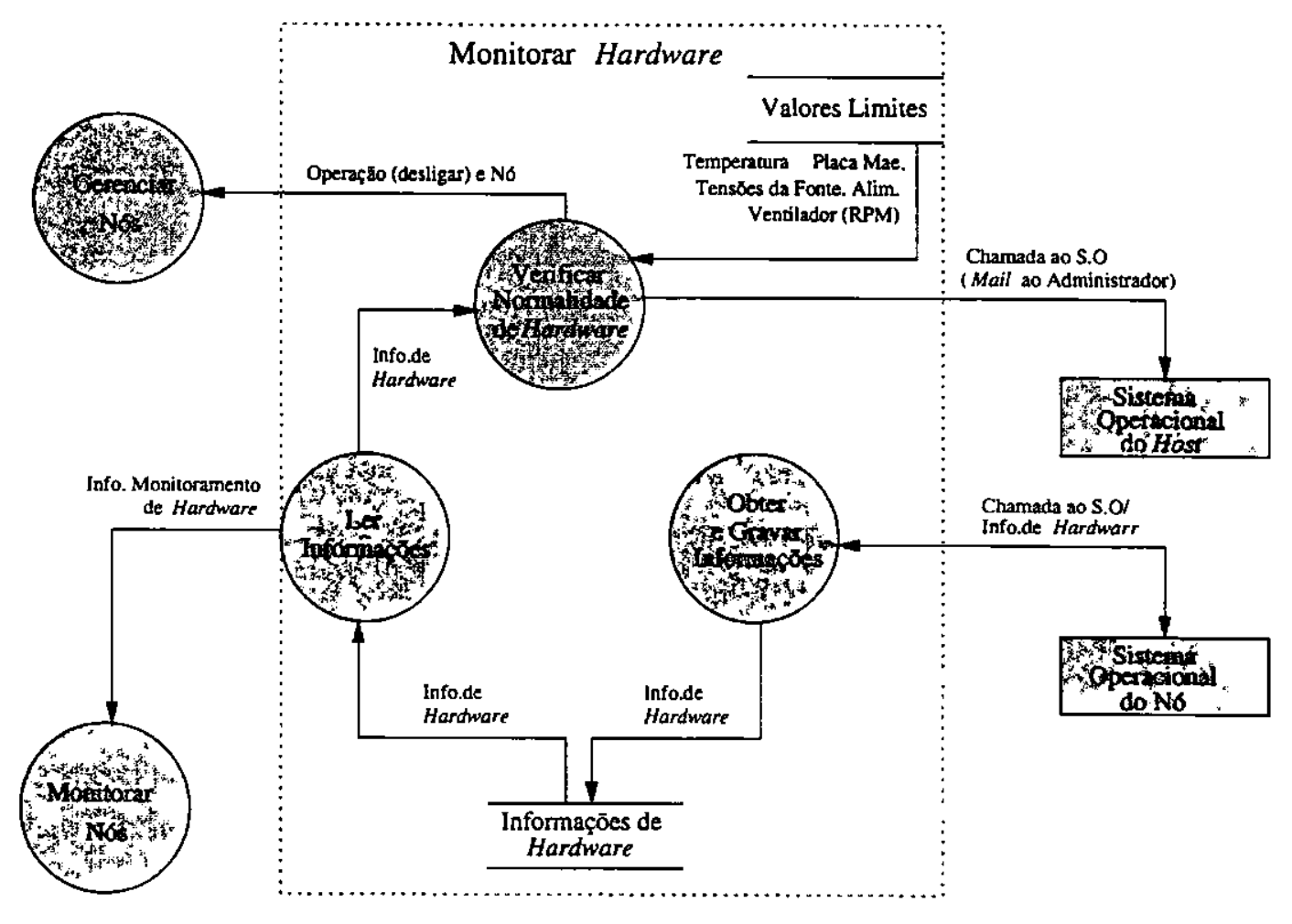

Figura 4.5: DFD da função Monitorar Hardware

\subsubsection{Monitorar Nós}

A função Agrupar Informações de Hardware e Informaçōes de Nós, apresentada na figura 4.6, é responsável pelo agrupamento de todas as informações de monitoramento do sistema. A base de dados Informações dos Nós contém as informações de monitoramento referentes 
à carga de CPU, utilização de memória, data/hora e tarefas em execução dos nós. As informações de hardware são obtidas da função Monitorar Hardware.

Após o agrupamento, as informações são passadas para a função Executar Funções/ Coletar Informações.

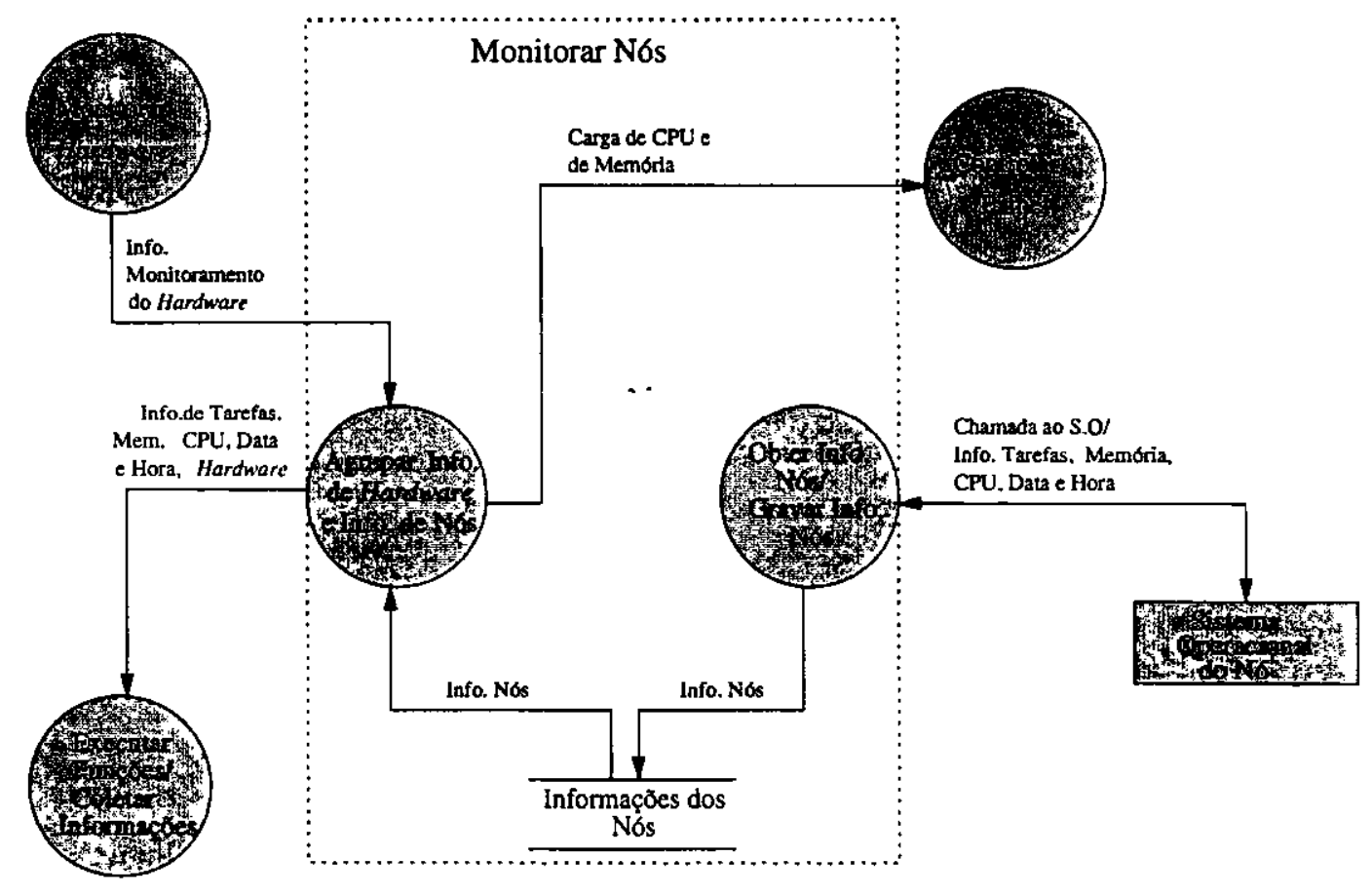

Figura 4.6: DFD da função Monitorar Nós

As informações de carga de CPU e memória também são direcionadas à função Controlar Painel, que é responsável por toda a comunicação com o Painel de Monitoramento e Gerenciamento.

\subsubsection{Gerenciar Nós}

O gerenciamento dos nós é realizado tanto por software (sistema operacional), como por hardware. A tabela 4.1 mostra as diferenças entre esses dois tipos de gerenciamento.

O DFD da figura 4.7 ilustra o gerenciamento dos nós. A função Contatar os Nós é responsável por enviar os comandos de gerenciamento aos nós, bem como informar o tipo de gerenciamento (por software ou hardware). A função Gerenciar o Nó executa os comandos através do sistema operacional do nó, ou os repassam à função Controlar Painel, caso seja um comando de gerenciamento via hardware. 
Tabela 4.1: Operaçōes de gerenciamento permitidas

\begin{tabular}{|c|c|c|c|c|c|c|c|}
\hline $\begin{array}{l}\text { Operação/ } \\
\text { tipo de Geren- } \\
\text { ciamento }\end{array}$ & $\begin{array}{l}\text { Atualizar } \\
\text { Data/Hora }\end{array}$ & Halt* & $\begin{array}{l}\text { Reiniciar } \\
\text { nó }\end{array}$ & $\begin{array}{l}\text { Reiniciar } \\
\text { nó em } \\
\text { pane** }\end{array}$ & $\begin{array}{l}\text { Desligar } \\
\text { nó }\end{array}$ & $\begin{array}{l}\text { Desligar } \\
\text { nó em } \\
\text { pane }\end{array}$ & Ligar nó \\
\hline software & $x$ & $x$ & $x$ & & & & \\
\hline hardware & & & $x$ & $x$ & $x$ & $x$ & $x$ \\
\hline
\end{tabular}

*Paralisação geral do sistema operacional do nó.

**O sistema operacional do nó, devido a alguma anomalia, não responde a nenhum comando do usuário.

A entidade Sistema Operacional do Nó recebe como entrada o comando a ser executado (Atualização de data/hora, paralisação ou reiniciação do nó).

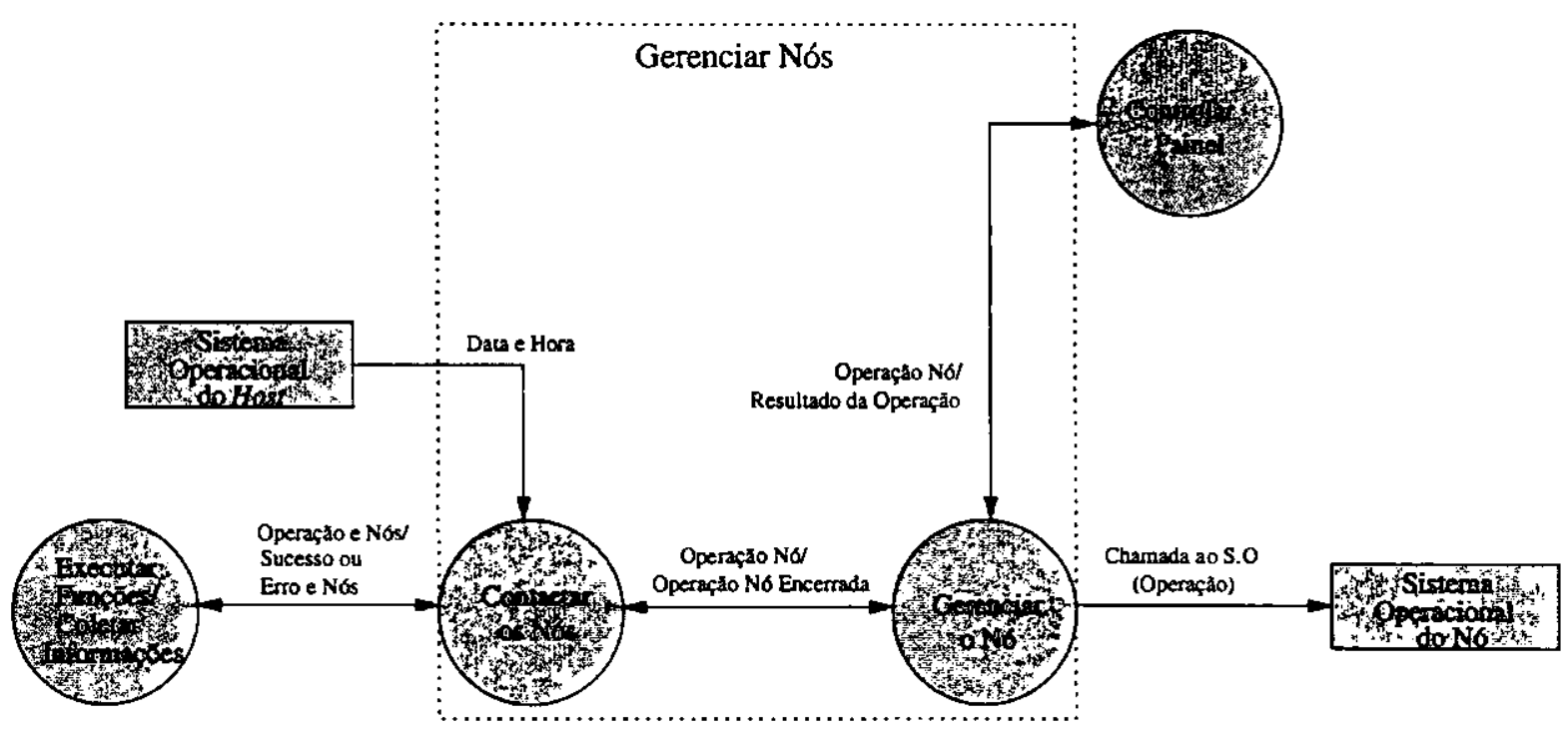

Figura 4.7: DFD da função Gerenciar Nós

\subsubsection{Executar Funções/Coletar Informações}

Toda a interação entre o usuário e a máquina paralela é realizada direta ou indiretamente através dessa função, como descrito na seção 2.7.10. A figura 4.8 apresenta seu DFD com o intuito de ilustrar as interações da função principal da ferramenta Mirador com as funções especificadas neste capítulo.

A base de dados Configuração da Rede Myrinet armazena a disposição dos nós na switch Myrinet, informando em quais portas estão conectados. A base de dados também 
disponibiliza o endereço IP da switch. Todos as entradas da base de dados são configuradas manualmente pelo administrador.

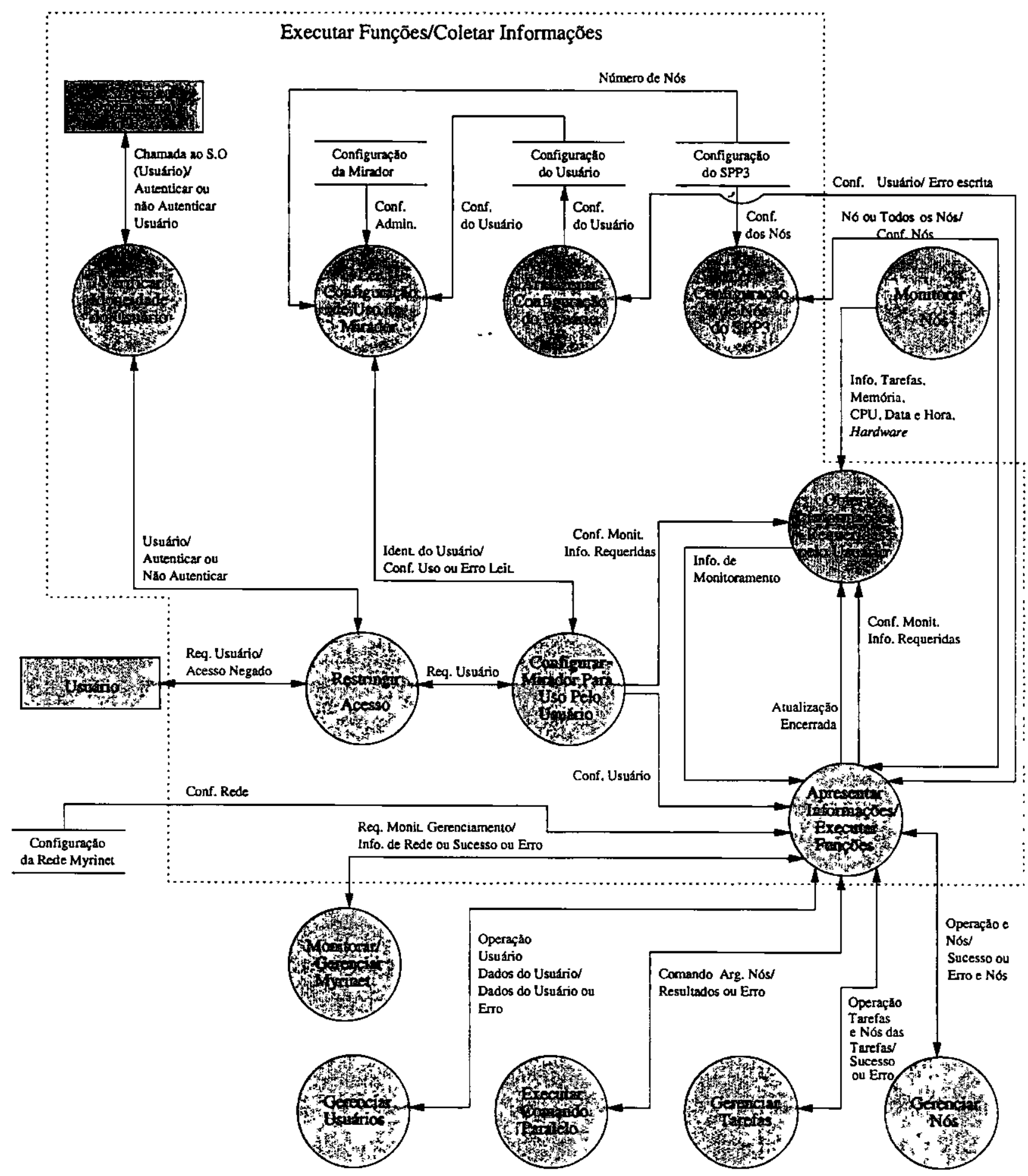

Figura 4.8: DFD da função Executar Funçōes/Coletar Informaçōes 


\subsubsection{Controlar Painel}

A função Controlar Painel é apresentada na figura 4.9. A função Controlar LEDs é responsável por ligar e desligar as barras de LEDs. A função Executar Operação é encarregada de executar os comandos de gerenciamento.

Esse tópico é amplamente discutido na seção 5.3.2 e no apêndice B.

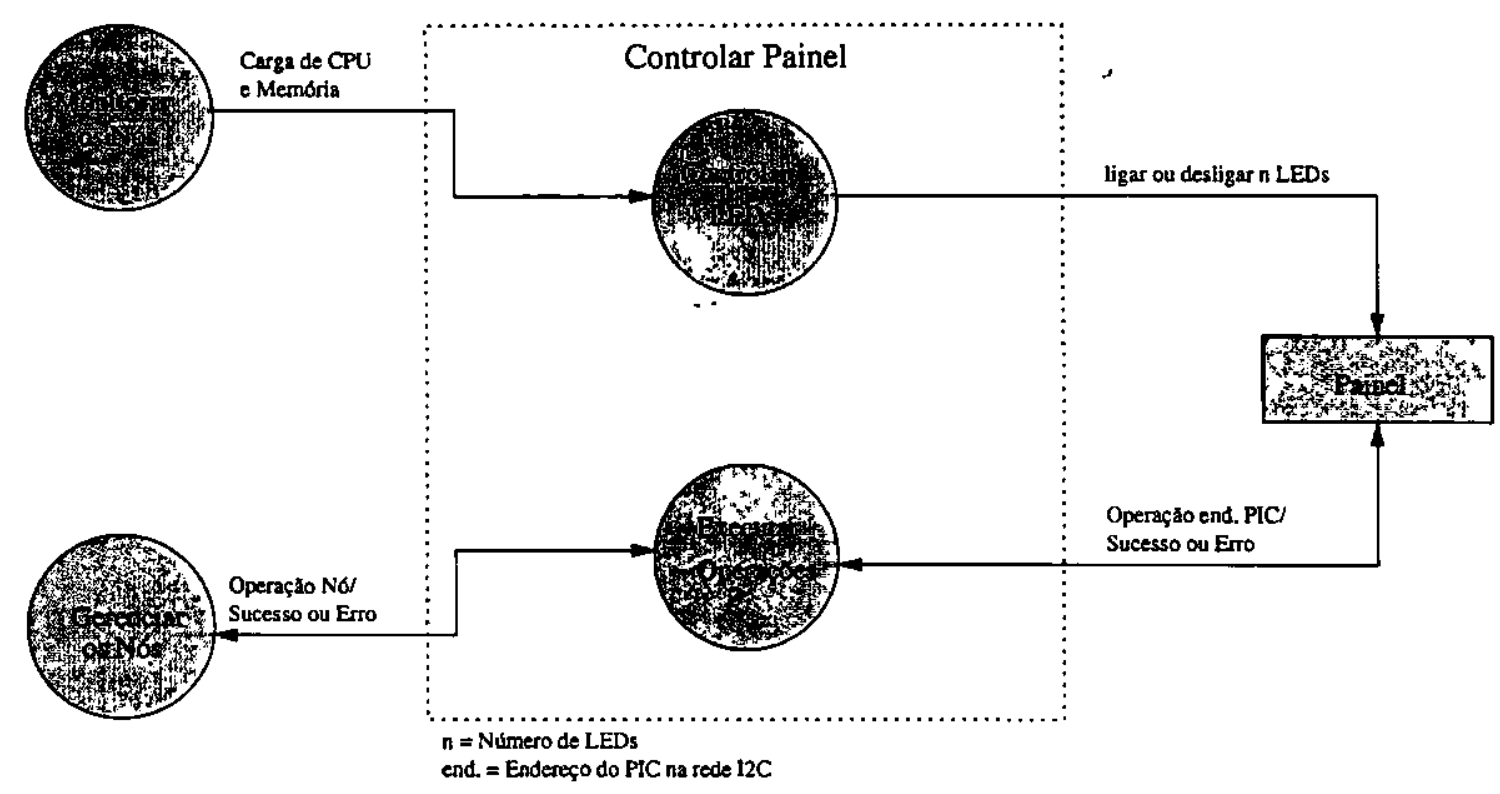

Figura 4.9: DFD da função Controlar Painel

\subsection{Consideraçōes Finais}

Este capítulo concentrou-se nas definições e especificações das extensões para a ferramenta Mirador. As análises de requisitos funcionais e não funcionais foram descritas, apresentando e justificando a necessidade de se estender as funcionalidades da ferramenta.

A seção 4.5 apresentou o DFD da ferramenta Mirador II. A descrição detalhada das funçōes que compõem o DFD, analisando seus fluxos de dados e suas interações, também foi apresentada

O próximo capítulo discorre sobre o projeto e a implementação das extensōes especificadas. 


\section{Capítulo 5}

\section{Projeto e Implementação das}

\section{Extensões}

\subsection{Considerações Iniciais}

Este capítulo discorre sobre o projeto e implementação das extensōes da ferramenta Mirador que foram especificadas no capítulo 4 .

A seção 5.2 descreve o ambiente utilizado na implementação das extensões. A seção 5.3 apresenta a arquitetura da ferramenta Mirador, dando ênfase às extensōes. Na seção 5.6 é feita uma breve descrição das principais funções implementadas. A instalação da ferramenta Mirador II e os testes realizados são discutidos na seção 5.7. As considerações finais referentes ao projeto e implementação das extensões se encontram na seção 5.8 .

\subsection{Ambiente de Implementação}

Com o intuito de permitir ao usuário monitorar e gerenciar a máquina paralela pela Internet usando diferentes plataformas, a ferramenta Mirador, no que diz respeito ao Módulo de Interação com o Usuário (interface), foi desenvolvida em Java, podendo ser executada como um Applet : via Internet, ou como uma aplicação stand-alone [Sun98], de algum ponto da rede local. Todos os demais módulos foram implementados na plataforma Linux, por ser o sistema operacional utilizado pelos nós da máquina paralela. Os códigos fontes foram escritos na linguagem $\mathrm{C}$, utilizando o compilador GNU gcc [GNU00]. Os módulos são compatíveis 
com as bibliotecas de sistema libc5 e glibc [GNU99]. Os threads implementados utilizam a biblioteca LinuxThreads [LER97]. A biblioteca ucd-snmp [Uni00] é utilizada na implementação das funções de monitoramento e gerenciamento da rede Myrinet. A listagem das ferramentas e bibliotecas utilizadas na implementação das extensões sâo mostradas na tabela 5.1.

Tabela 5.1: Ferramentas e bibliotecas utilizadas

\begin{tabular}{|l|l|l|}
\hline $\begin{array}{l}\text { Ferramenta/ } \\
\text { Biblioteca }\end{array}$ & Descrição & Versão \\
\hline JDK & compilador/máquina virtual Java & 1.1 .7 \\
\hline API Swing & biblioteca gráfica para aplicações Java & 1.1 .1 \\
\hline gcc & compilador C & 2.7 .2 .3 \\
\hline ucd-snmp & protocolo SNMP & 4.0 .1 \\
\hline LinuxThreads & implementação de threads & 0.7 \\
\hline libc5 & system calls & 5.4 .46 \\
\hline glibc & system calls & 2.0 .7 \\
\hline
\end{tabular}

\subsection{Arquitetura da Ferramenta Mirador II}

A figura 5.1 mostra a arquitetura da ferramenta Mirador II, onde estão representados os nós que compõe o SPP3 e suas redes de conexões. Os módulos da ferramenta Mirador II estão dispostos de acordo com suas localizações reais na máquina paralela. O host é o servidor de disco dos nós e também o gateway entre os nós e o usuário. Uma rede qualquer (LAN, WAN ou Internet) conecta o usuário ao host.

Toda a base de dados se encontra no host, juntamente com o módulo SINGOG e o módulo MRM (Monitor da Rede Myrinet) (seção 5.3.2). O módulo MH (Monitor de Hardware) e os módulos GNPi e MINPi estão localizados nos nós. Os PMG (Painéis de Monitoramento e Gerenciamento) (seção 5.4) se encontram em cada um dos nós e estão interconectados por uma rede $\mathrm{I} 2 \mathrm{C}$ (maiores detalhes, seção 5.4). O módulo $\mathrm{CP}$ (Controlador de Painel) (seção 5.3.2) se encontra em cada componente PMG.

O projeto das extensões foi elaborado procurando manter a arquitetura especificada 


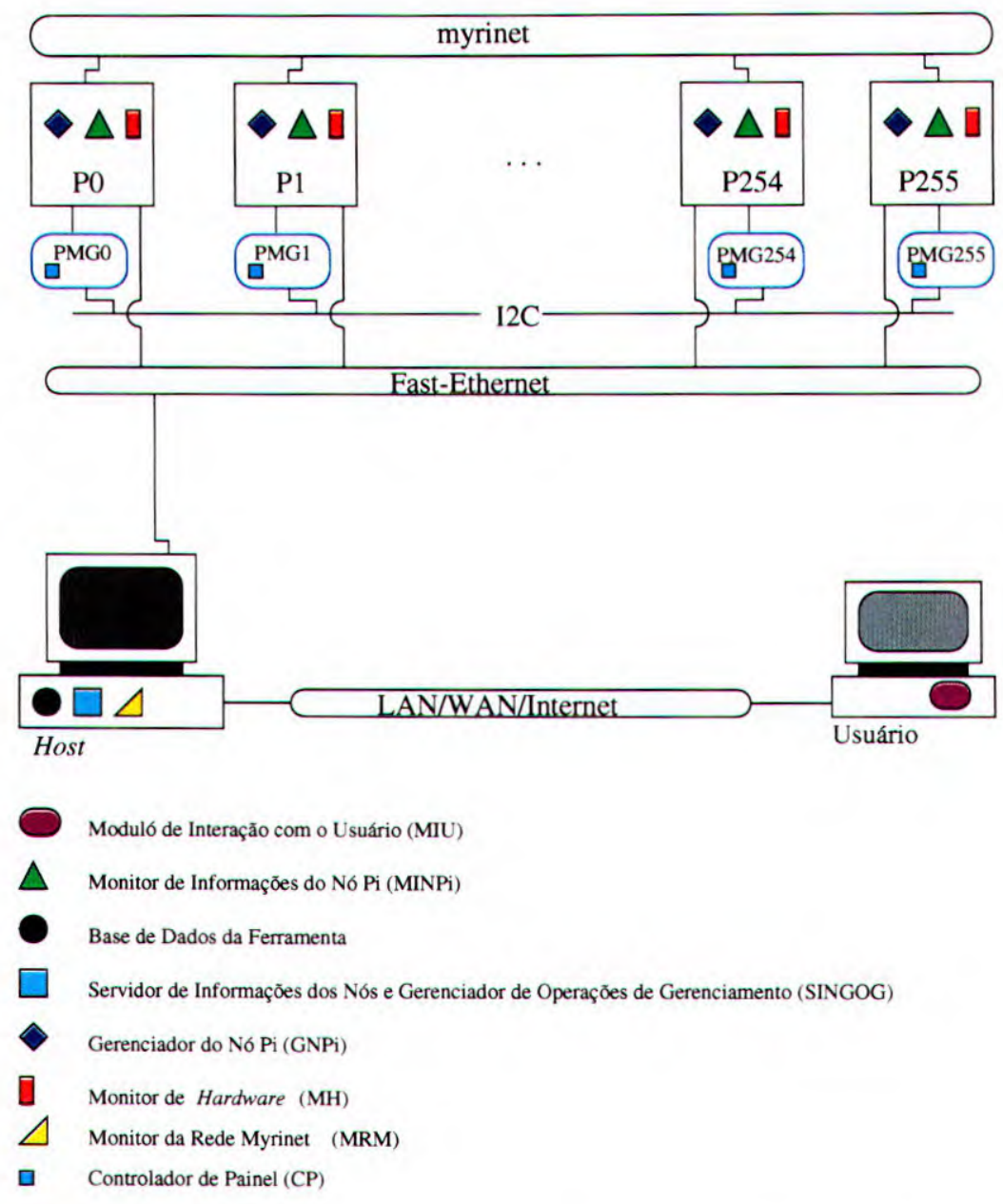

Figura 5.1: Arquitetura da ferramenta Mirador II

inicialmente (seção 2.7.10). Dessa forma, foi necessário o projeto de dois módulos adicionais: o MRM, responsável pelo monitoramento da rede Myrinet e o CP que controla o Painel de Monitoramento e Gerenciamento. As demais funções foram acomodadas nos módulos já existentes. A tabela 5.2 relaciona as funções especificadas no DFD 4.2 com os módulos onde estão implementadas. Algumas das funções apresentadas se encontram em dois módulos distintos. Isso se deve ao fato de estarem no nível 1 do DFD. Por exemplo: a função Executar Comandos Paralelos, quando analisada a partir do nível 2, é formada pelas funções Formatar Comando e Executar Comando, sendo que a primeira se encontra no módulo SINGOG e a segunda no módulo GNPi. 
Tabela 5.2: Relação entre funções e módulos

\begin{tabular}{|l|l|}
\hline Função & Módulo \\
\hline Monitorar Myrinet & MRM \\
\hline Executar Comando Paralelo & SINGOG/GNPi \\
\hline Monitorar Hardware & MH/MINPi \\
\hline Monitorar Nós & SINGOG/MINPi \\
\hline Gerenciar Nós & SINGOG/GNPi \\
\hline Gerenciar Tarefas & SINGOG/GNPi \\
\hline Gerenciar Usuários & SINGOG \\
\hline Executar Funções/Coletar Informações & SINGOG \\
\hline Controlar Painel & CP \\
\hline
\end{tabular}

\subsubsection{Protocolo de Comunicação da Ferramenta Mirador II}

A figura 5.2 apresenta o protocolo de comunicação utilizado entre os módulos da ferramenta Mirador II. Todos utilizam o mecanismo requisição/resposta.

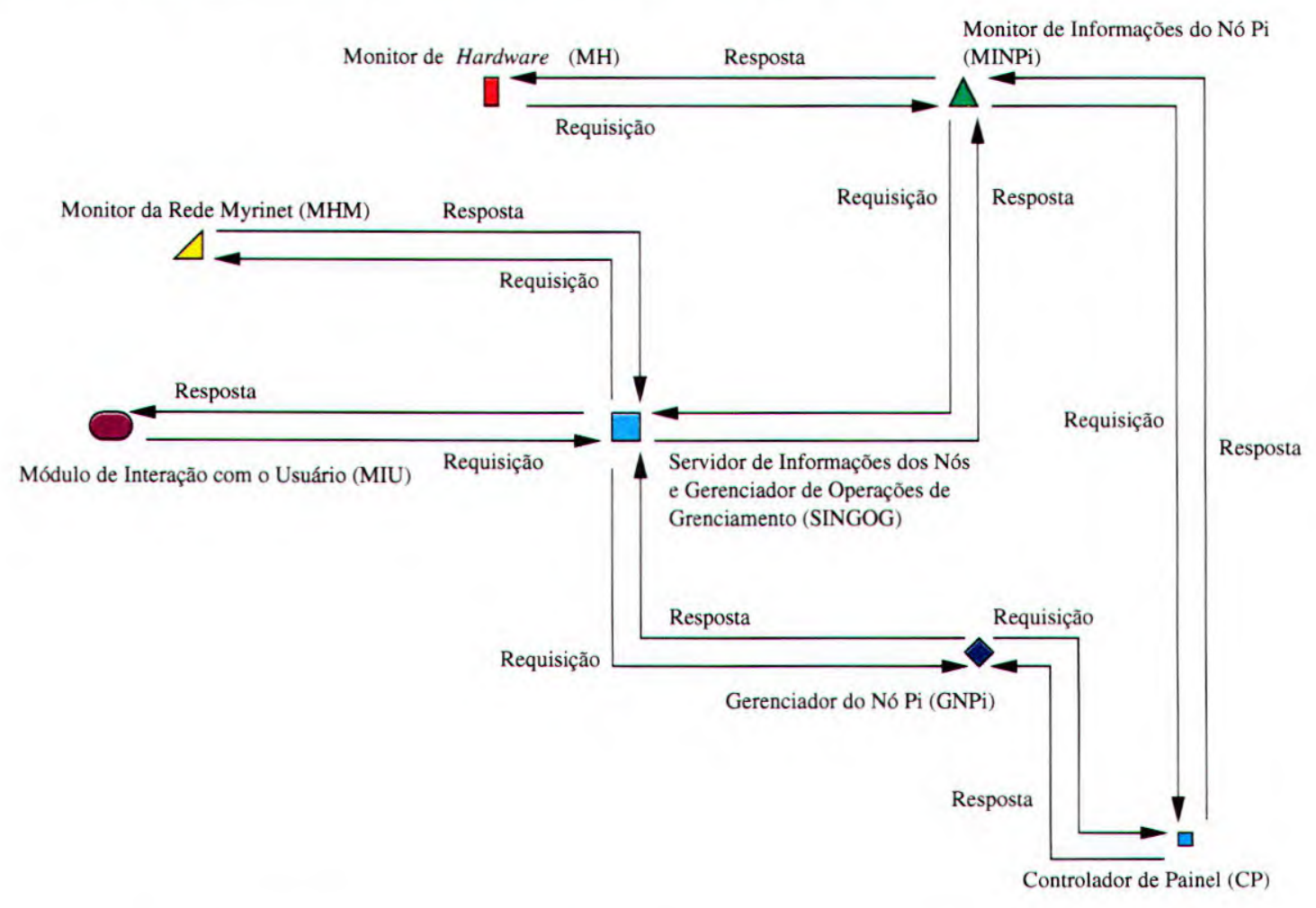

Figura 5.2: Protocolo de comunicação da ferramenta Mirador II 


\subsubsection{Projeto dos Módulos}

Esta seção descreve os módulos MRM, CP e MH. Informações sobre os demais módulos são encontradas na seção 2.7.10.

\section{MRM (Monitor da Rede Myrinet)}

Esse módulo é responsável pelo monitoramento da rede de alta velocidade Myrinet. De acordo com as especificações do fabricante [NJB95], as informações de monitoramento da rede são mantidas por agentes SNMP que executam na switch Myrinet. As informações são obtidas via conexão Ethernet, como ilustra a figura 5.3. A switch monitorada está diretamente conectada ao host por uma interface de rede Ethernet. No momento da iniciação da switch o host fornece, via DHCP, um endereço IP para a mesma, tornando-a um dispositivo acessivel.

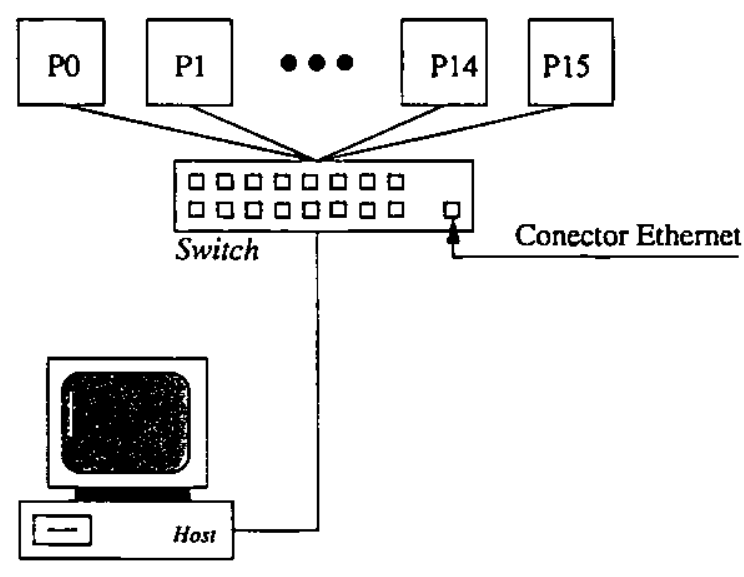

Figura 5.3: Monitoramento da switch

\section{CP (Controlador de Painel)}

Esse módulo é responsável pelo controle dos componentes PMG. O módulo implementa as funções de baixo nível que coordenam todas as atividades do componente, realizando tanto as tarefas de monitoramento como as de gerenciamento.

Todas as funções do módulo CP são implementadas e executadas no micro-controlador do componente PMG. 


\section{MH (Monitor de Hardware)}

O módulo MH consiste no aplicativo LMSensor [LmS98]. Tal aplicativo interage diretamente com o chip LM78 [Nat00]. Esse chip, presente na maioria das placas mãe atuais, age como sensor cic temperatura e de tensões, e mede as velocidades de rotação dos ventiladores, dentre outras informações.

\subsection{O PMG (Painel de Monitoramento e Gerencia- mento)}

O projeto do componente PMG visa atender dois objetivos básicos:

- Viabilizar o monitoramento de carga de CPU e memória utilizada por cada nó;

- Possibilitar o desligamento ou a reiniciação de nós quando esses se encontram em estado de pane, e permitir que os nós sejam ligados através de simples comandos de sistema.

\subsubsection{Descrição do Componente PMG}

O componente PMG possui duas barras de LEDs e um micro-controlador que armazena e - executa o módulo CP. O componente PMG possui uma interface RS232 que se conecta a porta serial do nó e viabiliza toda a comunicação componente/nó e vice-versa. O componente possui ainda três vias de comunicação. As duas primeiras são ligadas diretamente à placa mãe do nó, agindo como chaves de controle de reiniciação e de liga/desliga. A terceira via é usada para comunicação com outros componentes PMG. A figura 5.4 ilustra a interação do componente PMG com os nós e com a rede I2C.

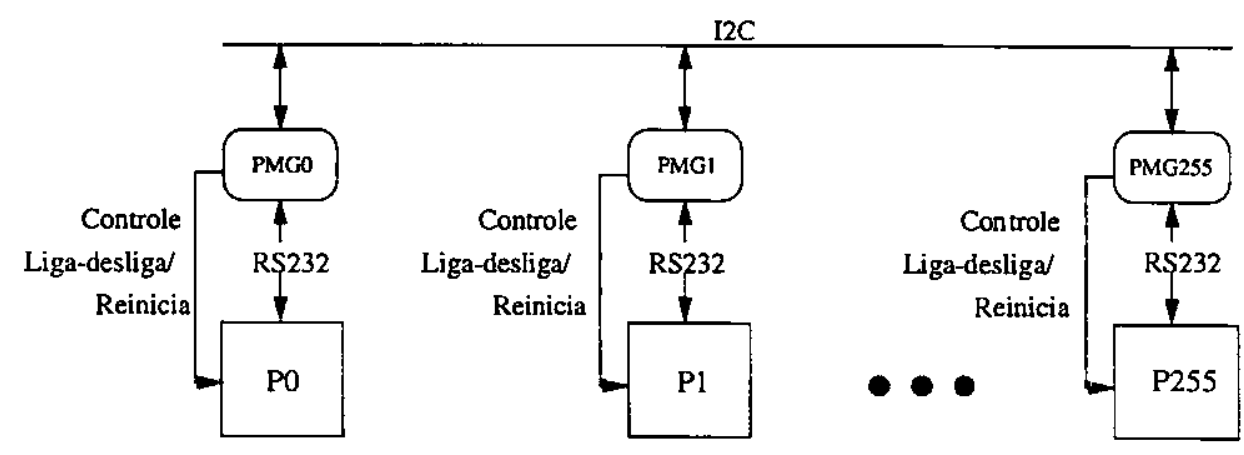

Figura 5.4: Interação entre componentes e nós 


\subsection{Projeto da Interface}

A ferramenta Mirador II apresenta melhorias na interface de interação com o usuário. O layout da interface principal foi modificado, como mostra a figura 5.5.

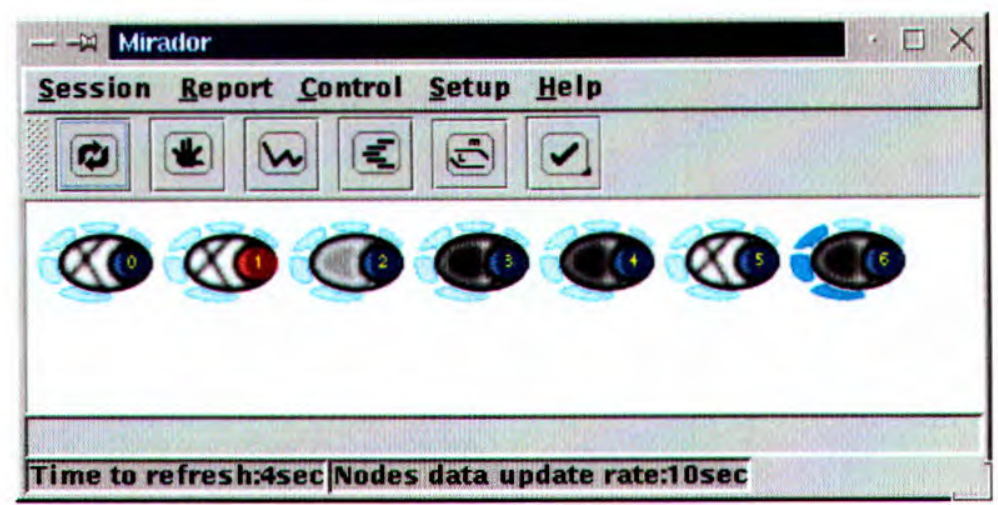

Figura 5.5: Interface da ferramenta Mirador II

De acordo com a figura, estão sendo monitorados cinco nós. As elipses rotuladas com um "X" indicam nós inoperantes. O pequeno círculo do lado direito de cada elipse indica se o nó está ou não selecionado para gerenciamento. O círculo vermelho representa nó selecionado. Enquanto que a cor da elipse representa a carga de CPU, os semicírculos em torno das elipses representam a utilização de memória. Seus valores são interpretados da seguinte forma:

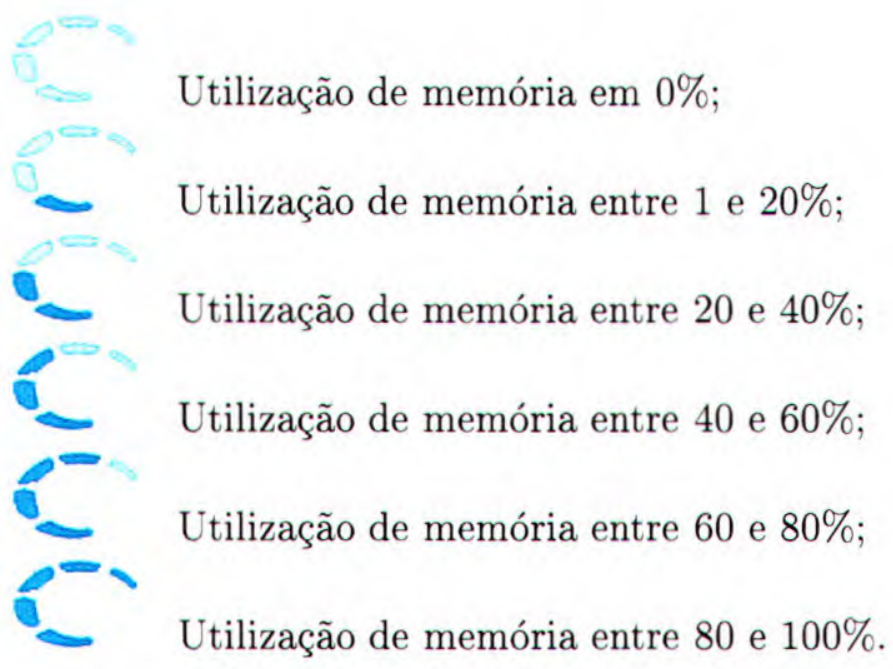

A figura 5.6 ilustra o monitoramento do nó 3. O usuário tem a opção de ver os valores monitorados (CPU e memória) em uma representação mais precisa, passando o mouse por sobre o ícone. 


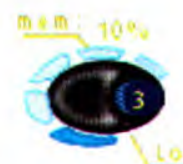

Figura 5.6: Monitoramento do nó

Por questões de consistência, a interface desabilita opções que somente podem ser executadas com privilégios de usuário root. Essas opções dizem respeito ao gerenciamento dos nós, gerenciamento de usuários e gerenciamento das switches.

Para realizar o monitoramento da rede Myrinet, a disposição dos nós é modificada de modo a representar a topologia da rede (figura 5.7). As conexões entre os nós e a switch refletem o tráfego na rede e suas cores são alteradas de acordo com a quantidade de pacotes que estão trafegando. A nomenclatura das cores e os respectivos valores que representam são os mesmos usados para representar a carga de CPU dos nós, ou seja:

$\begin{array}{llll}\text { Cor } & \text { Porcentagem } & \text { Cor } & \text { Porcentagem } \\ \text { Preto } & 0-10 \% & \text { Verde } & 50-60 \% \\ \text { Marrom } & 10-20 \% & \text { Azul } & 60-70 \% \\ \text { Vermelho } & 20-30 \% & \text { Anil } & 70-80 \% \\ \text { Laranja } & 30-40 \% & \text { Cinza } & 80-90 \% \\ \text { Amarelo } & 40-50 \% & \text { Cinza pontilhado } & 90-100 \%\end{array}$

Todas as variáveis MIB obtidas da switch Myrinet (seção 5.3.2) são apresentadas ao usuário em uma tabela (apêndice A).

\subsection{Implementação das Funções}

Nesta seção são discutidos os aspectos envolvidos na implementação das principais funções do sistema.

\section{Ler Informações da Switch}

Essa função acessa a switch Myrinet, obtendo os valores das variáveis disponíveis. 


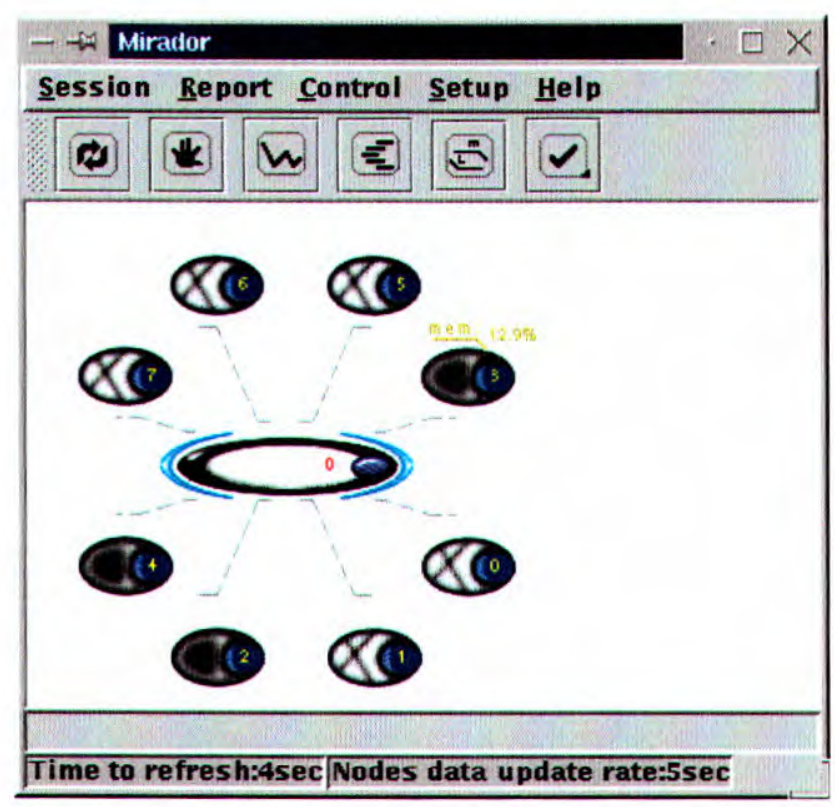

Figura 5.7: Monitoramento da rede Myrinet

Como visto na seção 2.8, uma requisição SNMP é formada basicamente pelos campos operação e nome (ou caminho, por exemplo 1.0.2.6) do objeto (ou variável). Desta forma, uma requisição contendo os caminhos de todas as variáveis na base de dados MIB é montada e enviada através do comando Get. Em seguida, uma lista contendo os valores das variáveis requisitadas é retornada, desmembrada, estruturada adequadamente e enviada ao usuário.

\section{Reiniciar Switch}

Uma requisição é enviada para a switch solicitando sua reiniciação. A requisição é formada pelo comando Set e o nome da variável a ser alterada (no caso, a variável reset). De acordo com as especificações do fabricante (seção 5.3.2), a alteração da variável reset força o agente a reiniciar a switch. Um flag indicando sucesso ou erro é retornado e enviado ao usuário.

A seguir, tem-se a lista de todas as variáveis que são mantidas pela switch. Certas variáveis são de escrita, permitindo que seus valores sejam alterados remotamente.

- ethernetAddress: endereço físico da interface de rede da switch;

- ipAddress: endereço IP da switch. Fornecido via DHCP;

- softwareVersion: versão do software (agente) que executa na switch; 
- timeout: timeout de conexão da switch. Variável do tipo read/write, permitindo ao usuário configurar seu valor;

- reset: variável do tipo read/write. É utilizada para reiniciar a switch;

- switchUpTme: contador do tempo (em segundos) em que a switch está em funcionamento desde a última iniciação;

- numPorts: número de portas contidas na switch;

- portTable: tabela de informações das portas, possuindo as seguintes entradas (variáveis):

- portNumber: número de uma determinada porta;

- upTime: tempo em que a porta está ativa desde a última iniciação;

- goodLow e goodHigh: número de pacotes com CRC [TAN98] correto que passaram pela porta;

- badLow e badHigh: número de pacotes com CRC incorreto que passaram pela porta;

- timeouts: timeout de conexão da porta;

- illegalSymbols: quantidade de illegal symbols detectados na porta;

- missedBeats: número de ocorrências de missed beats (perda de sincronismo);

- badRoutes: número de rotas incorretas;

- deadRoutes: número de rotas que não mais existem;

- state: estado da porta. Podendo assumir os seguintes valores:

0 - porta habilitada para transmitir e receber pacotes;

1 - porta detectando beats no outro extremo da conexão;

2 - porta transmitindo pacotes;

3 - porta recebendo pacotes.

- control: variável tipo read/write. Pode Assumir os seguintes valores:

7 - porta desabilitada para transmissão;

6 - porta desabilitada para recepção;

5 - porta será desabilitada após a detecção de 3 beats consecutivos;

4 - porta será desabilitada quando detectado um illegal simbol. 


\section{Executar Comando Paralelo}

A função recebe como parâmetro o comando, os seus argumentos e a lista dos nós que participam da execução. A seguir, tem-se a sintaxe de cada comando:

- ls [argumentos ${ }^{1}$ ] lista_de_nós;

- find [argumentos] lista_de_nós;

- cp [rcp_argumentos ${ }^{2}$ ] nóorigem lista_de_nós arq_origem arq_destino ou cp [rcp_argumentos] nó_origem lista_de_nós arq_origem1 arq_origem 2 ... diretório_destino;

- mv [rcp_argumentos] nó_origem lista_de_nós arq_origem arq_destino ou mv [rcp_argumentos] nó_origem lista_de_nós arq_origem1 arq_origem2 ... diretório_destino.

Os resultados (sucessos ou erros) da execução dos comandos são retornados pela função e visualizados em um console fornecido pela ferramenta Mirador II.

\section{Monitorar Hardware}

De acordo com o DFD da figura 4.5 essa função é composta de várias funções internas. Nesta seção as funções são analisadas como um todo, fornecendo uma visão geral de sua implementação.

Como visto nas especificações (seção 4.6.3), a atividade da função é monitorar os dispositivos de hardware dos nós. As informações monitoradas são listadas a seguir.

\footnotetext{
${ }^{\text {I }}$ consideram-se válidos os mesmos argumentos usados pelos comandos 'ls' e 'find' do sistema operacional.

${ }^{2}$ Os mesmos argumentos utilizados pelo comando remote copy ('rcp')
} 


$\begin{array}{llll}\text { dispositivo/tensão } & \text { Descrição } & \text { Mínimo } & \text { Máximo } \\ \text { Vcore } & \text { tensão interna da CPU 1 } & +1.85 \mathrm{~V} & +2.25 \mathrm{~V} \\ \text { Vcore2 } & \text { tensão interna da CPU 2 } & +1.85 \mathrm{~V} & +2.25 \mathrm{~V} \\ +3.3 \mathrm{~V} & \text { tensão } & +2.97 \mathrm{~V} & +3.63 \mathrm{~V} \\ +5 \mathrm{~V} & \text { tensão } & +4.48 \mathrm{~V} & +5.48 \mathrm{~V} \\ -5 \mathrm{~V} & \text { tensão } & -4.50 \mathrm{~V} & -5.49 \mathrm{~V} \\ +12 \mathrm{~V} & \text { tensão } & +10 ́ .82 \mathrm{~V} & +13.19 \mathrm{~V} \\ -12 \mathrm{~V} & \text { tensão } & -10.79 \mathrm{~V} & -13.18 \mathrm{~V} \\ \text { Fan1 } & \text { ventilador da CPU 1 } & 3000 \mathrm{rpm} & - \\ \text { Fan2 } & \text { ventilador da CPU 2 } & 3000 \mathrm{rpm} & - \\ \text { Fan3 } & \text { ventilador P.S (fonte de alim.) } & 3000 \mathrm{rpm} & - \\ \text { MainBoard } & \text { temperatura da placa mãe } & 0^{\circ} \mathrm{C} & 50^{\circ} \mathrm{C}\end{array}$

O mínimo e máximo delimitam os valores que são considerados normais para o dispositivo/tensãa. Esses limites podem ser reconfigurados pelo usuário.

As informações de hardware sāo coletadas pelo aplicativo LMSensor e armazenadas no pseudo filesystem proc. Em seguida, o módulo MINPi se encarrega de obter tais informações e reportá-las ao usuário juntamente com as demais informações de monitoramento (CPU, memória, tarefas, etc.).

O módulo MINPi também implementa funções para verificar a normalidade desses dispositivos/tensões, chegando a interferir no sistema (desligamento de nós) se necessário, como visto na seção 4.6.3.

\section{Controlar Painel}

Como dito anteriormente, os componentes PMG são controlados pelo módulo CP, que implementa a função Controlar Painel.

$\mathrm{Na}$ atividade de monitoramento, essa função recebe pela interface RS232 as informações referentes à carga de CPU e memória do nó. As informações são quaisquer valores inteiros que estão no intervalo de zero a dez.

Enquanto o monitoramento via hardware é uma atividade isolada, ocorrendo individualmente em cada componente, as tarefas de gerenciamento exigem, na maioria das vezes, um certo grau de interaçāo entre os componentes PMG. Para permitir essa interação, a rede 
I2C provê um protocolo de comunicação a baixo nível, por meio do qual os componentes se comunicam. Os detalhes do protocolo são discutidos no apêndice B.

Para que seja possível gerenciar a máquina paralela via hardware, é necessário que ao menos um nó esteja em p’eno funcionamento. A atividade de gerenciamento pode ser resumida nos seguintes parâmetros: 'comando' Lista_de_Nós Nó. Os comandos ${ }^{3}$ disponíveis são: reiniciar, ligar ou desligar. A Lista_de_Nós informa o domínio dos nós que serão afetados pela execução do comando. No início de uma atividade dé gerenciamento, um nó (o parâmetro Nó) é escolhido para ser a plataforma de execução do comando. Essa escolha leva em consideração os nós que estão ativos. Assim, o primeiro nó dentre aqueles que se encontram ativos é selecionado. Para exemplificar a execução de uma tarefa de gerenciamento via hardware, considere uma situação onde os nós 0,1 e 2 estejam sendo monitorados e que somente o nó 1 esteja ativo. Em uma operaçāo para o desligamento dos nós não ativos, o nó 1 seria escolhido para executar o comando. A execução da operação consiste em enviar uma requisição para os componentes PMG acoplados aos nós 0 e 2. Ao receber a requisição, os componentes examinam o comando e o executam enviando um sinal à placa mãe através das vias de controle (vide figura 5.4).

Em ambas as atividades (monitoramento e gerenciamento via hardware) a interface RS232 é o canal de comunicação entre a ferramenta Mirador Il e o componente PMG. A diferença básica de funcionamento das atividades é que as tarefas de monitoramento estão periodicamente sendo executadas, enquanto as tarefas de gerenciamento são executadas apenas a mando do usuário (ou do sistema no caso de gerenciamento autônomo).

\subsection{Instalação da Ferramenta Mirador II e Resultados Obtidos}

A ferramenta Mirador II foi instalada e testada na máquina paralela SPP3. Os procedimentos de instalação e testes realizados são descritos a seguir.

\footnotetext{
${ }^{3}$ Existem comandos específicos para configurar os micro-controladores PIC na rede I2C. Esses são discutidos no apêndice $B$.
} 


\section{Instalação}

A instalação da ferramenta Mirador II é feita via utilitário make (as opçōes de instalação são mostradas no apêndice C). A ferramenta foi instalada no diretório /opt, sendo esse um diretório exportado para todos os nós do SPP3. Os arquivos e diretórios que compõem a ferramenta se encontram sob o diretório /opt/mirador. São eles:

- cmd: diretório contendo os arquivos executáveis (via comandos de linha) que controlam os Painéis de Monitoramento e Gerenciamento;

- minpi: diretório contendo o arquivo executável minpi;

- gnpi: diretório contendo o arquivo executável gnpi;

- singog: diretório contendo o arquivo executável singog. Durante o processo de compilação, o código objeto myri.o (responsável pelo monitoramento e gerenciamento da rede Myrinet) é agregado ao executável singog. O diretório contém ainda os arquivos de configuração mirador.conf (configuração geral da ferramenta Mirador II) e myri.conf (configuração das switches Myrinet). O sub-diretório users_conf armazena as configurações individuais dos usuários. Para cada usuário é gerado um arquivo nome_usuário.conf contendo suas opções de uso da ferramenta;

- miu: diretório contendo o código desenvolvido em Java. O arquivo mirador.hosts armazena o endereço do host (servidor que executa o módulo SINGOG) a ser contatado. O sub-diretório images contém todas as imagens utilizadas na interface. No subdiretório JRPC estão os objetos ${ }^{4}$ que implementam as rotinas RPC para a linguagem Java;

- lm_sensor: diretório contendo os programas responsáveis pela coleta das informações de monitoramento dos dispositivos/tensões de hardware dos nós.

A figura 5.8 apresenta uma visão geral da ferramenta Mirador II em funcionamento.

\footnotetext{
${ }^{4}$ Objetos desenvolvidos pela Distinct ${ }^{\top \mathrm{M}}$ [Dis99].
} 


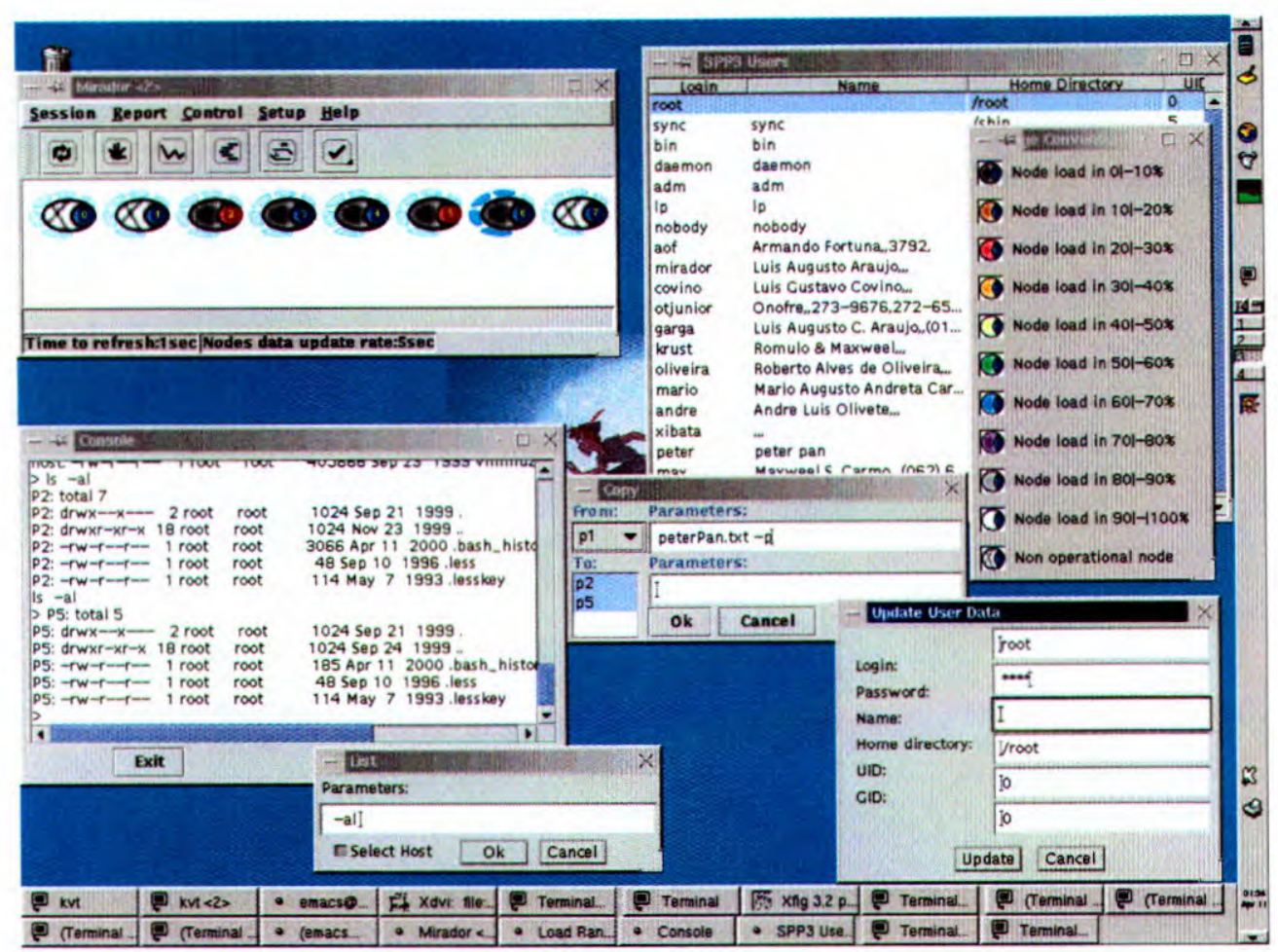

Figura 5.8: Visão geral da ferramenta Mirador II

\section{Resultados}

A ferramenta Mirador II foi submetida aos testes descritos na seção 3.3 e a testes adicionais para verificação das extensões. Em relação aos testes adicionais e seus resultados podem ser citados:

- Testes realizados com os comandos paralelos revelaram que em determinadas circunstâncias é necessário um timeout prolongado (entre o usuário e o servidor, e entre o servidor e os nós) para que haja sucesso na execução dos comandos. Como exemplo pode ser citado o comando 'find $/{ }^{*}$-name arq.txt p0, p1, p2, p3, p4'. De acordo com os parâmetros, o arquivo arq.txt será procurado nos 5 primeiros nós. Essa procura pode exigir um tempo considerável, caso o arquivo não se encontre nas proximidades do diretório raiz;

- O monitoramento de hardware foi testado alterando os valores limites para permitir a interferência da ferramenta no sistema;

- Os comandos de gerenciamento por hardware (ligar, desligar e reiniciar nós) foram 
testados sob diferentes estados em que se encontravam os nós (um nó ativo e os demais inoperantes, todos os nós ativos, alguns nós ativos e outros inoperantes);

- O monitoramento da rede Myrinet foi simulado em função da falta de uma switch com suporte ao protocolo SNMP. Parte das informações de rede que são comuns, como versão de protocolo e endereço IP do dispositivo, foi coletada contactando interfaces de rede Ethernet da rede local e remota (via internet). As demais informaçōes, presentes apenas nas switches Myrinet, foram coletadas de um arquivo local. Esse foi gerado de forma a refletir o tráfego numa switch, com 8 nós a ela conectados.

\subsection{Considerações Finais}

Este capítulo discorreu sobre o projeto e a implementação das extensões para a ferramenta Mirador. Foi descrito o ambiente de desenvolvimento das extensões, citando as ferramentas e bibliotecas utilizadas. A arquitetura da ferramenta, após a implementação das extensões, foi apresentada, ilustrando o que efetivamente foi alterado na organização dos módulos. $O$ projeto de interface foi discutido e os novos layouts apresentados. Um tópico foi destinado ao projeto do componente PMG, onde foram descritas suas características e funções. Em seguida foi feita uma breve descrição das principais funções implementadas. Encerrando o capítulo, a seção 5.7 discorreu sobre os procedimentos de instalação e testes da ferramenta Mirador II no SPP3.

O capítulo 6 apresenta uma visão panorâmica do que foi realizado, fazendo uma avaliação geral da ferramenta e das contribuições deste trabalho. Também são apresentadas sugestões de trabalhos em continuidade ao até aqui desenvolvido. 


\section{Capítulo 6}

\section{Conclusões}

\subsection{Considerações Iniciais}

Com a crescente utilização de arquiteturas paralelas MIMD na resolução de problemas que exigem alto poder computacional, surge a necessidade de ferramentas que auxiliem no processo de monitoramento e gerenciamento dessas arquiteturas e das aplicações executadas. A concepção dessas ferramentas exige uma concentração de esforços, devido, principalmente, à própria natureza das arquiteturas. Fatores como a existência de vários fluxos de execução e a multiplicidade de recursos dificultam o seu desenvolvimento. Em particular, o processo de monitoramento se torna um tanto complexo. A coleta e a centralização das informações monitoradas exigem certos cuidados para evitar a sobrecarga do sistema monitorado e, principalmente, evitar tráfego excessivo na rede, proveniente das informações de monitoramento que são transportadas da máquina paralela ao usuário.

A ferramenta Mirador II, como uma extensão à ferramenta Mirador, procura suprimir as principais deficiências existentes na mesma (revisão de software descrita no capítulo 3). A ferramenta Mirador II também implementa novas funcionalidades que visam facilitar a interação entre o usuário e a máquina paralela SPP3. Essas extensões são especificadas, projetadas e implementadas neste trabalho e descritas nos nos capítulos 4 e 5 . Dentre as principais extensões pode-se citar: monitoramento das redes de alta velocidade Myrinet, monitoramento dos dispositivos de hardware dos nós e gerenciamento dos nós via hardware.

Neste capítulo, na seção 6.2 é feita uma avaliação da ferramenta Mirador II. A seção 6.3 discorre sobre as contribuições do trabalho. Na seção 6.4 são apresentadas sugestões para o desenvolvimento de trabalhos futuros. 


\subsection{Avaliação Final da Ferramenta Mirador II}

Da avaliação de funcionamento da ferramenta Mirador II, os seguintes pontos devem ser destacados:

- A ferramenta Mirador, por permitir o monitoramento e gerenciamento da máquina paralela via Internet, impõe sérias restrições quanto ao volume de tráfego proveniente da comunicação entre o usuário e o servidor de nós. As extensões foram desenvolvidas respeitando tais restrições;

- A otimização do módulo SINGOG, através da utilização de threads, aumentou consideravelmente a eficiência, permitindo que múltiplos usuários utilizem a ferramenta Mirador II sem problemas de desempenho;

- A autenticação de todas as requisições do usuário que chegam ao servidor aumenta a margem de segurança, restringindo o acesso aos usuários cadastrados no sistema operacional do servidor de nós;

- O monitoramento dos dispositivos de hardware (tensão, temperatura, etc.), auxilia na preservação e manutenção dos nós do SPP3;

- A implementação dos comandos paralelos facilita a interação entre o usuário e os nós da máquina paralela;

- As alterações no layout da interface com o usuário possibilitam uma melhor disposição das informações monitoradas e tornam essa interação mais intuitiva.

\subsection{Contribuições do Trabalho}

Dentre as principais contribuições do trabalho pode-se citar:

- A ferramenta Mirador II, através do uso dos Painéis de Monitoramento e Gerenciamento, oferece maior controle sobre a máquina paralela, se comparada com demais ferramentas do gênero;

- A abrangência da ferramenta Mirador II, permitindo a realização de diversas atividades (gerenciamento de contas de usuários, execução de comandos paralelos, monitoramento 
de tarefas específicas, etc.), a torna uma excelente alternativa para o gerenciamento e monitoramento de máquinas paralelas, reunindo características geralmente encontradas em aplicativos distintos;

- O monitoramento e gerenciamento remoto (via WWW) e a execução de forma independente de plataforma são características da ferramenta Mirador ausente nas demais ferramentas;

- A extensibilidade da ferramenta Mirador possibilita ao usuário desenvolver novas funcionalidades que se adequem às suas necessidades específicas de monitoramento e/ou gerenciamento;

- O monitoramento das redes de conexão de alta velocidade é uma característica desejável, principalmente em se tratando de aplicações paralelas que realizam consideráveis trocas de mensagens entre os nós. Essa característica não é encontrada em nenhuma outra ferramenta de monitoramento e gerenciamento analisada neste trabalho.

\subsection{Propostas para Trabalhos Futuros}

A ferramenta Mirador II pode ser estendida de modo a incorporar uma série de novis funcionalidades. Como sugestôes para trabalhos futuros podem ser citadas:

- A criação de módulos especializados na visualizaçāo das informações de monitoramento. Esses módulos receberiam os dados pertinentes ao monitoramento e ficariam responsáveis pela renderização e apresentação gráfica das informações;

- Implantação de mecanismos de pré-alocação de clusters de processadores, permitindo ao usuário reservar um conjunto exclusivo de nós para a execução de suas tarefas;

- Criação de mecanismos de balanceamento dinâmico de carga, possibilitando que as tarefas em execução (ou na fila de execução) sejam migradas de um nó para outro de acordo com a carga dos nós;

- Estudos para a transformação da ferramenta Mirador II em um framework que ofereça suporte ao desenvolvimento de aplicaçōes de gerenciamento e monitoramento de máquinas 
paralelas. A interface de comunicação, que fornece as informações de monitoramento, pode ser usada como interface base no desenvolvimento de outras aplicações;

- Criação de agentes que executem nas interfaces de rede Myrinet, permitindo o monitoramento em cada nó, e não somente da switch, como é feito atualmente. 


\section{Referências Bibliográficas}

[ALL84] Allen, J.R. e KenNedy, K. PFC: a program to convert Fortran to parallel form In Proceedings of SUPERCOMPUTERS: DESIGN AND APPLICATIONS, IEEE, p.186-205. Computer Society Prëss, 1984.

[All87] Allen, J.R., Callahan, D., e Kennedy, K. PFC: a program to convert Fortran to parallel form In Proceedings of ACM SYMP. ON THE PRINCIPLES OF PROGRAMMING LANGUAGES, 14, p.63-76, 1987.

[ALM94] Almasi, G.S. e GotTlieB, A. Highly parallel computing 2.ed., The Benjamin Cummings Publishing Company, 1994.

[ARA98] ARAÚJO, L.A.C. MIRADOR - Uma ferramenta para monitoramento e gerenciamento do SPP2 São Carlos: Universidade de São Paulo, 1998 (Dissertação de Mestrado).

[BA90] Ben-Ari, M. Principles of Concurrent and Distributed Programming PrenticeHall, 1990.

[BAR90] BARRETT, G. The development of occam: typec, classes and sharing In OCCAM USERS GROUP: REAL-TIME SYSTEMS WITH TRANSPUTERS, 13, p.119147. IOS Press, 1990.

[Beg91] Beguelin, A., Dongara, J.J., Geist, A., Mancheck, R., e Sunderam, V. A User's Guide the Parallel Virtual Machine Oak Ridge National Lab., Junho 1991 (Relatório Técnico).

[BRI72] BRINChII, HANSEN P. Structured multiprogramming Communications ACM, v.15, n.7, p.574-578, Julho 1972. 
[CAL88] Callahan, D., Cooper, K., e Torezon, L. ParaScope, a parallel programming environment J. Supercomput. Appl., v.5, n.4, 1988.

[CAL89] Callahan, D., Kennedy, K., e Kremer, U. A Dynamic Study of Vectorization in PFC Rice University - Center for Research on Parallel Computation, Setembro 1989 (Relatório Técnico).

[Cal92] California : Applied Parallel Research FORGE 90 Version 8.0 - Baseline System - User's Guide, 1992.

[Cal95a] California : Applied Parallel Research The FORGE Explorer TOOLBOX - The Distributed Memory Fortran Parallelizer FORGEX/DMP - User's Guide. Release 2.0, Fevereiro 1995.

[Cal95b] California: Applied Parallel Research FORGE Technical Note - On Parallel Program Execution - Running Programs Parallelized By FORGEX/DMP, and XHPF For Distributed Memory Systems. Release 2.0, Março 1995.

[CAR99] Carvalho, Mario Augusto Andreta Um Ambiente de Desenvolvimento para Aplicações ParalelasAnálise de requisitos e Definição Universidade de São Paulo, Novembro 1999 (Dissertação de Mestrado).

[CAS90] Case, J., Fedor, M., Schoffstall, M., e Davin, J. A Simple Network Management Protocol (SNMP) RFC 1157, http://rfc.fh-koeln.de/rfc/html/ rfc1157.html, Maio 1990.

[Cha99] Chatterton, David, Goodwin, Mark, McDonell, Ken, e Milewska, ANIA Performance Co-Pilot (TM) Programmer's Guide Bill Tuthill, 1999.

[COM95] COMER, D.E Internetworking with TCP/IP, v.I 3.ed., Prentice Hall, 1995.

[Cra95] Cray Research Inc, http://www.cray.com Cray T3D system architecture overview, 1995.

[DDR99] DDRI, Diversified Data Resources, Inc., http://www.ddri.com An Introductory Overview of SNMP, 1999.

[DIJ68] Dijkstra, F.W. Co-operating sequential processes 43-112, 1968. 
[Dis98] Distinct Corporation, http://www.distinct.com/javarpc/docs/java.rpc.doc0000.htm ONC RPC/XDR for Java, Dezembro 1998.

[Dis99] Distinct Corporation, http://www.distinct.com Distinct, Outubro 1999.

[DUN90] Duncan, R. A survey of parallel computer architectures IEEE Comput. Mag., v.23, n.2, p.5-16, Fevereiro 1990.

[EPC95] EPCC Training and Education Center, http://www.epcc.ed.ac.uk/epcotec/package.html EPCC MPI course, 1995.

[FEL94] Felderman, R. ATOMIC: A. High-Speed Local Communication Architecture Journal of High Speed Networks,, n.1, p.1-28, 1994.

[FOS95] FOSTER, Y. Designing and building parallel programs: concepts and tools for parallel software engineering Addison-Wesley Publishing Company, 1995.

[GEI92] Geist, G.A. e Sunderam, V.S. Network Based Computing on the PVM System J. Concurrency: Practice and Experience, v.4, n.4, p.293-311, Junho 1992.

[GeI94] Geist, G.A., Beguelin, A., Dongarra, J., Jiang, W., Mancheck, R., e Sunderam, V.S. PVM : Parallel Virtual Machine - A Users' Guide and Tutorial for Networked Parallel Computing The MIT Press, 1994.

[GEO93] Georges, Thomas L. Using the Carnegie Mellon University (CMU) SNMP Library To Build an SNMP Manager Harris Corporation, http://netman.cit.buffalo.edu/Doc/HowTo-CMU-SNMP.html, Março 1993 (Relatório Técnico).

[GNU99] GNU, http://www.gnu.org/software/libc/libc.html GNU C Library, Dezembro 1999.

[GNU00] GNU, http://www.gnu.org/software/gcc/onlinedocs GCC online documentation, Março 2000.

[GUE97] GUERRERO, DAVID Network Management And Monitoring with Linux http://www.develnet.es/david/papers/snmp, Junho 1997.

[HAL98] HALL, BRADLEY asMon http://rio.dhs.org/asmon, 1998. 
[HAM98] HAMILTON, M. Linux/SGI Gr_Monitor http://home.clear.net.nz/pages/michael.hamilton/gifts.html, 1998.

[HEN90] Hennessy, J. e PatTerson, D. Computer Architecture a Quantitative Approach morgan Kaufmann Publishers, 1990.

[HEY90] HEY, A.J.G. Scientific applications on transputer arrays : Some experiments in MIMD parallelism In TRANSPUTER/OCCAM INTERNATIONAL CONFERENCE, 3, p.150-157, Maio 1990.

[HOA74] HOARE, C.A.R. Monitors : an operating system structuring concept Communications $A C M$, v.17, n.10, p.549-557, Outubro 1974.

[HOA85] HOARE, C.A.R. Communicating Sequential Processes Prentice-Hall, 1985.

[IBM93] IBM Corporation, http://www.rs6000.ibm.com IBM solutions: Scalable Power Parallel System 1, 1993.

[IET99] IETF, http://www.ietf.org The Internet Engineering Task Force, 1999.

[Int99] The Internet Society, ftp://ftp.isi.edu/in-notes/rfc2570.txt Introduction to SNMPv3, Abril 1999.

[ISO87] ISO, Information processing systems - Open Systems Interconnection - Specification of Basic Encoding Rules for Abstract Syntax Notation One (ASN.1) International Organization for Standardization, 1987 (Relatório Técnico ISO 8825:1987(E)).

[JOH97] JohnsonM, M.K. Linux Kernel Hackers' Guide http://khg.redhat.com/HyperNews/get/khg.html, 1997.

[KDE00] KDE, www.kde.org The K Desktop Environment, Fevereiro 2000.

[KEN92] KENNEDY, K. Software for supercomputers of the future Journal of Supercomputing, v.5, p.251-262, Setembro 1992.

[KOH97] KOHL, J. XPVM: A graphical console and monitor for PVM http://www.netlib.org, 1997. 
[LAM00] LAM Team, http://www.mpi.nd.edu/lam/software/xmpi LAM / MPI Parallel Computing, Março 2000.

[LAU96] LAURIA, M. High Performance MPI Implementation on a Network of Workstations Universidade de Illions, 1996 (Dissertação de Mestrado).

[LER97] LEROY, XAVIER The LinuxThreads library http://pauillac.inria.fr/xleroy/linuxthreads, 1997.

[LmS98] LmSensors Group, http://www.netroedge.com/ lm78/index.html Linux System Hardware Monitoring, Julho 1998.

[MCC91] MCCloghrie, K. e Rose, M. Management Information Base for Network Management of TCP/IP-based internets: MIB-II RFC 1213, $\mathrm{ftp}: / /$ goodall.com/pub/rfc/rfc1213.txt, Março 1991.

[MCD89] MCDowell, C.E. e HeLmbold, D.P. Debbuging concurrent programs ACM Computing Mag., v.21, n.4, p.593-622, Dezembro 1989.

[MER94] MERLIN, J. IDA - User's Guide Southampton : University of Southampton, 1994.

[MER98a] MERKEY, P. Beowulf Project at CESDIS www.beowulf.org, 1998.

[MER98b] MERKEY, P. Beowulf Software http://www.beowulf.org/software/software.html, 1998.

[MET90] Metcalf, M. e Reid, J. FORTRAN 90 Explained Oxford Science Publications, 1990.

[Mic95] Microchip Technology Microchip PIC16C7X data sheet, 1995.

[Mob99] Mobile Lifestreams, http://www.mobileipworld.com/wp/wp2.htm An Introduction to $S M S, 1999$.

[Nat00] National Semiconductor Corporation, http://www.national.com/pf/LM/LM78.html LM78 Microprocessor System Hardware Monitor, Fevereiro 2000. 
[NAV89] NAVAux, P.O.A Introdução ao processamento paralelo RBC-Revista Brasileira de Computação, v.5, n.2, p.31-43, Outubro 1989.

[NEW96] NewnhaM, MARK Getting started with Tkined http://wwwhome.cs.utwente.nl/ schoenw/scotty/docs/getstart.html, Julho 1996.

[NJB95] N. J. Boden, Robert E. Felderman Myrinet - A Gigabit-per-Second LocalArea Network IEEE MICRO, Fevereiro 1995.

[OTT93] OTTEN, H.A.H The Beholder Cookbook IETF, http://dnpap.et.tudelft.nl/ DNPAP/Software/btng.html, Dezembro 1993.

[PER96] Perez, P.A.S. P2D - Um Ambiente de Auxílio à Paralelização de Aplicações Fortran São Carlos: Universidade de São Paulo, Setembro 1996 (Dissertação de Mestrado).

[PET81] Peterson, G.L. Myths about the mutual exclusion problem Information Processing Letters, v.12, p.115-116, 1981.

[Phi95] Philips Semiconductors, http://www.mcc-us.com/i2chowto.htm The I2C-bus and how to use it(including specifications), Abril 1995.

[POl89] Polychronopoulos, C.D., Girkar, M., Haghighat, M.R., Lee, C.L., LeUng, B., e Schouten, D. Parafrase 2: An Environment for Parallelizing Partioning, Synchronizing Programs on Multiprocessors In Int. Conf. Parallel Processing, p.765-777, 1989.

[RAD98a] RADAJEWSKI, J. bWatch i.0.2 http://www.sci.usq.edu.au/staff/jacek/bWatch, 1998.

[RAD98b] RADAJEWSKI, J. e EADLINE, D. Beowulf Howto http://www.sci.usq.edu.au/ staff/jacek/beowulf/BDP/HOWTO/, 1998.

[SCH00] SCHÖNWÄLDER, J. Scotty - Tcl Extensions for Network Management Applications http://wwwhome.cs.utwente.nl/s̃choenw/scotty/, Fevereiro 2000.

[Scr99] Scriptics Corporation, http://www.scriptics.com Scriptics, 1999. 
[SUN90] Sunderam, V.S. PVM: A Framework for Parallel Distributed Computing Concurrency: Practice \& Experience, v.2, n.4, p.315-339, Dezembro 1990.

[Sun98] Sun MicroSystems, http://www.javasoft.com The Source of Java Technology, 1998.

[Sun99] Sun Microsystems, Inc. Java 2 Platform, Standard Edition, v1.2.2 API Specification, 1999.

[TAN92] Tanenbaum, A.S. Modern Operating Systems Prentice Hall International, 1992.

[TaN95] Tanenbaum, A.S. Distributed Operating Systems Prentice Hall, 1995.

[TAN98] Tanenbaum, A.S. Rede de Cömputadores Prentice Hall International, 1998.

[TRI95a] Trindade, O., Marques, E., e Jeukens, I. A parallel architecture based on personal computers - requirements and definitions Simpósio Nipo-Brasileiro de Ciência e Tecnologia, p.203-212, Agosto 1995.

[Tri95b] Trindade Jr, Onofre, Marques, Eduardo, e Jeukens, Ivan a Parallel Architecture Based on Personal Computers - An Overview XV Conferencia Internacional de La Sociedad Chilena de Ciencia de La Computación, Novembro 1995.

[Uni97] University of Tromsoe, Norway, http://geekcorp.com/snmpmonitor SNMP critical values monitoring, Agosto 1997.

[Uni00] University of California at Davis, http://ucd-snmp.ucdavis.edu The UCD-SNMP Home Page, Março 2000.

[WEL94] WELSH, M. Linux installation and getting started LDP - Linux Documentation Project, http://www.suncite.unc.edu, 1994.

[YES99] YeSHA, Y. CESDIS http://cesdis.gsfc.nasa.gov/, Abril 1999. 


\section{Apêndice A}

\section{Interface da Ferramenta Mirador}

Neste apêndice são mostradas todas as janelas de interação com o usuário.

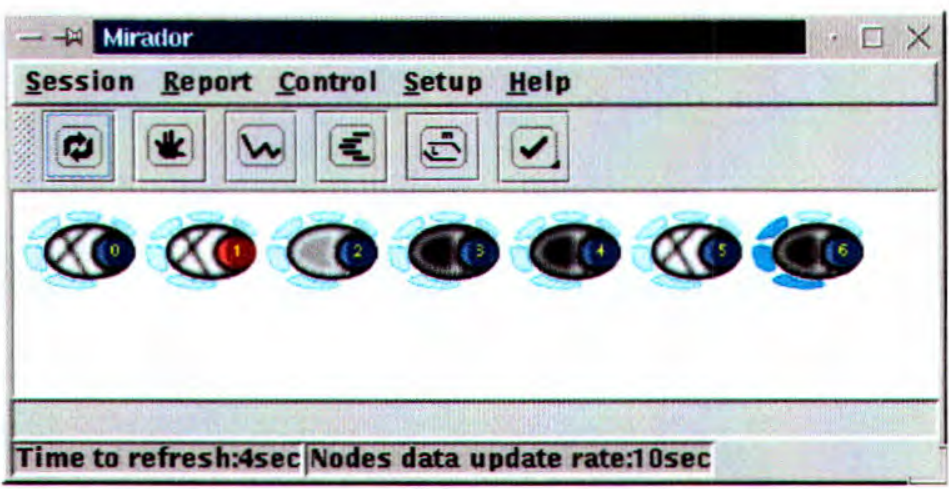

Figura A.1: Interface principal da ferramenta Mirador. 7 nós estão sendo monitorados, sendo que os nós 0,1 e 5 estão inoperantes

Open
Close Connection
Quit

Figura A.2: Menu Session 


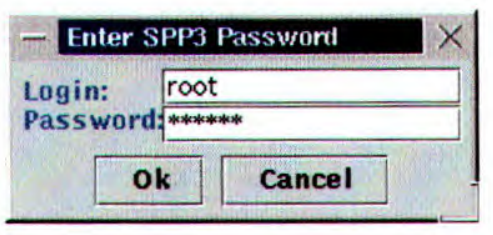

Figura A.3: Login e password requeridos para autenticação

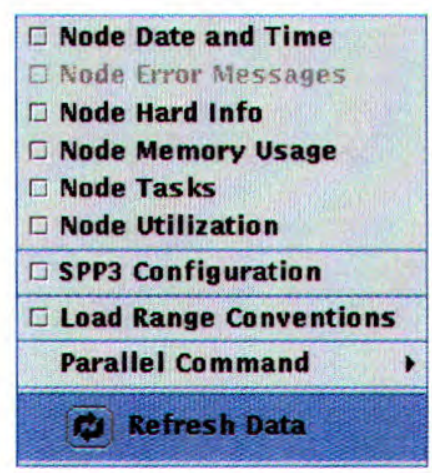

Figura A.4: Menu Report

Node Date and Time
\begin{tabular}{|l|l|l|}
\hline Node & Date and Time & Host Date and Time \\
\hline 2 & Sat May 22 12:04:00 1971 & Thu Mar 16 17:23:27 2000 \\
3 & Thu Mar 16 18:12:39 2000 & Thu Mar 16 17:23:28 2000 \\
4 & Thu Mar 16 17:43:00 2000 & Thu Mar 16 17:23:30 2000 \\
6 & Thu Mar 16 19:52:04 2000 & Thu Mar 16 17:23:39 2000 \\
\hline
\end{tabular}

Figura A.5: Data e hora dos nós monitorados

Node Sensor Info
\begin{tabular}{|llllllllllll|}
\hline Node & Vcore & Vcore & $+3.3 \mathrm{~V}$ & $+5 \mathrm{~V}$ & $-5 \mathrm{~V}$ & $12 \mathrm{~V}$ & $-12 \mathrm{~V}$ & Fan(rpm) & Fan PS(rpm) & Mb. $\left.{ }^{\circ} \mathrm{C}\right)$ \\
\hline 2 & 2.03 & 2.01 & 3.45 & 5.0 & -5.13 & 12.19 & -12.97 & 4010 & 0 & 37.0 \\
3 & 2.03 & 2.01 & 3.45 & 5.0 & -5.13 & 12.19 & -12.97 & 4010 & 0 & 37.0 \\
4 & 1.98 & 2.0 & 3.5 & 5.02 & -5.05 & 12.22 & -11.96 & 5444 & 0 & 30.0 \\
6 & 2.03 & 2.01 & 3.45 & 5.0 & -5.13 & 12.19 & -12.97 & 4010 & 0 & 37.0 \\
\hline
\end{tabular}

Figura A.6: Informações de hardware dos nós monitorados

\begin{tabular}{|c|c|c|c|c|}
\hline$-\infty$ & Tlode Mem & y Usage & & $\square$ \\
\hline Node & $\operatorname{Ram}(K)$ & Used (K) & $\operatorname{Swap}(K)$ & Used $(K)$ \\
\hline 2 & 63596 & 8248 & 0 & 0 \\
\hline 3 & 63596 & 8240 & 0 & 0 \\
\hline 4 & 63596 & 7716 & 0 & 0 \\
\hline
\end{tabular}

Figura A.7: Informações de memória dos nós monitorados 


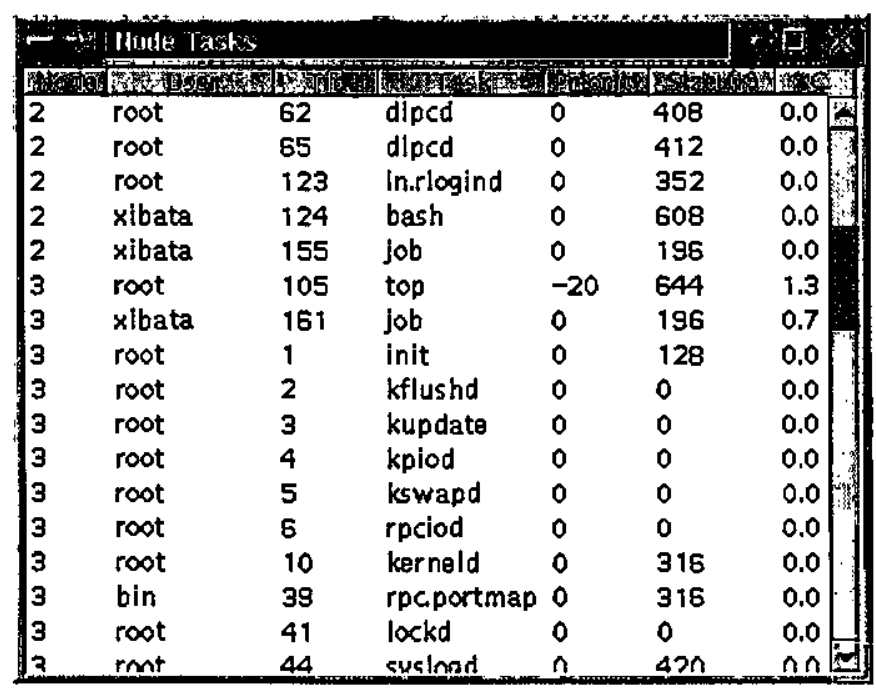

Figura A.8: Monitoramento das tarefas em execução nos nós

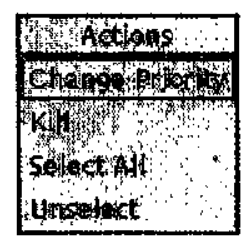

Figura A.9: Menu suspenso. Ativado ao se clicar em um campo do formulário de informação de tarefas, oferece opções de alterar prioridade e encerrar tarefas em execução

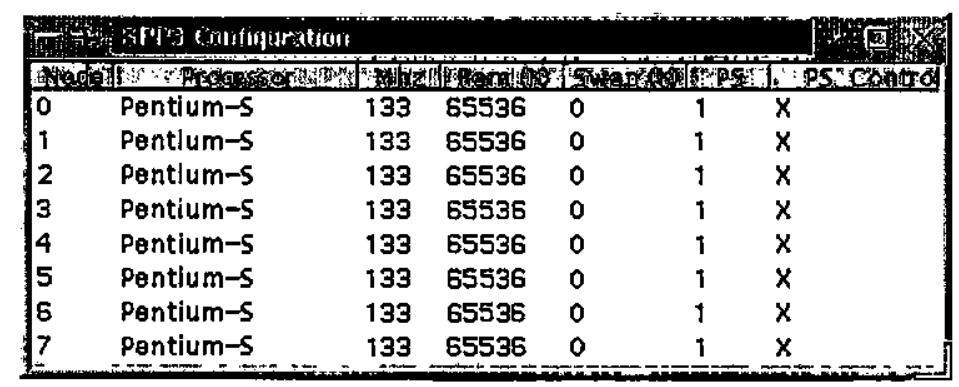

Figura A.10: Descrição dos nós da máquina paralela

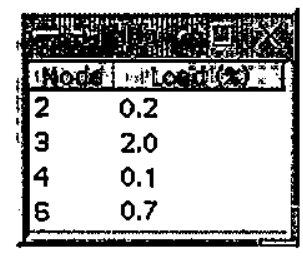

Figura A.11: Informações de utilização de CPU dos nós monitorados 


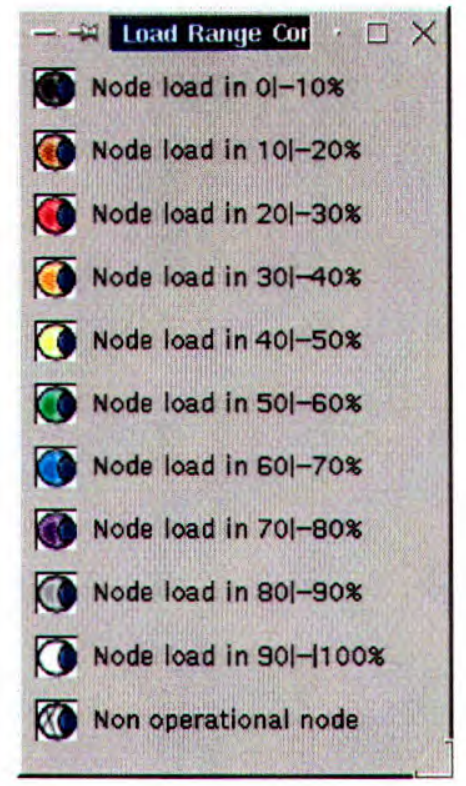

Figura A.12: Legenda das cores utilizadas na representação de carga de CPU

\begin{tabular}{|l|}
\hline List \\
\hline Find \\
\hline Move \\
Remove \\
Copy \\
\hline
\end{tabular}

Figura A.13: Menu dos comandos paralelos disponíveis 


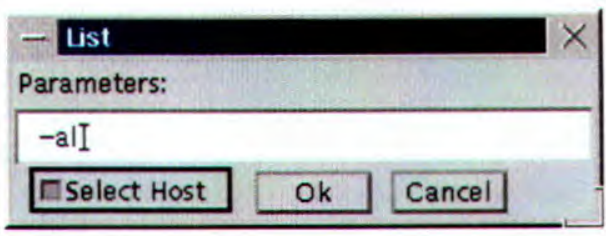

Figura A.14: Comando 'list'

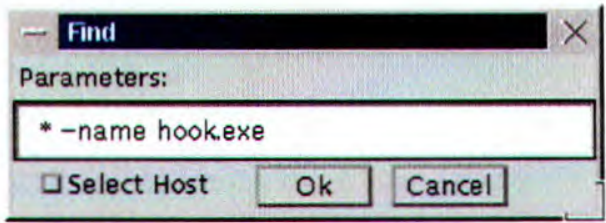

Figura A.15: Comando 'find'

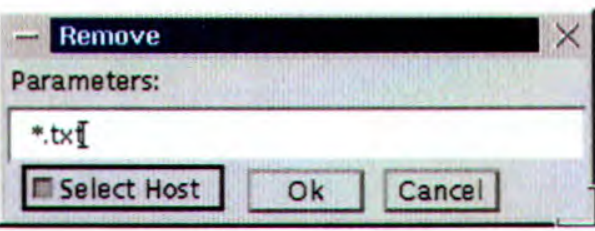

Figura A.16: Comando 'remove'

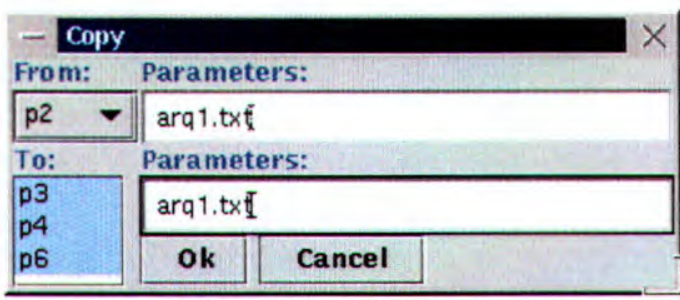

Figura A.17: Comando 'copy' 


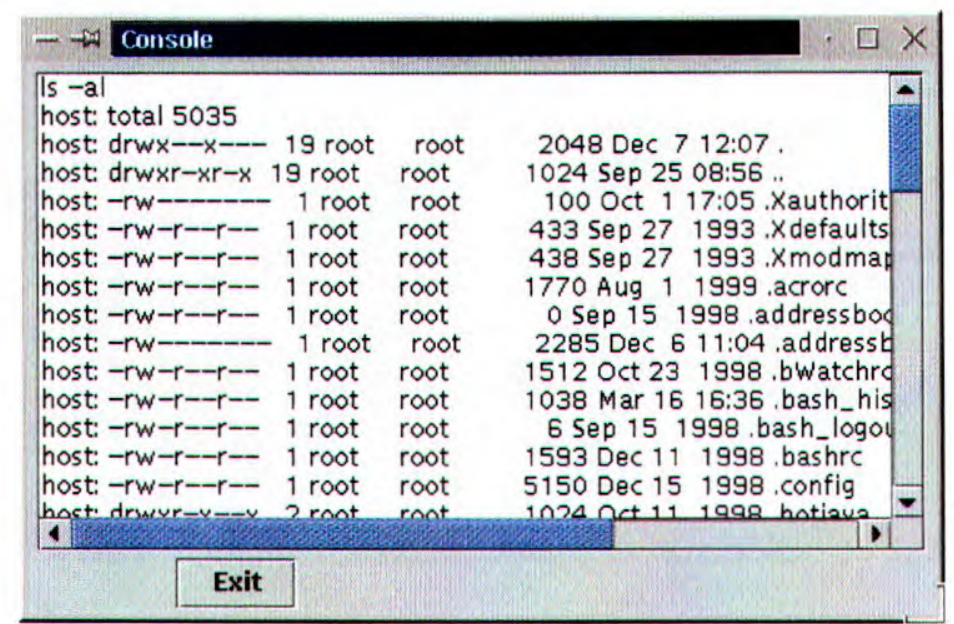

Figura A.18: Console para apresentação das saídas referentes às execuções dos comandos paralelos

\begin{tabular}{|l|}
\hline$\square$ Command Console \\
Manager Node \\
\hline Synchronize Node Date and Time \\
\hline User Management \\
\hline Myrinet \\
\hline
\end{tabular}

Figura A.19: Menu de controle

\begin{tabular}{|l|}
\hline Reset Node by Hardware \\
\hline Reset Node by Software \\
Turn Node On \\
Turn Node Off \\
\hline
\end{tabular}

Figura A.20: Menu de gerenciamento dos nós, oferecendo opções para reiniciar nós via software e via hardware, e ligar e desligar nós

\begin{tabular}{|l|}
\hline Add User \\
Remove User \\
Update User Data \\
\hline Show SPP3 Users \\
\hline
\end{tabular}

Figura A.21: Menu de gerenciamento de usuário 


\begin{tabular}{|c|c|c|c|}
\hline \multicolumn{3}{|c|}{ - - I SPP3 Users } & \multirow{2}{*}{$\frac{D \times}{U I D}$} \\
\hline Login & Name & Home Directory & \\
\hline root & & /root & \\
\hline sync & sync & /sbin & 5 \\
\hline bin & bin & /bin & 1 \\
\hline daemon & daemon & /sbin & 2 \\
\hline adm & adm & /var/adm & 3 \\
\hline Ip & ID & /var/spool/lpd & 4 \\
\hline nobody & nobody & /dev/null & 65534 \\
\hline aof & Armando fortuna.,3792. & /SPP2/home/aof & 1000 \\
\hline mirador & Luis Augusto Araujo... & $/ S P P 2 /$ home/mirador & 1001 \\
\hline lac & $\angle A C \ldots$ & /SPP2/home/lac & 1005 \\
\hline covino & Luis Gustavo Covinow, & /SPP2/home/covino & 1007 \\
\hline otjunior & Onofre..273-9676.272-65... & /SPP2/home/otjunior & 1008 \\
\hline grupo1 & Grupo $1-$ SCE-217,... & /SPP2/home/grupo1 & 1009 \\
\hline grupo2 & Grupo 2-SCE-217... & /SPP2/home/grupO2 & 1010 \\
\hline grupo3 & Grupo $3-$ SCE-217... & /SPP2/home/grupo3 & 1011 \\
\hline grupo4 & Grupo 4-SCE-217... & /SPP2/home/grupo4 & 1012 \\
\hline grupo5 & Grupo 5-5CE-217... & /SPP2/home/grupo5 & 1013 \\
\hline garga & Luis Augusto C. Araujo, $(01 \ldots$ & /SPP2/home/garga & 1014 \\
\hline krust & Romulo \& Maxwee $\mathrm{L}_{\ldots}$ & /SPP2/home/krust & 1016 \\
\hline oliveira & Roberto Alves de Oliveira... & /SPP2/home/oliveira & 1017 \\
\hline mario & Mario Augusto Andreta Car... & /SPP2/home/mario & 1018 \\
\hline andre & Andre Luis Olivete,... & /SPP2/home/andre & 1019 \\
\hline xibata & $m$ & /SPP2/home/xibata & 1022 \\
\hline peter & peter pan & /SPP2/home/peter & 1025 \\
\hline $\max$ & Maxweel S. Carmo, (062) 6... & /SPP2/home/max & 1026 \\
\hline grupo6 & SCE $-233_{\ldots}$ & /SPP2/home/grupo6 & 1027 \\
\hline romulo & Romulu's It.., & /SPP2/home/romulo & 1028 \\
\hline diped & $\ldots$ & /SPP2/home/diped & 1029 \\
\hline
\end{tabular}

Figura A.22: Lista de usuários cadastrados no sistema

Management Settings

Monitoring Settings

Services Timeout

Figura A.23: Menu de configuração do sistema

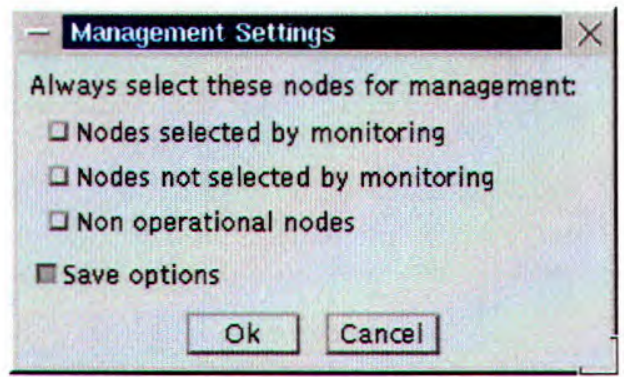

Figura A.24: Configurações de gerenciamento 


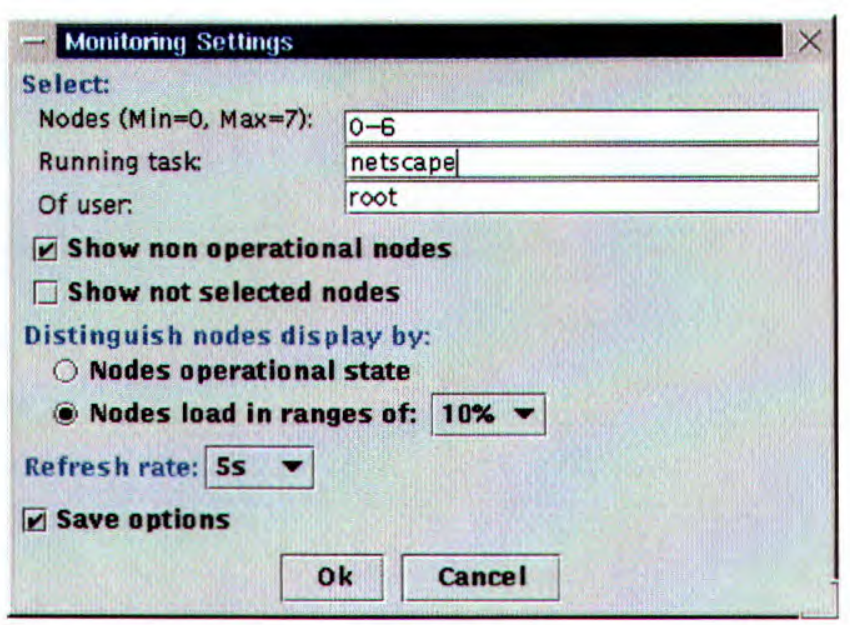

Figura A.25: Configurações de monitoramento

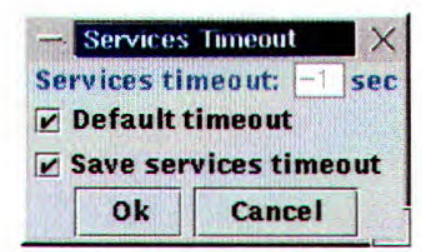

Figura A.26: Configurações de timeout de conexão

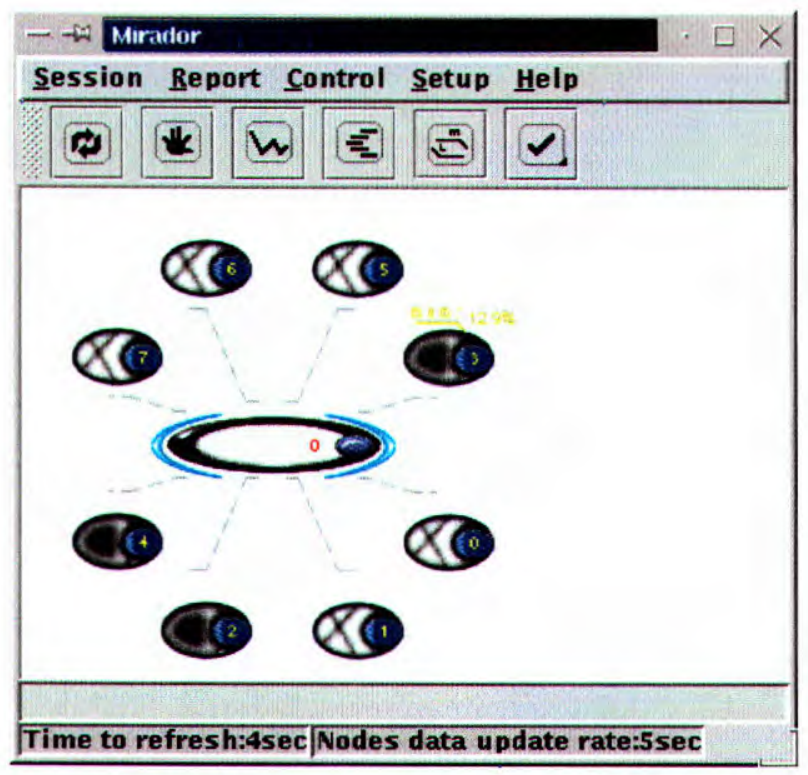

Figura A.27: Monitoramento da rede Myrinet (simulação) 


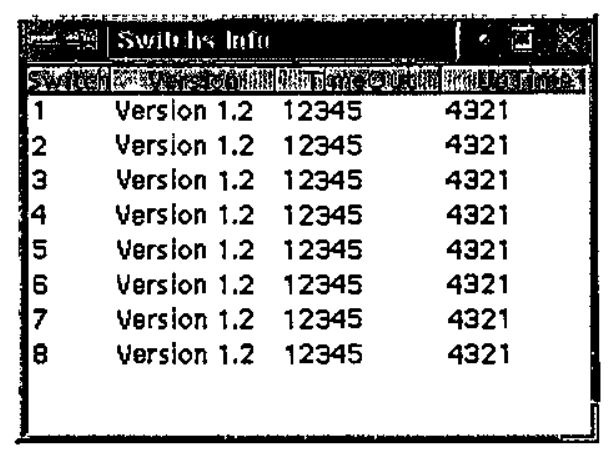

Figura A.28: Informações sobre a switch Myrinet (simulação)

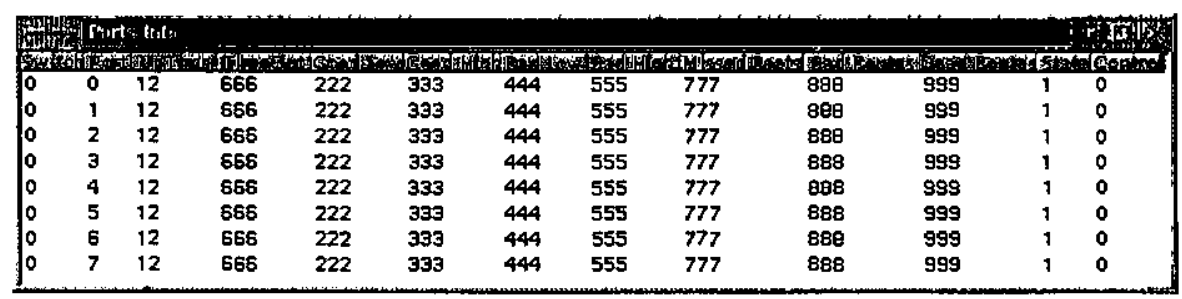

Figura A.29: Estatísticas sobre as portas da switch Myrinet (simulação)

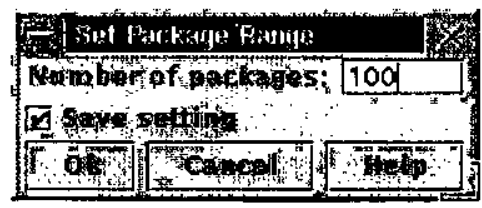

Figura A.30: Número de pacotes que trafegam pela rede Myrinet e que deve ser considerado como $100 \%$ de tráfego 


\section{Apêndice B}

\section{Painel de Monitoramento e}

\section{Gerenciamento}

O Painel de Monitoramento e Gerenciamento (PMG) foi concebido para a máquina paralela SPP3 com o objetivo de facilitar seu monitoramento e gerenciamento, oferecendo ao usuário um maior controle sobre a máquina. A figura B.1 apresenta seu esquemático.

\section{Especificação do Hardware}

O PMG é formado basicamente por um regulador de tensão que recebe como entrada $+12 \mathrm{~V}$ convertendo-a em $+5 \mathrm{~V}$ de saída. O componente MAX232 é utilizado para converter os sinais lógicos RS232 para os sinais lógicos TTL e vice-versa. O micro-controlador PIC16C74A é responsável pelo controle de todo o painel, estando a ele conectadas as duas barras de LEDs (representação da utilização de CPU e memória). A porta SDA representa a via utilizada para a comunicação entre os micro-controladores. A porta SCL representa o sinal de clock, necessário ao protocolo I2C. O pino 9 e 10 do micro-controlador estão ligados aos conectores RESET e ON/OFF da placa mãe do nó. Por meio do pino 9 é possível reiniciar o nó, enquanto que pelo pino 10 o nó é ligado ou desligado. O pino 8 tem seu nível lógico alterado todas as vezes que o nó é ligado, indicando ao micro-controlador que se auto reinicie. 


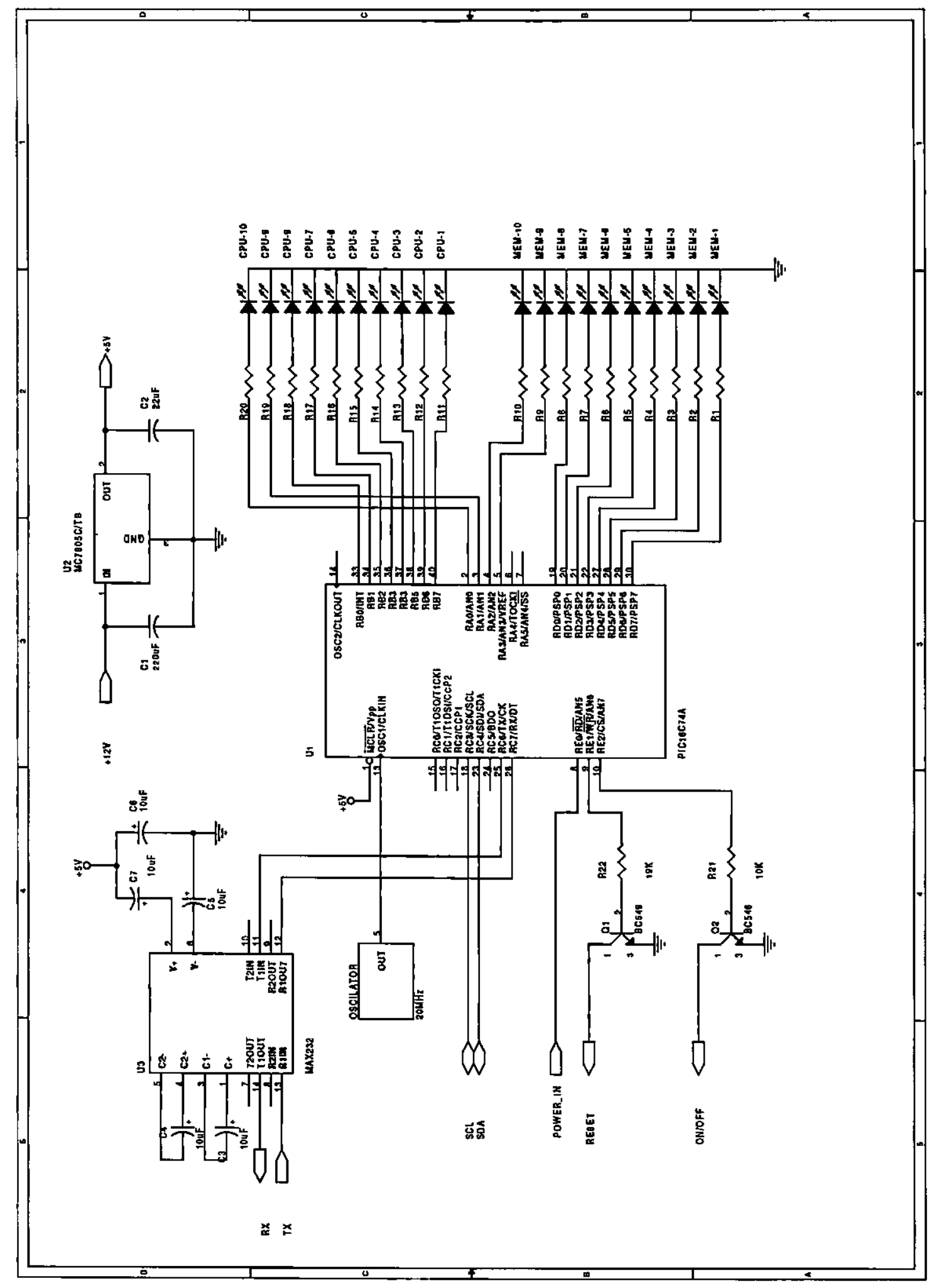

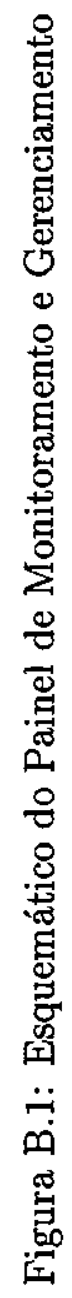




\section{Protocolo de Comunicação}

Seguem abaixo os comandos enviados ao PMG pela porta serial:

STX M n ETX: consumo de memória

Acende n LEDs na barra de consumo de memória.

STX P n ETX: carga de processador

Acende n LEDs na barra de carga de CPU.

STX C end ETX: configura nó local

Define end como o endereço do PIC local no barramento I2C. O endereço utilizado é dado pela expressão: end $=100+(2 *$ número do nó $)$.

STX U ETX: desconfigura nó local

Desconfigura o micro-controlador PIC do nó local.

STX R end ETX: reinicia nó

Caso o endereço especificado seja do nó local, o comando é executado localmente, caso contrário ele é enviado via I2C para o nó contendo o endereço end.

STX L end ETX: liga nó

Caso o endereço especificado seja do nó local, o comando é executado localmente, caso contrário ele é enviado via I2C para o nó contendo o endereço end.

STX D end ETX: desliga nó

Caso o endereço especificado seja do nó local, o comando é executado localmente, caso contrário ele é enviado via I2C para o nó contendo o endereço end.

Parâmetros utilizados:

STX = Caracter de controle indicando início de comando;

ETX = Caracter de controle indicando fim de comando;

$\mathrm{n}=$ número de LEDs a serem acesos (0 a 10);

end $=$ endereço no barramento $\mathrm{I} 2 \mathrm{C}(0,100$ a 130$)$. 
Algumas considerações sobre o protocolo:

- O micro-controlador PIC retorna ACK caso o comando seja executado corretamente e NAK caso contrário;

- Se após 30 segundos, um micro-controlador PIC que esteja configurado não receber comandos pela serial é apresentado um padrão indicativo nas barras de LEDs;

- Se dois micro-controladores PIC tentarem transmitir ao mesmo tempo, um deles retornará NAK e o comando deve ser reenviado.

\section{Padrões Visuais das Barras de LEDs}

As barras de LEDs do SPP3 são utilizadas para duas finalidades:

- Indicar o nível de utilização de CPU e memória do nó;

- Indicar estado operacional do nó.

\section{Nível de Utilização}

A indicação do nível de utilização tanto de memória como de CPU utiliza as seguintes convenções:

- Utilização menor que 5\% - os LEDs inferiores de cada coluna piscam;

- Utilização entre $5 \%$ e $10 \%$ - os LEDs inferiores de cada coluna permanecem acesos;

- A cada incremento de $10 \%$ no nível de utilização um novo LED é aceso na coluna correspondente à utilização de memória ou CPU.

Na figura B.2 são exemplificados níveis de utilização de memória entre $60 \%$ e $70 \%$ e níveis de utilização de CPU entre $20 \%$ e $30 \%$. 


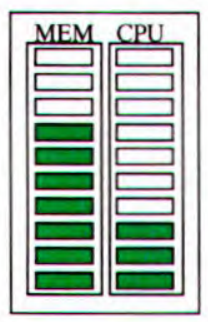

Figura B.2: Indicação de níveis de utilização do nó

\section{Estado Operacional do Nó}

As tentativas de ligação da fonte associada ao nó são indicadas por um padrão onde todos os LEDs piscam simultaneamente, como mostra a figura B.3.
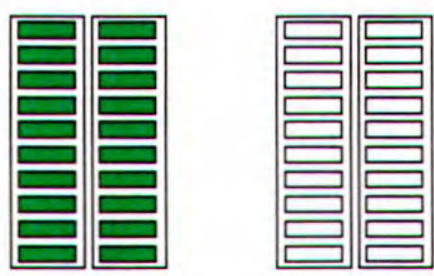

Figura B.3: Padrões mostrados alternadamente quando o painel está tentando ligar a fonte de alimentação associada ao nó

Quando o painel não se encontra configurado, todos os LEDs permanecem apagados. Durante a configuração, todos os LEDs acendem e em seguida vão apagando de cima para baixo, em sequência, conforme ilustra a figura B.4.
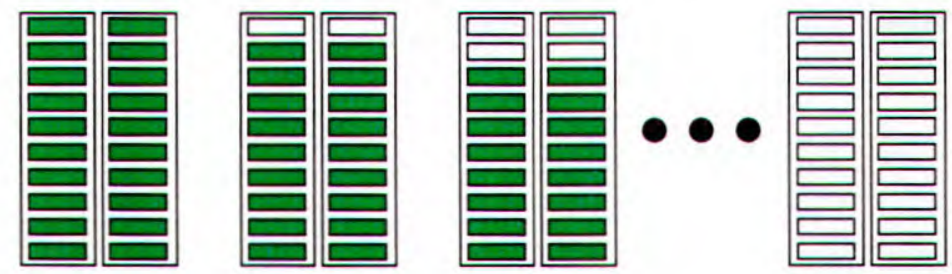

Figura B.4: Padrões mostrados sequencialmente quando o painel está sendo configurado

Após a configuração, se o painel perder a comunicação com o nó por mais de 30 segundos, os LEDs apresentarão o padrão ilustrado na figura B.5. 


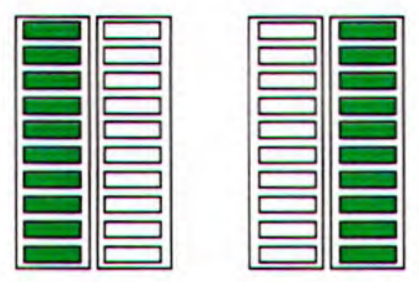

Figura B.5: Padrões mostrados alternadamente quando o painel perde a comunicação com o nó após ter sido configurado

\section{Comandos de Linha}

A ferramenta Mirador disponibiliza ao usuário um conjunto de utilitários que permitem a interação com o PMG via linha de comando. São eles:

- Resetpainel ["d" | nó];

- Resetno ["d" | nó];

- Configurapainel;

- Desconfigurapainel;

- Ligano ["d" | nó];

- Desligano ["d" | nó].

Os comandos sem argumento atuam no nó e painel locais. O parâmetro "d" (difusão) faz com que o comando atue em todos os painéis desconfigurados (endereço 0). A princípio essa opção deveria funcionar em todos os nós independentemente dos mesmos estarem configurados ou não. Contudo, a versão do $\mathrm{I} 2 \mathrm{C}$ utilizado pelo micro-controlador não implementa um endereço de difusão, causando essa limitação.

O parâmetro nó se refere ao número do nó SPP3 e não ao endereço do painel na rede $\mathrm{I} 2 \mathrm{C}$. 


\section{Mapa Simplificado de Estados}

A figura B.6 apresenta o mapa de estados do PMG. Após ser ligado, o painel tenta ligar a fonte associada a cada nó e começa atender os comandos. Os comandos podem ser via RS232 ou rede I2C. O ponto de atuação dos comandos depende do endereço do painel. Caso o endereço recebido no comando seja igual ao endereço local, o comando é executado localmente. Caso o comando seja recebido via RS232 e o endereço especificado não seja local, o comando é transmitido pela rede I2C.

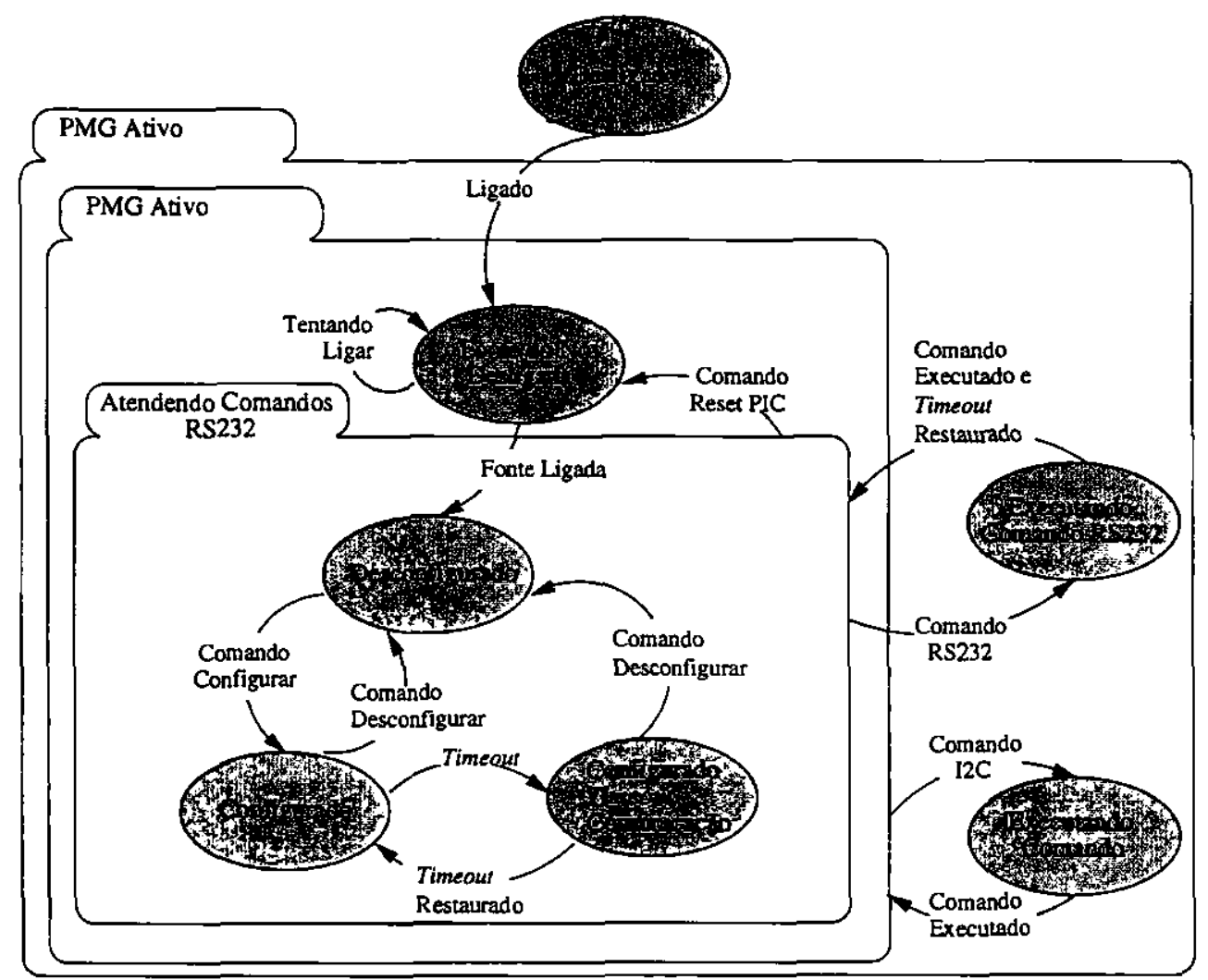

Figura B.6: Mapa de estados do painel 


\section{Apêndice $\mathrm{C}$}

\section{Instalação da Ferramenta Mirador II}

O utilitário make é usado no processo de compilação e instalação da ferramenta Mirador II.

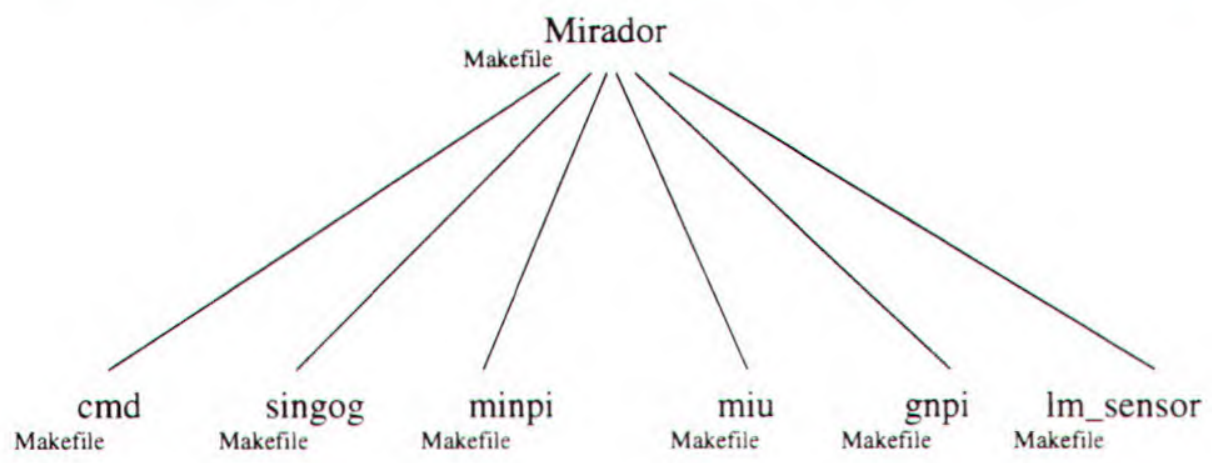

Figura C.1: árvore de diretórios da ferramenta Mirador II

A árvore de diretórios da ferramenta Mirador II é apresentada na figura C.1. Cada sub-diretório possui um arquivo Makefile contendo as regras de compilação para um módulo específico. A instalação da ferramenta como um todo se faz a partir do Makefile principal (situado no diretório mirador). As regras definidas para esse Makefile são: 'make'

compilação dos códigos fontes dos módulos, recursivamente;

'make install'

instalação dos códigos compilados e arquivos necessários:

'make cleanall'

remoção de todos os arquivos compilados:

'make all'

compilação e instalação dos códigos e arquivos necessários. 
É possível compilar um módulo individual, usando o comando 'make nome_do_módulo'. Esse comando deve ser executado a partir do diretório raiz (mirador/), ou a partir do diretório onde se encontra o módulo a ser compilado.

A remoção de um módulo em particular se faz via 'make clean nome_do . . 'द 'o' a partir do diretório raiz, ou do diretório onde se encontra o módulo a ser removido.

O diretório padrão para a instalação da ferramenta Mirador II é o /opt/mirador. Esse diretório pode ser mudado, alterando a variável BIN do Makefile principal. 